\title{
Aspects of blood volume regulation in pregnancy : a study in the awake late-pregnant rat
}

Citation for published version (APA):

Boekkooi, P. F. (1990). Aspects of blood volume regulation in pregnancy : a study in the awake latepregnant rat. [Doctoral Thesis, Maastricht University]. Maastricht University. https://doi.org/10.26481/dis.19901206pb

Document status and date:

Published: 01/01/1990

DOI:

10.26481/dis.19901206pb

Document Version:

Publisher's PDF, also known as Version of record

\section{Please check the document version of this publication:}

- A submitted manuscript is the version of the article upon submission and before peer-review. There can be important differences between the submitted version and the official published version of record.

People interested in the research are advised to contact the author for the final version of the publication, or visit the DOI to the publisher's website.

- The final author version and the galley proof are versions of the publication after peer review.

- The final published version features the final layout of the paper including the volume, issue and page numbers.

Link to publication

\footnotetext{
General rights rights.

- You may freely distribute the URL identifying the publication in the public portal. please follow below link for the End User Agreement:

www.umlib.nl/taverne-license

Take down policy

If you believe that this document breaches copyright please contact us at:

repository@maastrichtuniversity.nl

providing details and we will investigate your claim.
}

Copyright and moral rights for the publications made accessible in the public portal are retained by the authors and/or other copyright owners and it is a condition of accessing publications that users recognise and abide by the legal requirements associated with these

- Users may download and print one copy of any publication from the public portal for the purpose of private study or research.

- You may not further distribute the material or use it for any profit-making activity or commercial gain

If the publication is distributed under the terms of Article $25 \mathrm{fa}$ of the Dutch Copyright Act, indicated by the "Taverne" license above, 


\section{Aspects of blood volume regulation in pregnancy}

A study in the awake late-pregnant rat 


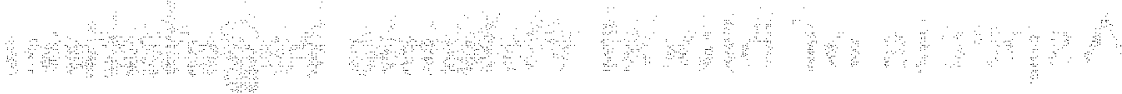

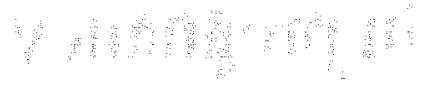

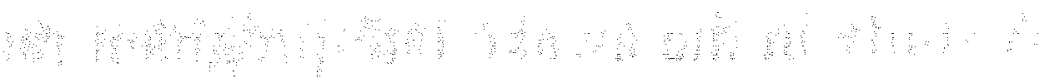




\section{Aspects of blood volume regulation in pregnancy}

\section{A study in the awake late-pregnant rat}

\section{PROEFSCHRIFT}

ter verkrijging van de graad van doctor aan de Rijksuniversiteit Limburg te Maastricht, op gezag van de Rector Magnificus, Prof. Dr. F.I.M. Bonke, volgens het besluit van het College van Dekanen, in het openbaar te verdedigen op donderdag, 6 december 1990 om 16.00 uur

door

Peter Focco Boekkooi

geboren te Eindhoven in 1963 
Promotor:

Prof. dr. J. de Haan

Co-promotor: Dr. L.L.H. Peeters

Beoordelingscommissie: Prof. dr. H.A.J. Struyker Boudier (voorzitter)

Prof, dr. J.G. Aamoudse, Rijksuniversiteit Groningen

Prof. dr. C.E. Blanco

Prof. dr. G. Kootstra.

Prof. dr. A.M. Rudolph, UCSF, San Francisco

CIP-GEGEVENS KONINKLIJKE BIBLIOTHEEK, DEN HAAG

Boekkooi, Peter Focco

Aspects of blood volume regulation in pregnancy : a study

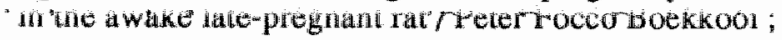

[11. by the author]. - Maastricht : Datawyse. - Ill.

Proefschrift Maastricht. - Met lit. opg. - Met

samenvating in het Nederlands.

ISBN 90-5291-039-1

SISO 605.5 UDC 618.2:612.1(043.3) NUGI 742

Trefw.: haemodynamica / zwangerschap

Produktie en layout: Datawyse Maastricht, Ruud Leliveld

Druk: Krips Repro Meppel

De publicatie van dit proefschrift werd mede mogelijk gemaakt door financiële bijdragen van het Scholten Cordes Fonds, de firma's Hoechst en Beecham. 
Aan mijn ouders

Je donne une oeuvre subjective ici, oeuvre cependant qui tend de toutes ses forces vers l'objectivité.

E. Minkowski. 


\section{INTRODUCTION}

\subsection{INTRODUCTION}

One of the circulatory adaptations to pregnancy is a rise in blood volume (BV) by about $30 \%$. BV expansion and fetal weight are positively correlated over a wide range. At the lower end of the spectrum, virtually no rise in BV is observed in pregnancies complicated by intrauterine growth retardation. At the upper end of the spectrum, multiple pregnancy is characterized by an extra rise in BV relative to singleton pregnancy. (Pirani et al, 1973; Goodlin et al, 1981; Goodlin, 1982; Gallery, 1982; 1984; Chesley and Lindheimer, 1988). It follows that adequate $\mathrm{BV}$ expansion represents an important adaptive change in pregnancy. However, neither the physiologic role of BV expansion in normal pregnancy, nor the role of insufficient $\mathrm{BV}$ expansion in intrauterine growth retardation and preeclampsia is well understood (Gallery et al, 1979; Lunell et $a l, 1982$; Groenendijk et al, 1984). Besides the rise in BV, both cardiac output $(\mathrm{CO})$ and the extracellular fluid compartment increase in the course of pregnancy (Lees et al, 1967; Martin, 1980). Furthermore, the osmoreceptors are reset resulting in a lower plasma $\mathrm{Na}^{+}$concentration relative to the nonpregnant state (Lindheimer and Katz, 1985). The teleological reason for these gestational adaptations remains obscure.

In this chapter, the current knowledge on BV regulation in the nonpregnant state, and the changes observed in BV in relation to other maternal adaptations to pregnancy are reviewed. In paragraph 1.5 , the possible consequences of the gestational rise in BV on the handling of volume loads are discussed. On the basis of this discussion a number of hypotheses are postulated on the hemodynamic response to imposed volume changes in pregnancy. These hypotheses are subsequently tested in a series of studies (chapters 2-6). 


\subsection{THE ROLE OF BLOOD VOLUME IN CARDIOVASCULAR FUNCTION}

Under normal conditions, BV is kept within narrow limits, with virtually no effect of fluid intake or fluid loss (figure 1). To explain the importance of a constant BV in the vascular bed, a more precise evaluation of the circulatory function is needed.

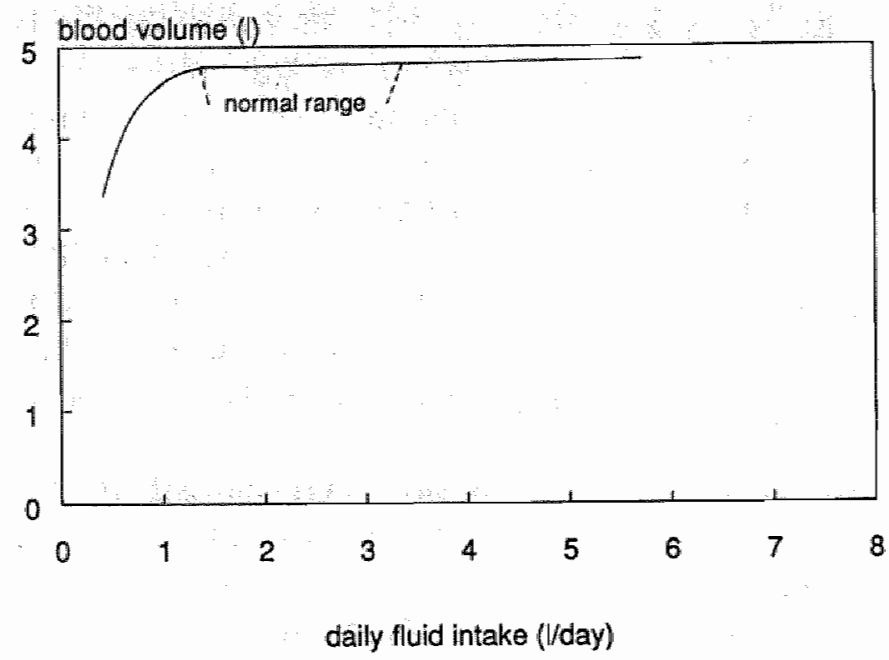

FIGURE 1.

Effect on BV of changes in daily fluid intake (after Guyton, 1986).

The solid line represents the blood volume.

\subsubsection{Starling forces and extra-/intravascular volumes}

In the macrocirculation, blood is transported between organ systems without leaving the intravascular space. In contrast, the function of the microcirculation is primarily to transport oxygen, nutrients and waste products across the vascular wall from the capillary to the tissue cells and back. Although this transport occurs mainly by diffusion, the concomitant across-wall movement of fluid (capillary filtration) may be of great importance, not only for interstitial solute transport, but also for blood rheology within the microcirculation (Peeters and Buchan, 1989). The balance between filtration and resorption of fluid across the capillary wall is a result of a dynamic balance over the length of the capillary, 
between hydrostatic and colloid-oncotic pressures in plasma and interstitium (Guyton, 1986). The lymphatic system buffers small transient disturbances in this relationship, thus contributing to the prevention of interstitial fluid depletion or edema formation. This protective mechanism is enhanced by the coordinated opening and closing of precapillary sphincters of capillaries supplying the same tissue area.

The total number of open precapillary sphincters at any given time determines organ flow, and is directly dependent on local tissue metabolism (Sweeney, 1989). The latter modulates local blood flow through both the vasoactive action of local metabolic products (lactate, ADP, adenosine, $\mathrm{H}^{+}$), and the local release of vasoactive agents (prostaglandins, leukotrienes, free radicals, serotonin, etc.). An increase in the perfusion of a certain area, while the perfusion of other areas is maintained, requires a concomitant rise in CO (Guyton, 1974).

\subsubsection{Effect of changes in cardiac output on the distribution of blood volume}

Under normal conditions, peripheral vasodilatation triggered by higher local flow requirements, leads to a rise in venous return which, in turn, increases the $\mathrm{CO}$. The beat-to-beat matching of $\mathrm{CO}$ to required peripheral flow is predominantly under the control of the arterial baroreceptor, which senses a change in afterload as a change in arterial pressure. This gives rise to such a readjustment in $\mathrm{CO}$ that the initial pressure change will be neutralized (Banet and Guyton, 1971; Hakumaki and Hyodynmaa, 1984; Zucker et al., 1985). This effect is accomplished by a change in cardiac contracting force and venous return. Increased firing of the baroreceptor in resporise to a fall in afterload does not only lead to an improved contractility of the heart, but also to arteriolar and venous constriction (Rothe and Drees, 1976; Rothe, 1983; Rothe, 1986). The latter is crucial in the regulation of $\mathrm{CO}$, since venoconstriction mobilizes extra blood, resulting in a higher venous return. The relation between $\mathrm{CO}$ and venous return was explored by Guyton and coworkers (Guyton et al., 1955; 1958; 1973). The amount of blood pumped by the heart is primarily determined by the right atrial pressure (figure 2). CO varies as a function of right atrial pressure (the cardiac output curve). Venous return is determined by the pressure gradient between the peripheral vascular bed and the right atrium, the geometry of venules and veins, and by the viscosity of the blood in the venous compartment. A rise in right atrial pressure diminishes the pressure gradient between venules and right atrium leading to a fall in venous return (the venous return curve, figure 2). Equilibrium is reached at that right atrial pressure where venous 
return equals $\mathrm{CO}$ (point $\mathrm{A}$ ). An increase in sympathetic tone shifts the $\mathrm{CO}$ curve to the left, and the venous return curve to the right. The equilibrium is then reached at the same right atrial pressure, but at a higher $\mathrm{CO}$ (point $\mathrm{B}$ ).

About $60 \%$ of the circulating blood is resides in the venules and small veins, which are normally distended at a pressure equal to the mean circulatory filling pressure (MCFP). This represents the upstream driving pressure from the peripheral tissue to the right atrium. The MCFP is estimated as the pressure obtained when the heart is suddenly stopped and the blood is rapidly redistributed within the cardiovascular system, at equal pressure in arteries and veins. It is shown in figure 2 as the right atrial pressure when the pressure gradient with the peripheral tissue amounts to zero. The MCFP has been measured in various species and amounts, under resting conditions, to about 7 mmHg (Rothe, 1983). MCFP has been determined at various blood volumes, and was found to be linearly related to changes in BV. Extrapolation of these data to a MCFP of $0 \mathrm{mmHg}$ provides the value for the residual volume in the vasculature. This is defined as "unstressed" volume and, in man, amounts to about 3.51 of blood (Rothe, 1986). Consequently, only about $1.5 \mathrm{l}$ of blood is actively circulating ("stressed volume"), while the remainder is stored in the venous compartment.

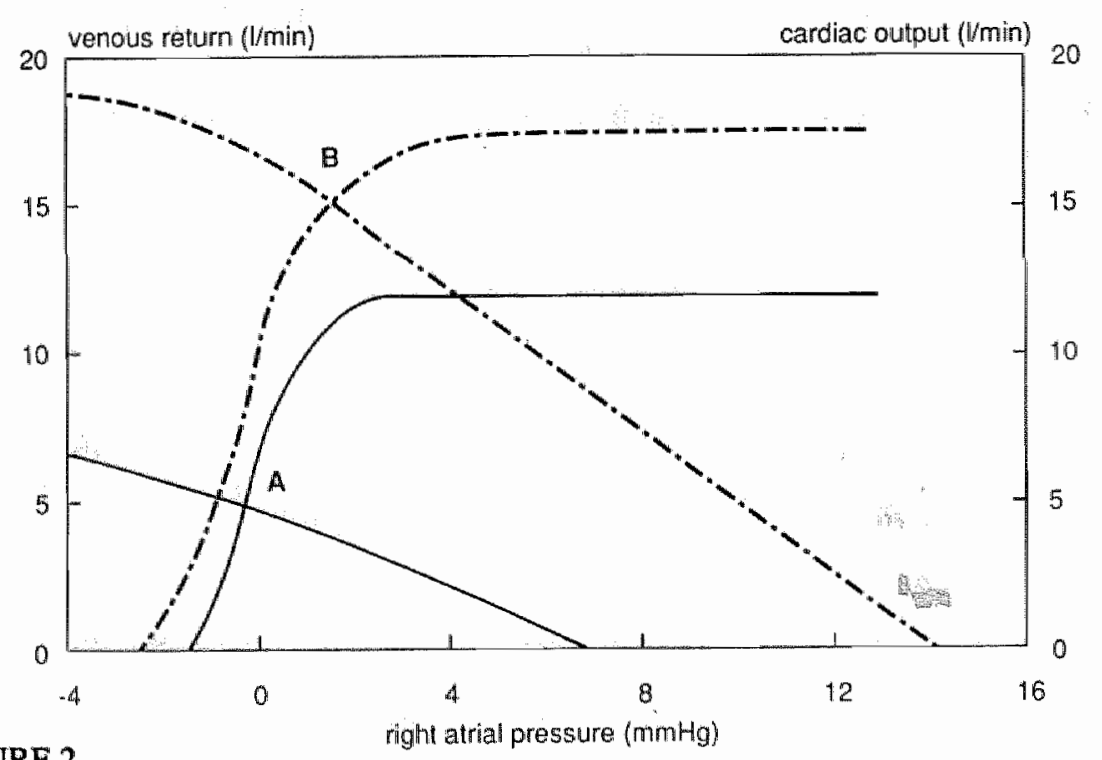

FIGURE 2.

right atrial pressure $(\mathrm{mmHg})$

The venous return and cardiac output curve (after Guyton, 1973). The solid line represent the cardiac output and venous return curve under resting conditions. They meet at point $A$ the $C O$ in rest. The dashed lines represent a shift to the left of the cardiac output curve, and a shift to the right of the venous reurn curves. The two lines meet at a higher cardiac output, point $B$. 
If peripheral flow demands are increased, mobilisation of the unstressed volume prevents the right atrial pressure from falling and thus allows $\mathrm{CO}$ to meet the increased peripheral flow requirements. It follows that venous return/CO can be varied over a wide range by simply changing the tone of the veins at unchanged BV (Greenway and Lister, 1974; Greenway and Lautt, 1986; Guyton et al., 1973).

\subsubsection{Effect of acute and chronic changes in cardiac output on blood volume}

Studies in anesthetized dogs have shown that opening of an arteriovenous shunt leads to an immediate rise in CO (Hilton et al., 1955; Frank et al., 1955). This effect is shown in figure 2: the afterload reduction shifts the $\mathrm{CO}$ curve to the left. Meanwhile, resistance to venous return decreases, leading to a shift of the venous return curve to the right. As a consequence, the intercept of the two curves is at a higher $\mathrm{CO}$ (point $\mathrm{B}$ ). The increased baroreceptor activity leads to peripheral arteriolar constriction to readjust afterload, as well as to venoconstriction to prevent a fall in venous return (Hakumaki and Hyodynmaa, 1984). When peripheral flow demands are chronically increased (e.g. in case of a large arteriovenous fistula), the excitability of the baroreceptor gradually returns to the pre-stress level over a period of 2 to 3 days in spite of continued increased stimulus. This implies that an initially adequate rise in venous tone in response to a fall in afterload weakens in concert with a declining signal output of the baroreceptor. This is paralleled by a gradual decrease in venous return which challenges the matching of $\mathrm{CO}$ to peripheral flow demands. The lower central venous and right atrial pressure leads to diminished excitation of volume receptors and a lower release of atrial natriuretic peptide (ANP) (Eskay et al, 1986; Hirth et al., 1986; Lang et al., 1987). In addition, the fall in mean arterial pressue (MAP) induces a decrease in "pressure diuresis", which is the diuretic response of the kidneys to only a slight change in renal arterial pressure. In combination, these effects lead to a fall in renal urine output (Guyton, 1986), eventually resulting in volume retention and with it, a higher venous return at the original venous tone. Thus, the balance between $\mathrm{CO}$ and peripheral demands will be restored. The newly attained steady state is characterized by a higher venous return at the original venous tone, but with an increased total $\mathrm{BV}$. This concept is supported by studies in dogs in which it was demonstrated that prolonged opening of a large arteriovenous shunt induces a gradual rise in BV over a period of days (Hilton et al., 1955; Frank et al., 1955). In addition, patients with chronic arteriovenous fistulas have a higher BV (up to 20\%) than normal controls (Crawford et al., 1963; Warren et al., 1951). 


\subsubsection{Effects of acute changes in blood volume on cardiac output}

In the relationship between $\mathrm{BV}$ and $\mathrm{CO}$ as described in the previous two paragraphs, BV varies in response to alterations in $\mathrm{CO}$. The question arises as to what is known about the effects of a rise in BV on CO. Studies in pentobarbital-anesthetized dogs have shown that an acute increase in BV induces a marked rise in MCFP, CO and MAP (Kaufmann et al., 1954; Huggins et al., 1956; Richardson et al., 1961; Prather et al., 1969; Haneda et al., 1986). Similar effects were observed in conscious rabbits (Ludbrook and Graham, 1984). After an acute volume load, CO seems to normalize through a rise in afterload associated with a higher MAP (Kohara et al., 1987).

\subsubsection{Effects of chronic changes in blood volume on cardiac output}

Studies on the cardiovascular response to chronic volume expansion are limited. In conscious dogs, a sustained BV expansion obtained by three bolus injections of dextran at intervals of two hours, did not change CO (Conway et $a l ., 1966)$. In anesthetized dogs, two hours after a bolus injection of dextran 6\%, CO had retumed to baseline despite a still elevated BV (Prather et al, 1969). In a study in healthy young volunteers, increasing the BV by intravenous saline infusion led to a rise in right atrial pressure. The authors were unable to demonstrate a concomitant rise in $\mathrm{CO}$ and MAP, both during the infusion and during the subsequent 30 minutes (Warren et al., 1948). Although methodological limitations may have obstructed to discern small changes in CO and MAP, these studies support the presence of rapid powerful compensatory mechanisms in the circulation which efficiently neutralize the expected effects on $\mathrm{CO}$ and MAP of acute volume loads. Firstly, the elevated MAP induces "pressure diuresis", resulting in a normalisation of BV. Secondly, a rapidly induced rise in capillary pressure causes a net filtration of fluid to the interstitial space. Thirdly, in the veins a phenomenon called "stress-relaxation" is triggered. In isolated veins of dogs anesthetized with morphine and pentobarbital, a sustained intraluminal pressure rise leads to a gradual secondary increase in their volume (Alexander et al., 1953; Alexander, 1955; Alexander, 1956; Porciuncula et al., 1964; Rothe and Drees, 1976). Decreasing venous pressure induces the opposite effect. This mechanism is thought to be responsible for the absence of a CO rise in response to a prolonged increase in BV. The extra BV would be stored in the veins by a gradual increase in venous capacitance allowing venous pressure to normalize (Prather et al., 1969). However, the data in these studies were obtained in an acute experimental preparation with uncertain applicability to chronic situations. In addition, morphine is known to affect 
venous tone, while barbiturates tend to diminish sympathetic tone. Denervated dogs respond quite differently to volume loads than normal controls (Guyton et al., 1973). Nevertheless, these studies, performed under anesthesia, provide evidence that nonacate short-term changes in BV can be buffered by alterations in venous volume capacity.

\subsubsection{Summary}

The data reported on the relationship of $\mathrm{CO}$ and $\mathrm{BV}$ in the nonpregnant state can be summarized as follows:

1. An acute rise in $\mathrm{CO}$ does not affect $\mathrm{BV}$. In contrast, a slow chronic rise in $\mathrm{CO}$ increases BV.

2. An acute rise in $B V$ increases $C O$. In contrast, a slow chronic rise in $B V$ appears to have no effect on $\mathrm{CO}$.

In the pregnant state, $\mathrm{BV}$ and $\mathrm{CO}$ rise slowly. In addition, the endocrine environment of pregnancy together with the gradually expanding plasma volume may influence BV regulation, and its relation to changes in $\mathrm{CO}$.

\subsection{CIRCULATORY CHANGES DURING NORMAL PREGNANCY}

During uncomplicated human pregnancy, both BV and CO increase by about one third relative to the nonpregnant state (Chesley, 1972; Hytten and Chamberlain, 1980; Longo, 1984b; Chesley and Lindheimer, 1988; Metcalfe et al., 1988). These changes are accompanied by a number of changes in other circulatory parameters. In this paragraph the most relevant variables related to BV regulation in pregnancy will be reviewed.

\subsubsection{Methodological aspects in the measurement of BV}

The increase in BV during pregnancy is a result of a rise in both plasma volume (PV) and erythrocyte volume (Walters and Lim, 1970; Martin, 1980). Yet these two parameters have rarely been measured together. Usually either PV or red cell volume is measured, while the other is calculated from the hematocrit. This imposes the first problem in measuring BV; the hematocrit (Hct) of blood taken from a large vessel is higher than the whole-body Hct, 
because of a much lower Hct in small vessels. In pregnancy whole-body Hct is $89 \%$ of the large vessel Hat (Paintin, 1963). This correction factor should be employed when using the Hct for calculating total BV.

$P V$ is generally determined using dye (Evans blue) or radioactive indicators (e.g. ${ }^{125}$ I-albumin). In early studies PV was found to decline after the $34^{\text {th }}$ week. However, it became clear that posture affected the measurement of PV. In these early studies, blood was collected with the subject positioned in dorsal recumbency, and thus the gravid uterus posed an obstruction to the blood flowing in the inferior vena cava (Pritchard et al., 1955). This phenomenon interferes with mixing of the dye in the circulation (Chesley and Duffus, 1971). In more recent studies performed in lateral recumbency, PV did not decrease in late pregnancy (Pirani et al., 1973). The measurement of red cell volume with labeled erythrocytes is a reliable technique in pregnancy (Hytten, 1985).

Vague definition of inclusion criteria for a normal population may lead to a disproportionally large methodological error in BV measurements during pregnancy (Hytten, 1985). Obviously, including obese, anemic and hypertensive women in an "unselected" group of patients does not result in a representative "normal" population. When measuring red cell volume, it is also important to exclude all women who receive iron supplementation. Finally, a standard reference should be used. For example, studies using 4-6 months after delivery as baseline yield a smaller increase in red cell mass than those using immediate post partum values as baseline.

\subsubsection{Plasma volume}

In a number of reviews, the relevance of PV measurements in pregnancy has been discussed and summarized (Longo and Hardesty, 1984a; Hytten and Chamberlain, 1980; Chesley et al., 1988). The study by Pirani and coworkers is often referred to as being methodologically sound (Pirani et al., 1973). Uncomplicated pregnant primigravidas were evaluated in the lateral position using the Evans blue technique. Until 34 weeks of pregnancy the increase in PV was 1246 $\mathrm{ml}$ with a relatively small individual variation $\left(S D=383 \mathrm{ml}\right.$ ). After the $34^{\text {th }}$ week PV had reached a plateau which was $50 \%$ above prepregnant values.

To our knowledge, it is still not known when exactly PV begins to rise in pregnancy. The early fall in plasma osmolality during pregnancy ( $\pm 5^{\text {th }}$ week) is paralleled by a rise in total body water (Hytten and Chamberlain, 1980; Davison et al., 1981; Brown. et al., 1988a). This phenomenon can be expected to contribute to an early increase in PV as suggested by the $11 \%$ and $19 \%$ higher PV by the $7^{\text {th }}$ and $15^{\text {th }}$ week of pregnancy, respectively (Clapp et al., 1988). The increase in PV may have been even larger, since the PV data in the latter study 
were derived from changes in Hct. It is conceivable that the gestational decrease in osmolality increased red cell volume and therefore, lead to underestimation of the change in PV. In one study, PV has been reported to increase already after the $6^{\text {th }}$ week of gestation (Lund and Donovan, 1967). However, this result should be interpreted with caution as the study design did not meet the criteria as delineated in paragraph 1.3.1.

The magnitude of the PV expansion correlates with fetal weight, which may explain the larger PV in multiple as compared to singleton pregnancies (Hytten and Paintin, 1963; Rovinsky and Jaffin, 1965; Fullerton et al., 1965; Duffus et al., 1971; Pirani et al., 1973; Ueland and Parer, 1976; Longo, 1984b). PV measured in both uncomplicated first and second pregnancies, increased by a higher fraction in the second pregnancy (Campbell and MacGillivray, 1972; Hytten and Paintin, 1963). As the newborns in multigravidas are usually larger than those in primigravidas, this observation supports the concept that PV expansion and fetal weight are also related within subjects. Correlations between the gestational rise in PV on the one hand, and maternal weight, height and nonpregnant PV on the other, are weak (Pirani et al., 1973). Therefore, it has been proposed to express the gestational increment in PV in absolute change rather than in percentage of nonpregnant PV. In fact, there is evidence that the smaller the mother, the larger the percentage rise in PV during pregnancy (Hytten, 1985).

\subsubsection{Erythrocyte volume}

Red cell volume in pregnancy is $15-20 \%$ higher than in the nonpregnant state (Taylor and Lind, 1979; Hytten, 1980). The pattern of increase in pregnancy is probably linear until term. Inasmuch as the increase in PV is larger than the increase in erythrocyte volume, the Hct falls gradually in the course of pregnancy to reach a nadir between 28 and 32 weeks (Martin, 1980).

The increment in BV during pregnancy could serve to protect the pregnant. individual against hemorrhage in the third stage of labor. It has been shown that blood loss during labor, amounting to as much as $500 \mathrm{ml}$ does not lead to demonstrable adverse effects on maternal hemodynamics (Pritchard, 1965a; Ueland, 1976; Robson et al., 1989).

\subsubsection{Extracellular fluid volume}

The changes in PV and red cell volume are accompanied by a highly variable rise in extracellular fluid. The average increase in extracellular fluid volume is 1.7 liter. Most of this rise occurs during the last trimester, when BV has already 
increased markedly (Durr, 1989). The occurrence of some pedal edema is normal in pregnancy. In a longitudinal study clinical signs of edema were found in $80 \%$ of uncomplicated pregnancies with a measurable increase in leg volume and finger circumference in the remaining 20\% (Robertson, 1971). Although during pregnancy the plasma colloid-oncotic pressure decreases as a result of a fall in plasma albumin, there is no direct relation between leg edema and plasma colloid-oncotic pressure (Robertson, 1969, Durr, 1989). Other parameters of the Starling forces have been measured in late-pregnant women (Oian and Malteau, 1985). The data indicate that interstitial hydrostatic pressure remains unaltered while capillary hydrostatic pressure increases. These changes are balanced by a larger decrease in the colloid-oncotic pressure in the interstitial fluid than in the plasma. The expected effect of these pressure is acceleration of the transcapillary fluid exchange. Accumulation of fluid and proteins in the interstitium appears to be prevented by an increased lymph flow (Fadness and Oian, 1989). The physiologic meaning of an increased interstitial fluid flux is unclear, but may reside in the facilitation of intercellular diffusion (Durr, 1989).

\subsubsection{Renal function}

Renal blood flow has not been measured directly in human subjects. It is estimated from the renal clearance of p-amino hippurate, a substance which is freely filtered by the glomerulus, and actively secreted by the tubules. Therefore, it is removed from the glomerular plasma after a single passage through the nephron. P-amino hippurate clearance is conventionally considered to represent effective renal plasma flow (ERPF). The latter increases to $50-80 \%$ above prepregnant levels in the first two trimesters, but decreases again by $25 \%$ in the last trimester (Dunlop and Davison, 1987). It is still unclear whether this fall is real or related to the methodology employed, since the quantitation of the ERPF with p-amino hippurate is subjected to a large measurement error. The glomerular filtration rate (GFR) increases gradually in early pregnancy to reach a plateau of $50 \%$ above nonpregnant values by the end of the first trimester. After the $36^{\text {th }}$ week GFR decreases again by about $20 \%$. Inasmuch as the increase in GFR is smaller than that in ERPF, the filtration fraction declines during the first trimester. The concomitant changes in GFR and ERPF in late pregnancy imply that the filtration fraction increases again to nonpregnant values by the end of pregnancy (Lindheimer and Katz, 1985). The rise in ERPF and GFR, together with changes in renal tubular function may account for the gestational glycosuria, amino-aciduria, and enhanced excretion of sodium, vitamins, and proteins (Atherton and Green, 1987). 
The mechanisms responsible for the rise in ERPF and GFR are largely unknown. It seems that renal function increases more than strictly required for the removal of the extra waste products generated by accelerated metabolism ( $\mathrm{L}$ indheimer and $\mathrm{Katz}, 1985$ ). The effect of various steroid homones on renal function has been studied extensively in rats (Elkarib et al., 1983; Baylis, 1984; Baylis et al., 1985; Walker and Garland, 1985; Garland et al., 1987; Conrad, 1987). No single hormone has been found to explain each of the observed renal changes, but prolactin might be involved in the rise in GFR (Elkarib et al., 1983). In anesthetized virgin rats an acute volume expansion did not trigger a rise in GFR (Baylis, 1987a; Reckelhof et al., 1989). It was concluded that the gestational hypervolemia may develop independently of the change in GFR. However, the experimental set-up with anesthetized animals subjected to rapid volume changes, does not allow conclusions about the interrelation between slow changes in BV and GFR in human pregnancy. It has also been suggested that changes in the levels of certain amino-acids caused by the altered metabolism, may be involved in the rise in GFR.

About $900 \mathrm{mEq}$ of sodium is retained during pregnancy, despite the natriuretic effect associated with the rise in GFR, the high levels of progesterone (anti-aldosterone action) and the presumably elevated ANP levels (Milsom et al., 1988). ANP is released by the left and right atria in response to atrial stretch (Eskay et al., 1986; Hirth et al., 1986; Lang et al., 1987). It causes natriuresis, and vasodilatation throughout the body. In pregnancy, it is thought to antagonize the antinatriuretic effects of angiotensin II (Mizelle et al., 1989; Brands and Freeman, 1989; Metzler et al., 1989). However, the role of ANP in pregnancy is still subject to debate. Although several cross-sectional studies and one longitudinal study have shown increased concentrations of ANP in pregnancy (Thomsen et al., 1987; Thomsen et al., 1988; Milsom et al., 1988), this has been disputed by data from a longitudinal study, in which plasma ANP levels remained unaltered in the last trimester of pregnancy (Steegers; 1990). The lack of rise in right atrial pressure throughout uncomplicated human pregnancy (Visser et al., 1987; Wallenburg, 1988) supports unchanged ANP levels. Experiments in rats suggest that, besides unaltered ANP levels, the response to a given ANP stimulus is unchanged in pregnancy despite a substantially increased BV (Kristensen et al., 1986; Nadel et al., 1988; St-Louis et al., 1988). It is difficult to interpret gestational changes in ANP levels, as they may be cause or effect of alterations in central volume. In preeclamptic patients maternal ANP levels seem to be markedly elevated (Visser et al., 1987; Thomsen et al., 1987). It is speculated that the increased levels of ANP may have contributed to the development of hypovolemia in these patients (Bond et al., 1989). It can be expected that the atrial ANP release is elevated for a prolonged 
period in early pregnancy in response to continuous slow expansion of the BV. If the accelerated ANP release fails to subside in concert with the fading strength of the stimulus, accelerated natriuresis will persist and a state of hypovolemia is likely to develop. Conversely, sustained increased levels of ANP may also lead to enhanced capillary leakage, giving rise to massive fluid loss into the interstitial space at the expense of the intravascular volume. The latter mechanism has been recently described for the nonpregnant rat (de Vries, 1990). As clinical symptoms in preeclampsia develop late, it is difficult to evaluate the exact role of ANP in the pathogenesis of this disease.

Factors enhancing sodium reabsorption are aldosterone, desoxycorticosterone, estrogens, and angiotensin II (for details: Lindheimer and Katz, 1985; Davison, 1984; Davison, 1985). In normal pregnancy, plasma levels of angiotensin II are 2-3 fold higher than in nonpregnant women. However, the effects of angiotensin II on sodium and chloride secretion are blunted in pregnancy. This indicates that the renal sensitivity to angiotensin II is markedly decreased in pregnancy (for details: Lindheimer and Katz, 1985; Broughton Pipkin, 1988). Renal handling of sodium loads changes little in both human (Brown et al., 1988b) and rat pregnancy (Katz and Lindheimer, 1973).

\subsubsection{Osmoregulation}

Early in the first trimester plasma osmolality decreases abruptly. At the same time, the set-point for release of pituitary vasopressin is shifted to the left as compared to the nonpregnant state. This implies that in pregnancy the osmotic threshold to trigger vasopressin release decreases from $288 \mathrm{mosmol} / \mathrm{kg}$ to 278 mosmol/kg (Davison et al., 1981). However, neither in pregnant rats (Durr et al., 1981) nor in pregnant patients (Davison et al., 1988; Brown et al., 1988a) has the response to variation in osmolality changed in comparison to the nonpregnant state.

It has been suggested that the change in osmolality is triggered as soon as plasma hCG levels surpass a certain threshold (Davison et al., 1988). However, this concept has not been confirmed by others. The exact mechanisms responsible for, and the physiologic meaning of the changes in osmoregulation remain obscure. In pseudopregnant rats osmolality does not change, suggesting that the presence of the fetoplacental unit is a prerequisite for the gestational fall in osmolality (Barron et $a l_{n}, 1988$; Lindheimer et al., 1987). Nevertheless, it is not possible to trigger a decrease in osmolality by the administration of placental extracts to virgin rats. Similar negative findings have been obtained for estrogen, progesterone, prolactin and angiotensin II. In pigs, osmoregulation by vasopressin secretion is independent of the estrous cycle (Rollin et al., 1989). 
Vasopressin secretion is not only influenced by osmolality, but also by BV and MAP (Baylis, 1987b; Share, 1988). However, studies in rats suggest only a minor role for the latter 2 variables in the osmoregulatory changes of pregnancy. This conclusion is based upon the comparable release of vasopressin in response to volume changes in pregnancy as compared to the nonpregnant state, despite a $50 \%$ larger intravascular compartment (Barron et al., 1984). Also the role of MAP in this respect is small, as suggested by a study in which increases in MAP induced by norepinephrine infusions, did not alter osmolality in pregnant rats (Barron, 1987).

The fall in plasma osmolality in pregnant women is paralleled by an about $900 \mathrm{mEq}$ sodium retention. This is needed to enable the physiologic expansion of both interstitial space and intravascular compartment. The contribution to the expansion of the intravascular compartment, suggests that the adaptations in osmolality have an indirect effect on the expansion of BV in pregnancy (Atherton et al., 1982; Barron and Lindheimer, 1988).

\subsubsection{Cardiac output}

It is generally accepted that thermodilution is the method of choise to measure $\mathrm{CO}$. However, this method requires pulmonary artery catheterization and is therefore associated with a small but definite risk. In recent studies, $\mathrm{CO}$ has been measured using the noninvasive Doppler technique. The diameter of the aortic root is measured (A-mode), from which a cross-sectional area is calculated. Continuous Doppler ultrasound is then used to measure aortic blood flow velocity during systole. Thus, stroke volume and $\mathrm{CO}$ can be calculated. This method has been validated using the thermodilution technique as a reference, in 12 late-pregnant preeclamptic patients (Easterling et al., 1987). The results obtained with the two techniques were closely correlated (linear regression, $r=0.91$ ). A similar study in nonpregnant subjects yielded comparable findings. The Doppler technique in experienced hands was found to be associated with an intra-individual/intra-observer variability of less than $5 \%$ (Robson et al., 1987). Although no validation study in uncomplicated pregnancies has been performed, studies using this technique appear reliable for the longitudinal study of $\mathrm{CO}$ during pregnancy, and are therefore included in this review.

The total increase in $\mathrm{CO}$ in pregnancy is already reached by the $20^{\text {th }}$ week, with no further rise until term (Lees et al., 1967; Capeless and Clapp, 1989). From then on, it plateaus until the end of gestation. The rise in $\mathrm{CO}$ is accomplished by a concomitant increase in heart rate $( \pm 15 \mathrm{bpm})$ and stroke volume $( \pm$ 10\%) (Hytten and Chamberlain, 1980). In multiple pregnancies the rise in CO 
is larger (Rovinsky and Jaffin, 1966; Veille et al., 1985), presumably accomplished by a larger rise in HR (Robson et al., 1989). In twins, the magnitude of volume expansion does not correlate with the rise in CO (Rovinsky and Jaffin, 1966). Unfortunately, BV and CO have not been studied serially in the same subject throughout normal primigravid pregnancy. Nevertheless, it seems that $\mathrm{CO}$ plateaus from 20 weeks of pregnancy until term, whereas the BV continues to rise until the $34^{\text {th }}$ week of pregnancy.

\subsubsection{Distribution of cardiac output}

The extra $\mathrm{CO}$ is distributed to various organs (table 1). Uteroplacental blood flow increases gradually during human pregnancy (Dunlop and Davison, 1987; Martin, 1980). Most studies are performed with electromagnetic flow probes during caesarean sections (Martin, 1980). Therefore, little is known about the pattern of increase during the course of pregnancy. In a longitudinal study using Doppler measurements of the uterine artery, uterine blood flow seemed to increase linearly throughout pregnancy (Thaler et al., 1990). This finding is in agreement with previous studies using other techniques (Martin, 1980). In early human pregnancy, uteroplacental blood flow is almost unchanged, whereas at term it amounts to almost $10 \%$ of maternal $\mathrm{CO}$. This increase in blood flow may be mediated by the action of estrogens, since studies in sheep have shown that estrogens increase uterine blood flow (Ueland and Parer, 1966; Resnik et al., 1974; Rosenfeld et al., 1976; Resnik, 1983).

Changes in the breasts begin early in human pregnancy, often representing the first symptomatic evidence of conception. Estimated mammary blood flow in women (plethysmography) suggests an increase throughout pregnancy (table 1) (Metcalfe et al., 1988). However, no quantitative data have been reported about mammary blood flow in the pregnant woman. Data from pregnant pigmy goats (Linzell, 1960) and near-term ewes (Rosenfeld, 1977) have also demonstrate a rise in mammary blood flow during pregnancy.

Blood flow to the hands also increases during pregnancy, presumably indicating a higher skin flow. Because metabolic rate is increased in pregnancy, skin flow may rise to meet the increased blood flow demand for heat dissipation (Metcalfe et al., 1988).

Effective renal plasma flow (ERPF) increases already in the first trimester to reach a plateau at 30 weeks of about $80 \%$ above nonpregnant values. This aspect of pregnancy was elaborated in paragraph 1.3.5. Also, blood flow to the lower urogenital tract has increased in pregnancy (Batra et al., 1985; Batra et al., 1986). 
TABLE 1.

Regional blood flows (ml/min) during pregnancy (after Dunlop and Davison, 1987)

\begin{tabular}{lcccc}
\hline Blood flows & Nonpregnant & $12^{\text {th }}$ week & $28^{\text {th }}$ week & $40^{\text {th }}$ week \\
\hline uterus & $<50$ & 50 & 200 & 500 \\
breasts & $<100$ & 250 & - & - \\
skin & 450 & 800 & - & - \\
kidneys & 480 & 840 & 890 & 775 \\
liver & 1500 & 1500 & 1500 & 1500 \\
brain & 750 & 750 & 750 & 750 \\
& & & & \\
\hline
\end{tabular}

The decreased arteriovenous oxygen difference in pregnancy has been explained to reflect enhanced arteriovenous shunting (Ueland et al., 1969) as the gestational rise in $\mathrm{CO}(30 \%)$ exceeds that in nutritional flow demands $(\approx 10$ $15 \%$ ) (Martin, 1980). However, changes in the microcirculatory exchange function such as increased capillary fluid flux (paragraph 1.3.4) and expansion of the interstitial space (paragraph 1.3.6), may have lowered the peripheral oxygen extraction.

\subsubsection{Vascular responsiveness}

Plasma levels of renin, angiotensin and aldosterone are higher in pregnancy (Broughton Pipkin, 1988). There is evidence that the increased concentration in prorenin is of placental origin (Brar et al., 1986). The concomitant lower vascular responsiveness to e.g. angiotensin II illustrates the limited value of plasma levels only (Chesley et al., 1965; Gant et al., 1973; Everett et al., 1978; Naden et al., 1984). Recent studies suggest that altered prostacyclin release by the endothelium may be involved in a change in angiotensin II receptor sensitivity (For more details: Dekker, 1988; Broughton Pipkin, 1988). In addition, estrogens may have an influence on both the renin angiotensin aldosterone system and vascular response to angiotensin in both man and sheep (Laragh et al., 1967; Menard et al., 1970; Rosenfeld and Jackson, 1984; Tamai et al., 1984; Naden and Rosenfeld, 1985).

In pregnancy the pressor response to catecholamines appears to be attenuated (for a more detailed review: Dekker, 1989).

Finally, progesterone is generally thought to induce vascular relaxation. Its physiologic meaning in human pregnancy, however, remains to be elucidated. 


\subsubsection{Blood pressure}

In uncomplicated human pregnancy, blood pressure decreases slightly to reach a nadir at the $24^{\text {th }}$ week of pregnancy, and returns to prepregnant levels by the end of gestation (De Swiet, 1988; Barron et al., 1990; Steegers, 1990). This implies that the systemic vascular resistance (SVR) has decreased during pregnancy.

\subsection{HYPOTHESES}

In figure 3 a simplified scheme is given with the possible interrelationships between $\mathrm{BV}$ and $\mathrm{CO}$ in the pregnant state. In the subsequent paragraphs each possible concept that can explain the interrelation between these two variables will be discussed. The first two possibilities are that the endocrine environment of pregnancy causes a rise in either BV or $\mathrm{CO}$ (arrow 1 and 2). Then, a change in one of these parameters may be the trigger for the increase in the other parameter (arrow 3 and 4). The two parameters may also increase independently of each other (arrow 5). Finally, pregnancy could alter a possible relation between $\mathrm{BV}$ and $\mathrm{CO}$ (arrow 6).

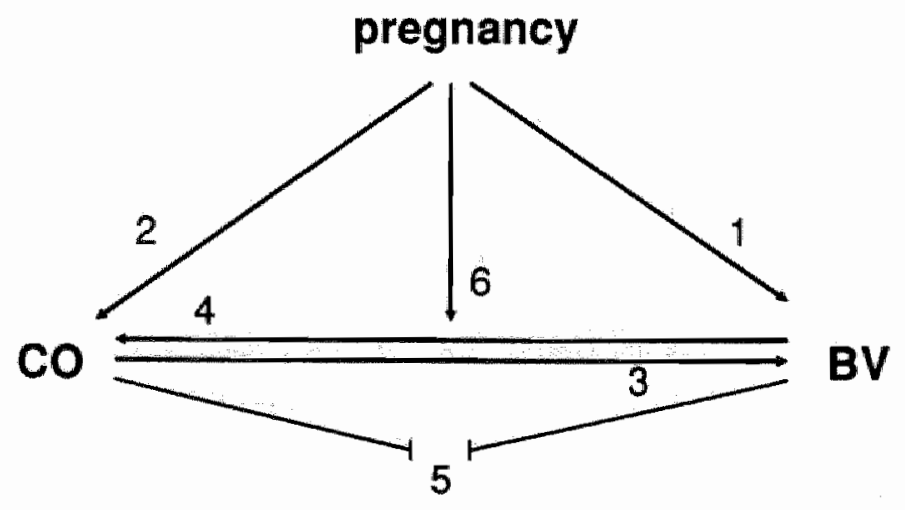

FIGURE 3.

Possible relationships between pregnancy, cardiac output, and blood volume. 


\subsubsection{Effect of pregnancy on blood volume}

It is still largely unknown, when, how, and to what extent the rapidly changing endocrine environment in pregnancy contributes to the expansion of PV in pregnancy (Túlchinsky et al., 1972; Braunstein et al., 1976; Hytten and Chamberlain, 1980; Tulchinsky, 1983; Kase and Reyniak, 1985). Ewidence for a direct effect of estrogens on PV in man and laboratory animals has been provided by numerous workers (Ueland and Parer, 1966; Walters and Lim, 1969; Ueda et al., 1986). These data have been reviewed and summarized by Longo (Longo and Hardesty, 1984a; Longo,1984b). Longo proposed a model of $\mathrm{PV}$ regulation in which the fetal adrenal controls the rise in maternal BV by secreting estrogen precursors, (Longo, 1983). This would explain the relation between fetal weight and maternall PV expansion. However, BV also increases in the absence of a fetus in pseudopregnant patients with a hydatiforme mole (Pritchard, 1965b). This does not only suggest that hCG plays a role in the rise in PV, but also that, besides estrogens, a number of other factors should be involved in the development of the gestational increase in PV. The hypothesis proposed by Longo ignores the threshold changes such as the abrupt fall in osmolality (Brown et al., 1988a) as well as other hemodynamic changes in early pregnancy (Clapp et al., 1988), when fetal adrenal glands are not yet formed and the uterine fraction of $\mathrm{CO}$ is small. The hypothesis also fails to take into account why the rise in PV seems to precede that in plasma levels of estrogen and other pregnancy hormones.

In summary, it is certain that estrogens increase PV, but also that estrogen is not the only factor that contributes to the gestational rise in BV.

\subsubsection{Effect of pregnancy on cardiac output}

The rise in $\mathrm{CO}$ may be a direct effect of placental hormones. In guinea pig pregnancy BV and $\mathrm{CO}$ are both increased, the latter possibly due to left ventricular enlargement. A rise in left ventricular size could be reproduced by chronic administration of estrogens in nonpregnant guinea pigs (Morton et al., 1984; Hart et al., 1985). This was associated with a rise in both CO and BV, whereas chronic administration of progesterone did not influence $\mathrm{CO}$ or $\mathrm{BV}$. It was hypothesized that a primary left ventricular enlargement induced by estrogens leads to a higher stroke volume in pregnancy (Metcalfe et al., 1988). The concomitant fall in end-diastolic pressure would increase venous return and thus reduce "unstressed" volume in the venous compartment. The latter in turn, triggers volume retention. This concept assumes a primary effect of estrogen on the heart. However, from these experiments it cannot be excluded that estrogens 
had triggered increased blood flows to estrogen-sensitive organs (paragraph 1.3.7). A rise in these blood flows could have induced a chronic increase in $\mathrm{CO}$ which, in turn, induced the observed cardiac and BV changes (Schrier and Durr, 1987; Schrier, 1988a; Schrier, 1988b). Therefore, these data do not allow conclusions about a primary effect of estrogens.

Estrogens administered to male transsexuals led to a rise in $\mathrm{CO}$ by $16 \%$ and in BV by $9 \%$ (Slater et al., 1986). Although high doses of estrogens were administered, the rise in BV was much less than seen in normal human pregnancy. This is additional evidence for the concept that estrogens can only partly explain the increases in $\mathrm{CO}$ and $\mathrm{BV}$ in pregnancy. Also, it is not possible to identify whether these changes are related causally or independently.

In summary, the effect of estrogens on $\mathrm{CO}$ and $\mathrm{BV}$ can be explained by two mechanisms: 1. A direct effect on the heart causing a shift of the $\mathrm{CO}$ curve to the left (figure 2). This would comply with the observation that in pregnancy $\mathrm{CO}$ increases, while right atrial pressure remains unchanged. 2. An indirect effect, via a rise in blood flow to the estrogen-sensitive tissues (uterus, breasts, lower urinary tract and skin). Little is known about the contribution of other factors to the BV and CO rise in pregnancy.

\subsubsection{Primary rise in cardiac output}

Although the high flow/low-resistance uteroplacental circulation has been kept responsible for most of the afterload reduction in pregnancy (Burwell, 1938; Assali and Vaughn, 1977; Longo, 1983; Goodlin et al., 1985), it reaches a maximum of only about $10 \%$ of $\mathrm{CO}$ in late pregnancy (Hytten and Chamberlain, 1980). Therefore, the shunt effect by the low-resistance placental vascular bed appears to be limited, particularly in early pregnancy (Glaviano, 1963). On the other hand, the higher flow requirements of uterus, kidneys, skin, and mammary gland combined may also have contributed to the gradual increase in PV (Winner, 1965). The combined effect of these higher blood flows is a chronically elevated $\mathrm{CO}$ in early pregnancy. The change in $\mathrm{BV}$ in response to this hemodynamic state may then resemble the one described in paragraph 1.2.4 for the prolonged opening of a large artificial arteriovenous shunt. The gestational rise in $\mathrm{CO}$ during pregnancy may be a result of generalized vasodilatation rather than of the presence of a large shunt. Support for this hypothesis comes from a study in the baboon, in which it was demonstrated that the rise in CO preceded that in BV by several weeks (Phippard et al., 1986). However, the endocrinology of baboon pregnancy is quite different from that in human pregnancy which limits the value of these data for the understanding of the $\mathrm{CO} / \mathrm{BV}$ relationship in human pregnancy. Unfortunately, as mentioned earlier, 
in human pregnancy $\mathrm{CO}$ and $\mathrm{BV}$ have not yet been measured simultaneously in the same subject. The available data do not show a rise in CO prior to PV expansion. In addition, if a change in $\mathrm{CO}$ causes a rise in $\mathrm{BV}$, one would expect low values for central venous pressures. This is not the case in normal human pregnancy (Clark et al., 1989; Visser et al., 1987). Lastly, this assumption fails to explain the marked increase in GFR already in early pregnancy.

\subsubsection{Primary hypervolemia}

It is generally believed that the rise in BV in the course of pregnancy precedes that in CO and uterine blood flow (Goodlin et al., 1981; Goodlin et al., 1983; Longo and Hardesty, 1984a). The following phenomena support this concept.

First, in pregnant mongrel dogs (Douglas et al., 1967) and rabbits (Goodlin et al., 1984) the MCFP was higher than in nonpregnant controls. As discussed in paragraph 1.2.4, a rise in MCFP can be caused by a rise in BV. This would imply that the cardiovascular alterations in pregnancy are triggered by a primary hypervolemia. However, most studies on MCFP published so far have been performed in anesthetized animals. Anesthesia is known to increase sympathetic tone and may therefore also lead to a change in vascular responsiveness (paragraph 1.3.9). A recent study in conscious guinea pigs showed that MCFP had not increased in pregnancy. However, in this species the gestational increase in both BV and CO is small (Peeters et al., 1980; Davis et al., 1989).

Second, the GFR is already increased in early pregnancy, without a concomitant increase in diuresis/natriuresis. These phenomena are suggestive of a primary hypervolemia. However, the rise in GFR can be caused by some other factors. There are a number of hormones that are increased in pregnancy, although until now this has not yet been substantiated (paragraph 1.3.5). Finally, the higher GFR may reflect a change in renal function which include a diminished natriuretic response triggered by hypervolemic stress.

\subsubsection{Blood volume and cardiac output increase independently}

Theoretically, as discussed in paragraph 1.2.3, CO and BV may increase independently of each other. $\mathrm{CO}$ is basically regulated by peripheral flow demands, via baroreceptor regulation. A rise in $\mathrm{CO}$ without concomitant change in $\mathrm{BV}$ can be obtained by way of venoconstriction. Also, BV can increase without a concomitant increase in $\mathrm{CO}$. In the latter case, the rise in BV should be paralleled by a rise in venous capacitance so as to accommodate the extra volume as "unstressed" volume (Rothe, 1986). If these principles apply to the 
pregnant state as well, BV and CO may have increased independently of each other. This hypothesis is supported by the possibly different time course of the changes in these two parameters. BV continues to increase till the $34^{\text {th }}$ week of pregnancy, while $C O$ plateaus from 20 weeks until term.

Nevertheless, experimental data supporting this hypothesis are scarce, and the time periods used in various studies to perform the $\mathrm{CO}$ and $\mathrm{BV}$ measurements, are relatively short (up till several hours).

\subsubsection{Gestational effects on BV/CO interaction}

Since most studies on the interaction of $\mathrm{BV}$ and $\mathrm{CO}$ are performed in nonpregnant animals, it remains unclear how pregnancy alters the hemodynamic response to changes in either $\mathrm{CO}$ or BV. One important aspect that may influence BV regulation in pregnancy, is the gestational rise in BV. The cardiovascular response to an additional rise on top of the already increased BV may be entirely different than in the nonpregnant state. In addition, it is unclear whether endocrine changes such as increases in estrogen and progesterone levels affect venous tone, and thus the ability to accomodate extra volume. This may be particularly important in pregnancies complicated by preeclampsia or intrauterine growth retardation. The usually contracted PV compartment in these pregnancies has led to increased popularity of symptomatic treatment with volume expansion therapy. For this reason, the effect of pregnancy on BV regulation is an important yet unknown subject.

\subsection{THE PRESENT THESIS}

As delineated in this review, it is still unsettled:

1. why and by what mechanisms BV increases during pregnancy.

2. whether BV regulation in pregnancy is altered due to the higher baseline BV and/or the different endocrine environment.

3. whether BV and $\mathrm{CO}$ in pregnancy are related causally or independently.

By reviewing the literature, it became clear that the response of $\mathrm{CO}$ to an imposed change in BV varies with the rate of BV change. Similarly, the response of $\mathrm{BV}$ to an imposed change in $\mathrm{CO}$ (shunt) varies with the rate of $\mathrm{CO}$ change. In pregnancy, $\mathrm{BV}$ and $\mathrm{CO}$ change at a much slower rate (months) than the rates of change in these variables used experimentally. As a consequence, 
these data provide little information about the spontaneous interdependence between $\mathrm{BV}$ and $\mathrm{CO}$ in pregnancy. However, they do emphasize that the rate of change in either variable plays an important role in this relationship. Inasmuch as the mechanisms of the gestational rise in $\mathrm{BV}$ and $\mathrm{CO}$ are also poorly understood, the emphasis of this thesis was put upon addressing the second question specified above: What is the response of CO (and other hemodynamic variables) to imposed rapid, subacute and chronic BV changes in pregnancy as compared to the nonpregnant state?

The objective of the subsequent studies was to increase our understanding of BV regulation in pregnancy. It was expected that the results of these studies with respect to the "time factor" would also improve our understanding of the spontaneous CO/BV relationship in pregnancy.

The following questions were addressed in this thesis:

1. Does the hemodynamic response to an induced BV rise vary with the rate of BV expansion and if so, how?

2. Is the hemodynamic response to a decrease in BV achieved by the same mechanism as observed after a rise in BV?

3. Is the hemodynamic response to induced, different rates of BV changes altered in pregnancy?

\subsection{ANIMALS}

The experimental studies were performed in the awake late-pregnant rat. Awake, because anesthesia may affect reflex pathways involved in cardiovascular regulation. The rat was chosen, as extensive information is available about the cardiovascular function in this species. In addition, many different strains are available, such as hypertensive rats, Brattleboro rats, etc. The studies were performed in late-pregnancy (19 days, term is 21 days) as at that time, BV has increased to $\approx 40 \%$, and ERPF and GFR to $\approx 50 \%$ above nonpregnant values (Atherton et al, 1982; Barron et al, 1984; Lindheimer and Katz, 1985). At term, uteroplacental blood flow amounts to $\approx 10 \%$ of $\mathrm{CO}$ in anesthetized late-pregnant rats (Yamaguchi et al, 1979; Bruce, 1976; Ahokas et al, 1983; Ahokas et $a l, 1984)$. In addition, the endocrine environment in the last week of rat pregnancy resembles that in the 3rd trimester of human pregnancy (Longo and Hardesty, 1984a). Finally, the rat placenta is hemotrichorial resembling the human hemomonochorial placenta in several aspects. Data available from sheep 
(Metcalfe and Parer, 1966) and guinea pig (Metcalfe et al., 1988) gestation are less complete, and gestational changes in $\mathrm{BV}, \mathrm{CO}$, and renal function in these species differ markedly from those in human pregnancy. 


\section{Circulatory effects of rapid and slow volume expansion in awake late-pregnant and nonpregnant rats}

Peter Focco Boekkooi, Ben JA Janssen*, Carla M Verkeste,
and Louis LH Peeters

From the Department of Obstetrics and Gynecology, and the *Department of Pharmacology, University of Limburg, Maastricht, the Netherlands

\section{ABSTRACT}

In the present study the hypothesis was tested that 1 . the cardiovascular response to an imposed volume load is determined by the ability of the venous compartment to accomodate this volume load, and that 2 . this response was not altered in pregnancy when baseline blood volume is markedlly increased as compared to the nonpregnant state. To this end, the effect was studied of a rapid (bolus), as compared to a subacute volume load (infusion). Late-pregnant and nonpregnant Wistar rats were instrumented with intravascular catheters and an electromagnetic flow probe around the ascending aorta. After recovery from surgery, cardiac output, mean arterial pressure, and the fluid balance were monitored continuously. The change in the diameter of the central veins was estimated by comparing $\mathrm{X}$-ray pictures of the inferior vena cava in baseline, with those made after an intravenous bolus injection, and after a 2 hour continuous infusion with Haemaccel ${ }^{\circledR}$. The response to the bolus injection consisted of an immediate transient increase in cardiac output and mean arterial pressure, while the outline of the inferior vena cava had not changed. Although the continuous infusion led to a comparable rise in cardiac output, mean arterial pressure had returned to baseline and the outline of the inferior vena cava had consistently increased. These responses to rapid and subacute volume load did 
not differ between pregnant and nompregnant rats. It was concluded that the hemodynamic response to an imposed rise in blood volume: 1. varies with the rate of volume loading due to the protacted response of the venous compartment, and 2 . is not altered in pregnancy.

\section{INTRODUCTION}

In the first weeks of human pregnancy, both maternal cardiac output (CO) and blood volume (BV) begin to increase gradually to reach a plateau of $\approx 30 \%$ above nonpregnant values by the $16^{\text {th }}$ and $34^{\text {th }}$ week, respectively (Lees et al, 1967; Pirani et al, 1973; Capeless and Clapp, 1989; Clapp et al, 1988). The magnitude of the rise in BV correlates well with fetal weight (Pirani et al, 1973) suggesting a direct relationship between fetal growth and the gestational BV expansion. Nevertheless, the exact mechanism responsible for the BV rise in pregnancy remains to be identified.

In human pregnancy, the interrelationship between $\mathrm{BV}$ and $\mathrm{CO}$ has not yet been studied longitudinally. Theoretically, part of the $\mathrm{CO}$ rise in pregnancy could be induced mechanically, in response to the increased BV. This concept is supported by the observation that the mean circulatory filling pressure is elevated in pregnant rabbits and dogs relative to nonpregnant controls (Douglas et al, 1967; Goodlin et al, 1984), and by the markedly elevated renal blood flow in early pregnancy (Lindheimer and Katz, 1985). In pregnancy BV increases over a period of weeks to months. This brings up another aspect of the physiologic BV expansion in pregnancy. The rate of change may vary during the period of BV expansion, associated with feedback responses in the volume regulatory system. Therefore, an adequate regulatory response to volume fluctuations, also when a certain degree of hypervolemia has been reached, may be important in the hemodynamic adaptation to pregnancy.

The objective of the present study was to test the hypothesis that the elevated BV in normal pregnancy does not affect the response of CO and other hemodynamic variables to an imposed volume load. More specifically, it was hypothesized that an additional rise in BV on top of the already raised $\mathrm{BV}$ is accommodated as so-called "unstressed volume" (hemodynamically inactive volume) in the venous compartment without a concomitant rise in $\mathrm{CO}$. Inasmuch as the rate of the change in $\mathrm{BV}$ affects the response, it was decided to compare the hemodynamic response to rapid volume load (bolus) with the response to subacute volume load (continuous infusion). The impact of pregnancy was determined by comparing the induced responses in the pregnant state with those 
observed in the nonpregnant state. The awake Wistar rat was considered a suitable model for this study, as BV in the late-pregnant rat has increased to $\approx$ $40 \%$, and glomerular filtration rate and effective renal plasma flow to $=50 \%$ above nonpregnant values (Lindheimer and Katz, 1985; Atherton et al., 1982; Barron et al., 1984; Baylis, 1984).

\section{MATERIALS AND METHODS}

\section{Experiment 1}

The study was performed in 19-days pregnant $(P, n=6)$ and age-matched virgin Wistar rats (NP, $n=6$ ), obtained from a local breeder (HSD, Zeist, the Netherlands). The rats ( $\mathrm{P}$ on day 14 of pregnancy) were anesthetized with ketamin $(20 \mathrm{mg})$ and xylazine $(4 \mathrm{mg})$ intramuscularly, and the trachea was intubated (PE-240). After establishing positive pressure respiration ( 60 breaths/ min, tidal volume $2.5-3 \mathrm{ml}$ ), the surgery was carried out under aseptic conditions. The skin and muscle overlying the $3^{\text {rd }}$ right intercostal space were incised and separated. The $3^{\text {rd }}$ and $4^{\text {th }}$ rib were spread and the ascending aorta was dissected free. An electromagnetic flow probe $(O D=2.3 \mathrm{~mm}$; Skalar, Delft, Holland) was fitted around the ascending aorta just above the heart. The thorax was closed and the probe cable fixed to the ribs. The cable was guided to the neck where the connector was exteriorized. The surgical procedure has been described in detail elsewhere (Smith and Hutchins, 1979; Smits et al., 1982). Four days after the probe implantation (in P: day 18 of pregnancy) the rats were anesthetized with ether, and polyethylene catheters (PE-10, $\mathrm{OD} / \mathrm{ID}=0.61 / 0.28$ $\mathrm{mm}$, heat-sealed to a piece of $\mathrm{PE}-50$ tubing, $\mathrm{OD} / \mathrm{ID}=0.92 / 0.58$ ) were inserted into the abdominal aorta and IVC, via the femoral artery and vein. The catheters were tunneled subcutaneously to the same exit site as the probe cable.

On the next day (in P: $19^{\text {th }}$ day of pregnancy) the rats were placed in small experimental cages $(22 \times 13 \times 13 \mathrm{~cm})$ on sawdust, and connected to the measuring equipment. The flow probe was connected to a sine-wave electromagnetic flow meter (Skalar, Delft, the Netherlands), and the arterial catheter to a pressure transducer. Data were recorded continuously and stored on a hard disk of a real-time data processing system (developed by the department of instrumental services, University of Limburg, Maastricht, the Netherlands). This system corrects for baseline before each beat, taking late-diastolic flow as zero flow. This implies that the drift is virtually zero. Linearity and accuracy of the system were $1 \%$ and less than $7 \%$, respectively, as specified by the manufacturer. 
Calibration of the flow probes is performed by the manufacturer by perfusion of the lumen. The rats were allowed to habituate for at least 45-60 minutes, before recording of the hemodynamic variables was started. $\mathrm{CO}$; heart rate (HR) and mean arterial pressure (MAP) were monitored continuously. In NP rats, measurements were continued until 30 minutes after discontinuation of volume loading. Stroke volume (SV) and systemic vascular resistance (SVR) were calculated from $\mathrm{CO}, \mathrm{HR}$ and MAP. After the experiments, the animals were sacrificed and in the $P$ rats the fetuses were counted and weighed.

During the experiment, changes in $\mathrm{BV}$ were calculated from the changes in the hematocrit (Hct, vol\%) (Katz et al., 1988). The Hct was measured in duplicate with the microcapillary technique. The method to determine BV changes from Hct changes was validated in a preceding study in 4 pregnant rats. In these rats, BV changes were induced by a steady-state infusion with Haemaccel $^{10}$ (Hoechst) at a rate of $6 \mathrm{ml} /$ hour for a period of 2 hours. Prior to the infusion, in baseline conditions, $0.8 \mathrm{ml}$ of a suspension of radioactively labeled erythrocytes and albumin was injected. Red cell volume and plasma volume were calculated separately according to the indicator dilution technique, by extrapolation to time zero of the radioactivity in the samples $(0.2 \mathrm{ml})$ obtained after $5,10,15$ and 20 minutes, respectively. Together with the last sample, 0.05 $\mathrm{ml}$ extra blood was withdrawn to measure baseline Hct. Then, volume loading as detailed above, was started. Two hours later the BV measurement was repeated by readministering a suspension of radioactively labeled erythrocytes and albumen. Prior to injection, a sample was withdrawn to determine background radioactivity. In order to obtain reliable data, the radioactivity in this second suspension was 3 times higher than the one used in baseline. By adopting this approach, the background activity was adequately exceeded. The subsequent procedure was similar as in baseline and included the measurement of the Hct. The induced BV changes ranged from 28-64\%. The difference between the $\mathrm{BV}$ change determined from the Hct change and that determined using the "radioactive" method ranged from $-3 \%$ to $+3 \%$. Therefore, the Hct method was adopted to estimate changes in $\mathrm{BV}$ as emerged in response to imposed volume changes, in all subsequent studies. Moreover, the method is simple and needs minimal blood sampling.

The experiment consisted of an intravenous bolus injection ( $2 \mathrm{ml}$ ) immediately followed by a continuous infusion as detailed above. Haemaccel ${ }^{\text {(B) }}$ is an isotonic colloid solution, composed of a polymer of urea and polypeptides. It is readily excreted by the kidneys with minimal metabolic breakdown. During infusion, the agent remains within the intervascular compartment with no measurable effect on fluid flux to the interstitial space (Davies, 1987). HaemaccelR is known to be well tolerated in rat with no measurable effect on MAP, HR 
and respiratory rate, even when infused in great amounts (Lowe and McNaughton, 1984). It does not cause changes in serum concentrations of electrolytes. Because of the latter aspect, and the isotonicity of the solution, the effect of Haemaccel $^{(3)}$ on red cell volume was expected to be negligible.

\section{Experiment 2}

The effect on the fluid balance of the rapid (bolus) and subacute (continuous infusion) volume load, was investigated in three 19-days pregnant animals. One day before the experiments, the rats were habituated to the large metabolic cages, in which the experiments were to be performed. The cumulative urine output and Hct was determined at 30 minutes intervals, while MAP and HR were monitored continuously throughout a 5 hours period of infusion with Haemaccel ${ }^{\circledR}$ at a rate of $6 \mathrm{ml} /$ hour.

\section{Experiment 3}

In a separate study we determined the impact of the imposed hypervolemia on the degree of filling of the inferior vena cava (IVC). Six pairs of nonpregnant and four pairs of 19-days pregnant Wistar rats were anesthetized with ether and positioned in pairs, in dorsal recumbency on a heated pad. In both rats, 2 catheters (PE-10) were inserted into a single femoral vein and advanced with their tip into the IVC just above the aortic bifurcation. After a stabilisation period of 20 minutes (baseline), $1 \mathrm{ml}$ of contrast (Hexabrix ${ }^{8}$ ) was rapidly infused intravenously with an infusion pump at a continuous rate of $6 \mathrm{ml} / \mathrm{min}$, over a period of 10 seconds. Then, at the end of expiration, an anterior posterior $\mathrm{X}$-ray picture was taken of both rats laying next to each other. The 2 rats were turned in lateral position and the procedure was repeated in order to obtain a lateral picture. One of the 2 rats (experimental) received a bolus injection with $2 \mathrm{ml}$ of Haemaccel ${ }^{3}$ while the other rat (control) was left untouched. The procedure to obtain $\mathrm{X}$-ray pictures of both rats simultaneously and from 2 sides was repeated, followed by a steady-state infusion with Haemaccel ${ }^{2}$ at a rate of $6 \mathrm{ml} /$ hour in the experimental rat. Two hours later, the procedure to take $\mathrm{X}$-ray pictures of both rats simultaneously was repeated once more. The procedure of $\mathrm{X}$-ray photographing was as standardized as possible in all rat-pairs. The difference in IVC diameter was determined by calculating the mean of 3 diameter measurements, determined at 3 distinct points on the abdominal portion of the IVC. The IVC diameters in the experimental animals after rapid (bolus) and subacute volume load (infusion), were compared with the IVC diameters in baseline (intra-animal). In the control rats the simultaneously 
measured IVC diameter, was also compared with the baseline measurement (intra-animal). Finally, the simultaneously photographed diameters in each rat pair were compared (inter-animal).

Data are presented as means \pm SD throughout the text. Differences between control and experimental observations were evaluated by the Wilcoxon Signed Rank Test. Differences between P and NP groups were tested by the MannWhitney test. A probability of less than $5 \%$ (two-sided) was considered significant.

\section{RESULTS}

\section{Experiment 1}

Table 1 lists baseline and experimental values for the $\mathrm{P}$ and the NP group. $\mathrm{P}$ rats had a higher HR, and a lower MAP and SVR as compared to NP rats. The change in these parameters in response to the volume load was comparable in the two groups, except for HR, which decreased after 2 hours in the $\mathrm{P}$ group only. Maternal weight was $277 \pm 31 \mathrm{~g}$ in the $\mathrm{P}$ group, significantly higher than $236 \pm 52 \mathrm{~g}$ in the NP group. The number of viable fetuses in the litters was $6 \pm$ 1. The average fetal weight was $1.6 \pm 0.2 \mathrm{~g}$.

TABLE 1.

Hemodynamic parameters before and during volume expansion

\begin{tabular}{|c|c|c|c|c|c|c|}
\hline & \multicolumn{3}{|l|}{$P(n=6)$} & \multicolumn{3}{|l|}{$N P(n=6)$} \\
\hline & $t=0$ & bolus & $t=2$ hours & $t=0$ & bolus & $t=2$ hours \\
\hline $\mathrm{CO}(\mathrm{ml} / \mathrm{min})$ & $88 \pm 11$ & $116 \pm 14^{*}$ & $117 \pm 12$ & $78 \pm 8$ & $105 \pm 8 *$ & $113 \pm 11$ \\
\hline MAP (mmhg) & $90 \pm 8$ & $99 \pm 12 *$ & $94 \pm 7$ & $115 \pm 12^{\#}$ & $121 \pm 13^{*}$ & $114 \pm 25$ \\
\hline HR (beats/min) & $445 \pm 24$ & $433 \pm 22$ & $416 \pm 31 *$ & $383 \pm 11^{\#+}$ & $405 \pm 24$ & $423 \pm 28$ \\
\hline SV $(\mu \mathrm{I})$ & $201 \pm 31$ & $268 \pm 421^{*}$ & $281 \pm 29^{*}$ & $203 \pm 20$ & $259 \pm 24^{*}$ & $266 \pm 19 *$ \\
\hline $\mathrm{SVR}(\mathrm{mmHg} / \mathrm{ml} / \mathrm{min})$ & $1.1 \pm 0.2$ & $0.9 \pm 0.2^{*}$ & $0.8 \pm 0.2 *$ & $1.5 \pm 0.2^{\#}$ & $1.2 \pm 0.2 *$ & $1.0 \pm 0.2^{*}$ \\
\hline
\end{tabular}

* significant difference from baseline $(\mathrm{p}<0.05)$

\# significant difference between groups $(p<0.05$ ) 
TABLE 2.

Percentage change after 2 hours infusion

\begin{tabular}{lccccc}
\hline & \multicolumn{2}{c}{ P.group } & \multicolumn{3}{c}{ NP-group } \\
\cline { 2 - 3 } \cline { 5 - 6 } & bolus & 2 hours & & bollus & 2 hours \\
\hline BV & - & & & & $+20 \pm 2 \%$ \\
CO & $+32 \pm 11 \%$ & $+35 \pm 18 \%$ & & $+32 \pm 12 \%$ & $+47 \pm 18 \%$ \\
SV & $+33 \pm 8 \%$ & $+42 \pm 20 \%$ & & $+29 \pm 14 \%$ & $+32 \pm 8 \%$ \\
HR & NS & $-7 \pm 4$ & & NS & NS \\
MAP & $5 \pm 2 \%$ & NS & & $6 \pm 2 \%$ & NS \\
SVR & $-18 \pm 4 \%$ & $-23 \pm 13 \%$ & & $-12 \pm 5 \%$ & $-31 \pm 13 \%$ \\
& & & & &
\end{tabular}

$\mathrm{NS}=$ nonsignificant change

Table 2 lists the percentage change in these variables after the bolus injection, and after 2 hours infusion. Figure 1 illustrates the patterns in CO, MAP, HR, SV and SVR during the infusion period. Only the NP rats were monitored until 30 minutes after discontinuation of the infusion. After the bolus injection, $\mathrm{CO}$ increased to a peak value of $\approx 30 \%$ above baseline in both groups. MAP also increased consistently by about $5 \%$ in both $\mathrm{P}$ and NP rats. Meanwhile HR remained unaltered and SVR decreased. After 2 hours infusion, $\mathrm{CO}$ was 35\% and $47 \%$ above baseline in $\mathrm{P}$ and NP rats, respectively. In both groups, $\mathrm{CO}$ had increased mainly because of a rise in SV. Only in the P group, HR had also decreased consistently by $7 \%$. The MAP after 2 hours infusion was similar as in baseline. Although the baseline SVR was lower in the P group, it decreased to a similar minimum in both groups. BV had increased by $18 \%$ and $20 \%$ in the pregnant and the nonpregnant animals, respectively (table 2). All parameters remained stable from 60 to 120 minutes. In the NP animals CO, SV, and SVR tended to return to baseline after discontinuation of the infusion.

\section{Experiment 2}

The fluid balance for the three 19-days $P$ rats subjected to prolonged infusion, is illustrated in figure 2 . Urine output started after $\approx 30$ minutes, and increased steadily to reach a plateau equal to the infusion rate by 2 hours. In steady state the total amount of infused Haemaccel ${ }^{3}$ exceeded the cumulative urine output by about $9 \mathrm{ml}$. 
CARDIAC OUTPUT

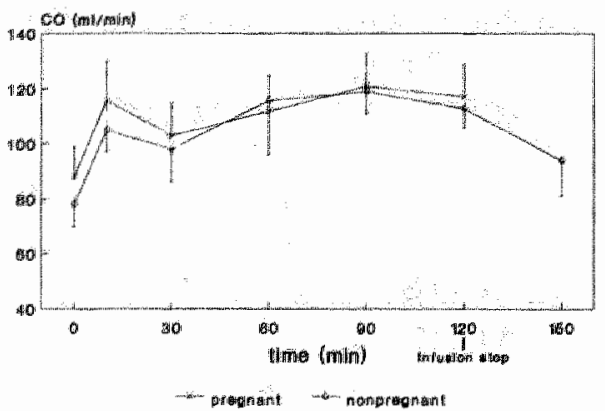

STROKE VOLUME

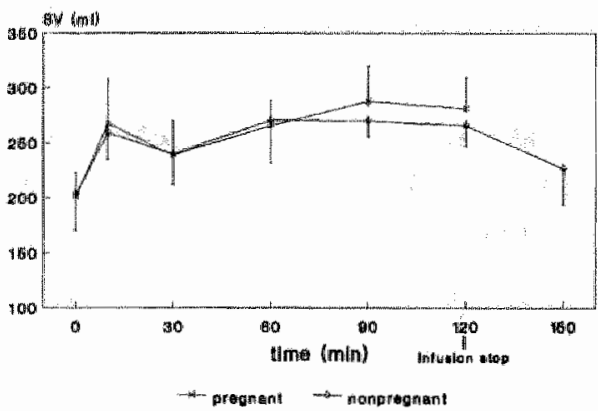

TOTAL PERIPHERAL RESISTANCE

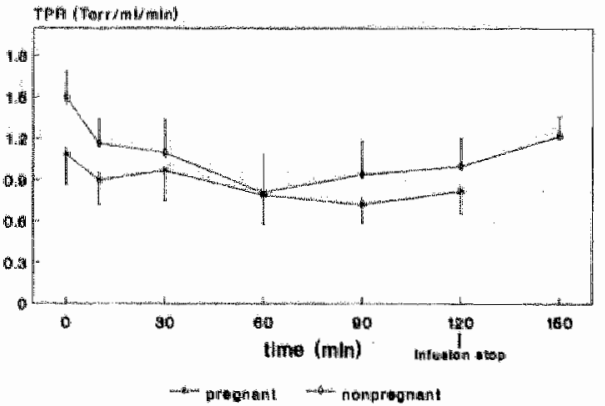

MEAN ARTERIAL PRESSURE

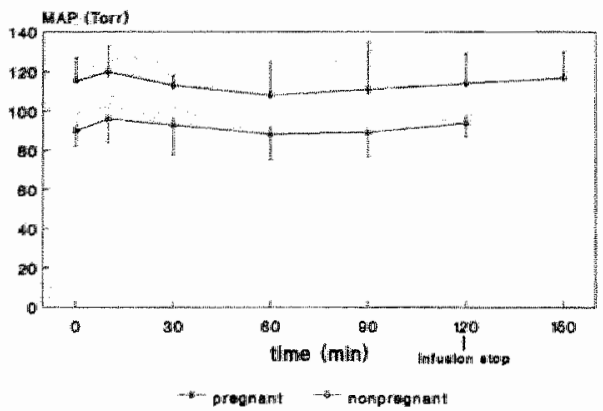

HEART RATE

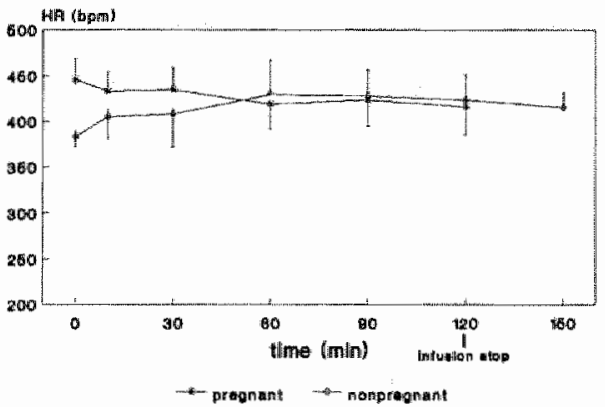

FIGURE 1.

Cardiovascular parameters in the $\mathrm{P}$ and NP group. Upper panel left: $\mathrm{CO}$, upper panel right: MAP, middle panel left: SV, middle panel right: HR, lower panel left, SVR. Data are represented as means $\pm \mathrm{SD}$. 


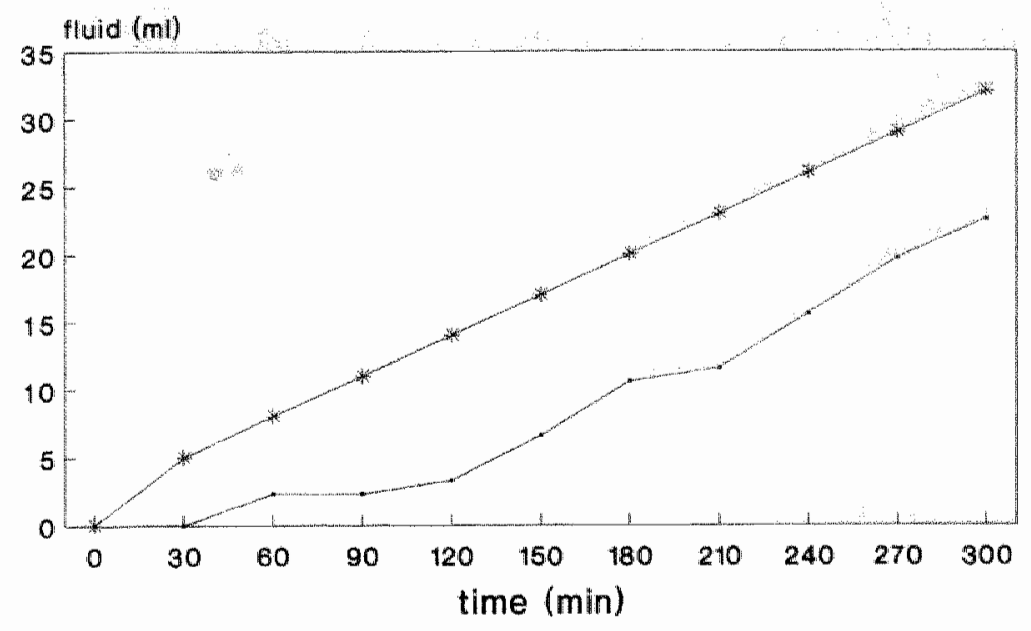

urine output - infused Haemaccel

\section{FIGURE 2 .}

Fluid balance over 5 hours. Data from the group of 3 19-days pregnant rats.

The accumulated fluid $(\mathrm{ml})$ is depicted on the ordinate.

\section{Experiment 3}

The diameter of the IVC, as measured by the X-photographs, did not change in the control group after 15 minutes, and after 2 hours. Differences with baseline measurements ranged between -8 and $+11 \%$. The concomitant changes in the experimental counterpair were always clearly larger, indicative of a change caused by the imposed volume load. Nevertheless, because of the lack of an independent method that could serve as a golden standard for this new $\mathrm{X}$-ray technique, the obtained results were only used to demonstrate a difference between baseline and experimental conditions.

After the bolus injection, the diameter had not increased relative to baseline. However, after the 2 hours volume load, the anterior posterior pictures in the rats subjected to X-ray imaging showed, in all rats, a consistent rise in IVC diameter by $24 \% \pm 11 \%$, and $28 \% \pm 13 \%$ in the P and the NP rats, respectively (intra-animal). No consistent change could be observed in the concomitantly obtained lateral pictures. Figure 3 illustrates an anterior posterior picture in baseline, and after 2 hours infusion in a pregnant rat. The values calculated from the comparison between counterpairs (inter-animal) after the subacute volume load were comparable to the ones obtained from the intra-animal comparison. 


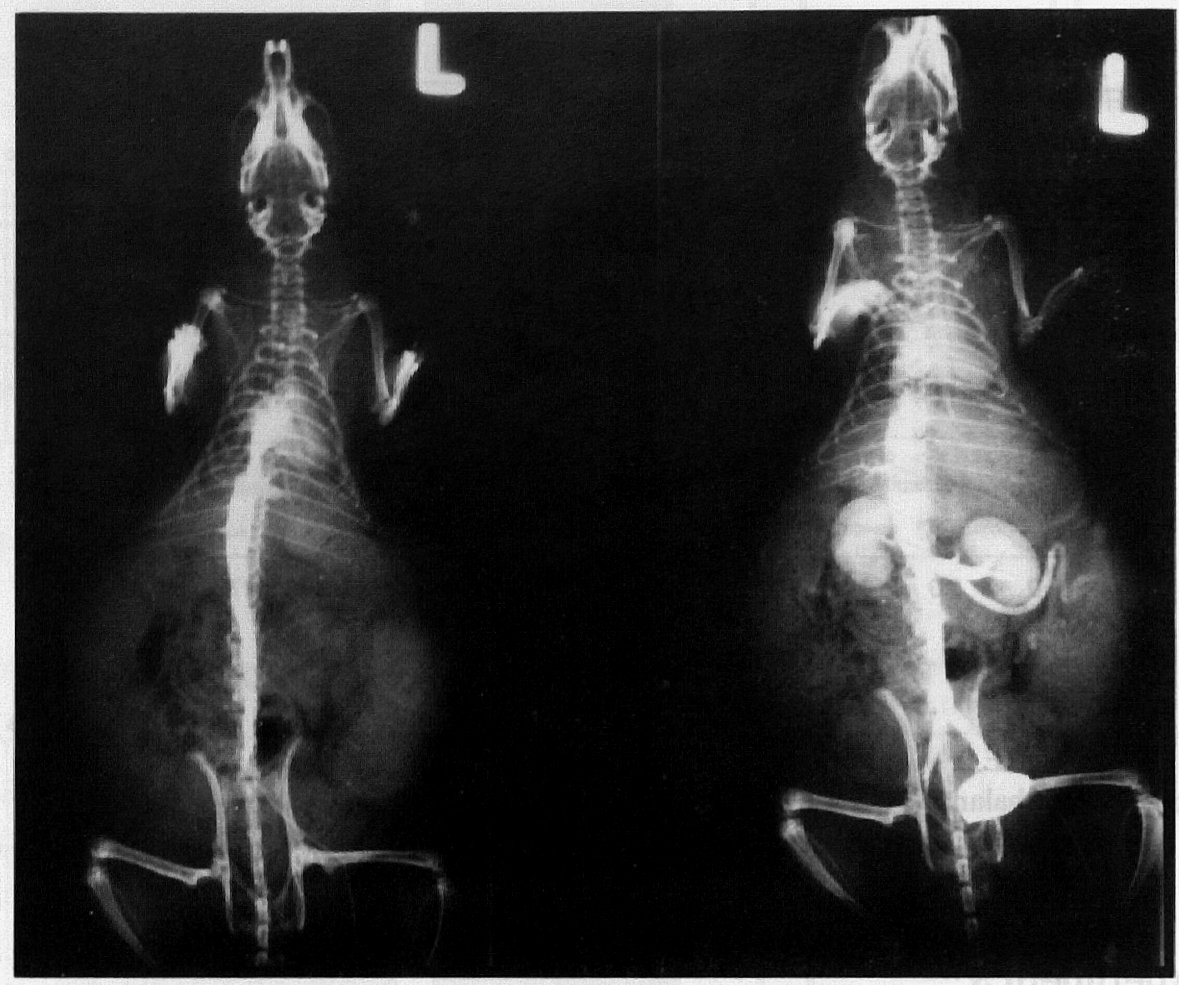

\section{FIGURE 3.}

Anterior posterior X-ray picture of the IVC in a 19-days pregnant rat. The rat is positioned in dorsal recumbency. Left panel: baseline, right panel: after 2 hours infusion.

\section{DISCUSSION}

To our knowledge, the electromagnetic flow probe has not yet been used to measure $\mathrm{CO}$ in awake pregnant rats. As compared to other techniques, this method has the attractive advantage of providing a continuous signal. However, the extensive surgery needed to implant the flow probe was associated with increased fetal wastage: The average number of viable fetuses in our pregnant rats had decreased to 6 as compared to a normal litter size of 12 . Nevertheless, the impact of pregnancy on the hemodynamic response to the volume load was considered adequately preserved in the present study, because firstly, pregnancy is an all-or-nothing phenomenon, secondly, the viable fetuses had grown to an appropriate weight for 19-days pregnancy and thirdly, the P animals differed clearly from the NP animals by their lower baseline MAP and SVR. 
Reliable and reproducible measurement of the venous filling state is complex and potentially subject to large error, particularly in a small animal such as the rat. In the present study, an impression of the venous filling state was obtained indirectly by measuring the IVC outline on X-ray pictures made in 2 directions, before and after volume load. In addition to intra-animal comparisons, we compared the calibre of the IVC before and after volume load with that of a control rat. By also performing this paired comparison, the methodological error was further reduced. In our hands, the method appeared to provide reproducible results with an average increase in anterior-posterior IVC calibre of $24 \%$, but with a coeffficient of variation of $\approx 45 \%$. This error did not differ between the intra-animal and paired comparisons. It follows that the technique has a large measurement error which could not be separated from biological variation. Because of this large error and the inability to validate the technique with some independent golden standard, the method was only used to obtain a qualitative result. Moreover, the objective of the present study does not require quantitative data on venous filling.

The purpose of the present study was to determine the effects of a rapid (bolus) and subacute volume load (infusion) on $\mathrm{CO}$ and venous filling state, in the pregnant and nonpregnant state. Rapid volume loading induced an immediate $\approx 30 \%$ rise in $\mathrm{CO}$ in both groups, almost entirely accomplished by a $\approx 30 \%$ rise in SV (table 2). The changes in CO and SV in the first 30 minutes after the bolus injection (peak after 15 minutes with trend to recovery in the subsequent 15 minutes) without an apparent change in venous filling supports the concept of a delayed mechanical adaptation of the central veins to the imposed rapid volume load. This so-called stress-relaxation phenomenon has been studied in anesthetized dogs and in isolated veins of dogs. It refers to the response of the large veins with passive dilatation to an imposed volume stress to accommodate a higher volume while venous return to the heart and $\mathrm{CO}$ gradually normalize (Guyton et al., 1973; Alexander, 1956; Porciuncula et al., 1964). On the basis of the X-ray pictures, no rise in venous diameter could be discemed after the bolus injection. The immediate $5 \%$ rise in MAP after the bolus injection indicates that baroreceptor activation is also involved in the immediate normalization of the acutely elevated $\mathrm{CO}$, as previously suggested by others (Ludbrook and Graham, 1984; Haneda et al, 1986).

After 2 hours subacute volume loading, the large capacitance veins in liver and intestines have adapted to the new state of hypervolemia (fig 2). This is supported by the, relative to baseline, consistently increased diameter of the IVC (fig 3 ). In this condition, MAP has returned to baseline indicating that the initial baroreceptor activation has subsided. $\mathrm{CO}$ is elevated and SVR proportionally reduced in both groups. These observations differ from the ones in the 
dog, where CO had normalized 2 hours after a bolus of $6 \%$ dextran, in spite of a still elevated BV (Prather et al, 1969). However, the volume load in the latter study was administered rapidly (bolus) which implies that the normal hemodynamic response may have been altered due to the lack of steady state in BV. In addition, this study was performed in anesthetized animals. Anesthesia affects sympathetic tone, a major determinant of vasomotor tone, so a possible venoconstriction may have been blunted. In the present study, no difference in response to the volume load between $\mathrm{P}$ and NP rats was observed. The rise in $\mathrm{CO}$ after the bolus and after 2 hours infusion was comparable in $\mathrm{P}$ and NP rats. This implies that despite a larger intravascular space relative to the nonpregnant state, $\mathrm{P}$ rats have a similar capacity to accomodate an additional rise in BV as compared to nonpregnant controls.

The normalisation of MAP while SVR had further decreased after 2 hours of slow volume load indicates that the balance between $\mathrm{CO}$ and peripheral flows was restored at a higher level. In the new steady state, at least part of the extra systemic flow will be distributed to the kidneys to sustain the accelerated diuresis. However, because peripheral blood flows were not determined in this study, it remains obscure whether the extra $\mathrm{CO}$ was utilized to meet nutritional flow demands only, or whether arteriovenous shunts were opened to funnel the surplus $\mathrm{CO}$. As we are not aware of comparable studies in awake animals, we can only speculate about the fate of the increased $\mathrm{CO}$.

In conclusion, our data suggest that both in the $\mathrm{P}$ and NP rat, a rapid volume load induces a rise in the "stressed" volume only, while slow subacute volume loading induces a rise in both "stressed" (higher $\mathrm{CO}$ ) and "unstressed" (increased venous capacity) volume. Although baseline BV is higher in the $P$ group, the hemodynamic response appears to be similar in the P and in NP state. Additional information is needed about the distribution of the extra $\mathrm{CO}$, to determine whether the rise in $\mathrm{CO}$ is entirely due to e.g. renal vasodilation or whether futile excess $\mathrm{CO}$ is generated. 


\title{
The effects of steady-state hypervolemia on regional blood flows in awake late-pregnant and nonpregnant rats
}

\author{
Peter Focco Boekkooi, Carla M Verkeste, \\ Pramod R Saxena*, Peter Kaufman", and Louis LH Peeters \\ From the Department of Obstetrics and Gynecology, \\ University of Limburg, Maastricht, the *Department of \\ Pharmacology, Erasmus University, Rotterdam, the \\ Netherlands, and the "Department of Anatomy, Rheinisch \\ Westfalische Technische Hochschule, Aachen, \\ West-Germany
}

\section{ABSTRACT}

In a previous study, cardiac output was found to increase in response to a 2 hour steady-state volume load with Haemacel ${ }^{3}$. However, the fate of the extra cardiac output remained obscure. In the present study the hypothesis was tested that both in the pregnant and the nonpregnant state the induced rise in cardiac output was entirely distributed to the kidneys to meet the extra blood flow demands associated with the accelerated diuresis. Cardiac output and organ blood flows were measured with radioactive microspheres in 7 awake late-pregnant and 6 nonpregnant rats. The volume load increased renal blood flow by $80 \%$ in both groups. Blood flow to the carcass increased in both groups without signs of a concomitant rise in muscle activity. Therefore, increased carcass flow was assumed to reflect enhanced arteriovenous shunting through small shunts $(5-11 \mu \mathrm{m})$ in muscle and connective tissue. Similarly, in the nonpregnant group, portal flow had increased consistently without increased food intake. Also this response was assumed to reflect accelerated shunting in the intestinal bed. 
Placental blood flow decreased consistently. Morphometric analysis of placentas subjected to the volume load showed variable microcirculatory congestion. In conclusion, a 2 hour steady-state volume load induces a rise in cardiac output, which is only partly used to meet the increased renal flow requirements. The remainder of the extra cardiac output is presumably directed towards small arteriovenous shunts in the systemic circulation. Placental blood flow decreased consistently, possibly associated with inadequate defensive mechanisms against a raised venous pressure.

\section{INTRODUCTION}

In a previous study (chapter 2) in awake late-pregnant rats, it was demonstrated that a subacute volume load which raised blood volume (BV) to $\approx 20 \%$ above the physiologically raised BV, induces an increase in cardiac output (CO) and a distension of the large veins. These data suggested that subacute, steadystate expansion of the BV has a dual effect on hemodynamics: Part of the extra BV is accomodated as "unstressed" volume in the venous system while the remainder is utilized as "stressed" volume to increase CO. Inasmuch as the CO distribution has not been determined in that study, it was not possible to discern whether the magnitude of the rise in $\mathrm{CO}$ matched or exceeded the extra flow requirements of mainly the kidneys. This is particularly important since excess "futile" CO not only puts extra strain upon the heart, but also represents a potential threat to the fluid exchange in the microcirculation, with susequent edema formation. Therefore, the results of that previous study raised the following questions:

1. Are $\mathrm{CO}$ and peripheral flow demands still in balance during an imposed subacute, steady-state expansion of the vascular compartment?

2. If the increase in CO exceeds the elevated peripheral (nutritional) flow requirements, does the response to volume load in the pregnant state differ quantitatively from that in the nonpregnant state?

3. What is the hemodynamic fate of such an excess or "futile" $\mathrm{CO}$, if any?

4. What are the consequences for placental perfusion?

The objective of the present study was to test the hypothesis that the increase in $\mathrm{CO}$, induced by a steady-state volume load was, in both the pregnant and nonpregnant state, entirely distributed to the kidneys, with in pregnancy no 
consistent effect on placental blood flow. To this end, we determined the effect of a subacute, steady-state volume load on $\mathrm{CO}$ and regional blood flows in awake late-pregnant and nonpregnant rats.

\section{MATERIALS AND METHODS}

The study was performed in 19-days pregnant $(\mathrm{P}, \mathrm{n}=7)$ and nonpregnant Wistar rats (NP, $n=6$ ) obtained from a local breeder (HSD, Zeist, the Netherlands). Two days prior to the experiment, the rats were anesthetized with ether, and polyethylene catheters (PE-10, $\mathrm{OD} / \mathrm{ID}=0.61 / 0.28$, heat-sealed to a piece of $\mathrm{PE}-50$ tubing, $\mathrm{OD} / \mathrm{ID}=0.92 / 0.58$ ) were inserted into the right carotid artery, a femoral artery and a femoral vein, and advanced into the left ventricle of the heart, the abdominal aorta, and the inferior vena cava, respectively. The catheters were tunneled subcutaneously and exteriorized between the shoulder blades. The day before the experiment, the rats were habituated to the metabolic cages in which the experiment was to be performed.

The experiment consisted of an intravenous bolus injection $(2 \mathrm{ml})$ immediately followed by a 2 hour infusion of Haemaccel ${ }^{(3)}$ (Hoechst) at a rate of 6 $\mathrm{ml} /$ hour. This particular infusion rate was chosen on the basis of a preceding evaluation, which showed that a lower infusion rate did not increase BV consistently within two hours, while a higher infusion rate often failed to lead to stability in fluid balance. Steady-state hypervolemia (baseline BV $+20 \%$ ) was reached within 2 hours. At that time, steady-state has been reached in fluid balance, mean arterial pressure (MAP), $\mathrm{CO}$, heart rate (HR), and systemic vascular resistance (SVR) (chapter 2). Haemaccel ${ }^{\circledR}$ is an isotonic colloid solution, composed of a polymer of urea and polypeptides. It is readily excreted in the urine, with negligible metabolic breakdown. The agent is isotonic (Davies, 1987), and known to be well tolerated in rat, with no measurable effect on MAP, $H R$, and respiration rate, even when infused in great amounts (Lowe and McNaughton, 1984).

In the present study, MAP and HR were monitored continuously, from 40 minutes before the bolus injection until after discontinuation of the infusion. $\mathrm{CO}$ and its distribution were measured with $15 \mu \mathrm{m}$ radioactive microspheres using the reference sampling technique (Peeters et al., 1980). To this end, approximately $1.2 \times 10^{5}$ microspheres (NEN, Dreieich, West Germany) suspended in 0.2 $\mathrm{ml}$ saline with Tween $80(0.05 \%)$ added to prevent aggregation, were injected into the left ventricle of the heart over a period of 15 seconds while a reference sample was withdrawn from the abdominal aorta at a rate of $0.5 \mathrm{ml} / \mathrm{min}$. 
Reference sampling encompassed the period between 10 sec before the microspheres injection and $30 \mathrm{sec}$ after its completion. The blood withdrawn was replaced with fresh heparinized blood from a donor Wistar rat. After 2 hours continuous infusion, the microspheres experiment was repeated with a different radioactive label. Changes in BV induced by the volume load were calculated from the observed changes in hematocrit (chapter 2; Katz et al., 1988).

After the $2^{\text {nd }}$ microspheres experiment, the animals were sacrificed with an overdose of pentobarbital. All organs were dissected and weighed. The radioactivity in each tissue aliquot and reference sample was determined with a sodium crystal scintillation counter (Packard, Delft). $\mathrm{CO}$ was calculated as follows:

$$
C O(\mathrm{~m} / \mathrm{min})=\frac{\text { counts per minute in total body * reference sampling rate }}{\text { counts per minute in reference sample }}
$$

Regional blood flows were then calculated as $\mathrm{CO} \times$ fractional entrapment of microspheres as described in detail elsewhere (Saxena et al., 1980). In all rats mixing of the microspheres was considered adequate on the basis of a difference of less than $5 \%$ in fractional entrapment of microspheres by the 2 kidneys (Ishise et al., 1980). The reference sample always contained 400-700 microspheres.

It was considered preferable not to measure baseline BV in the experimental group, because it would require extra blood sampling on top of the reference sampling. Baseline plasma volume was determined by injection of $0.5 \mathrm{ml}$ saline solution containing $1 \mu \mathrm{Ci}^{125} \mathrm{I}$ labeled albumin in a separate group of awake chronically catheterized $P(n=7)$ and NP $(n=6)$ rats. Samples of $0.2 \mathrm{ml}$ blood were withdrawn after $5,10,15$, and 20 minutes. Plasma radioactivity of each sample was plotted on a semilog scale, and extrapolated to zero time. After determining plasma volume, total BV was calculated using the arterial hematocrit (Crispell et al., 1950).

Finally, the placentas from three 19-days pregnant rats were studied morphologically. Immediately after the experiment, the placentas and the fetuses were weighed and the placentas incubated in buffered $4 \%$ formaldehyde. Three days later the placentas were sliced and stained using standard laboratory techniques. The placentas of two rats (19 days pregnant) served as controls. An experienced placentologist evaluated (blinded) the possible morphological implications of volume load for the placental microcirculation (Dr P. Kaufman, Dpt of Anatomy, Rheinisch Westfalische Technische Hochschule, Aachen, West-Germany). The placentas were studied under light microscopy at various magnifications. 
Data are presented as means $\# \mathrm{SD}$ throughout the text. Differences between control and experimental observations were evaluated by Wilcoxon Signed Rank Test. Differences between P and NP groups were evaluated using the Mann-Whitney Test. A probability of less than $5 \%$ was considered significant.

\section{RESULTS}

Baseline hemodynamic variables in the $\mathrm{P}$ and NP group are listed in table 1. Litter size in the 7 pregnant animals ranged from 10 to 14 fetuses. MAP and SVR were lower in the P-group. BV as measured in the separate group of rats, was clearly higher in $P$ than in NP rats: $23.3 \pm 2.2$ and $18.9 \pm 1.8 \mathrm{ml}$, respectively.

Two hours of volume load induced a rise in BV by $19 \%$ and $22 \%$ in the $\mathrm{P}$ and NP group, respectively. This was paralleled by an increase in CO by $\approx 45 \%$ in both groups (table 1). MAP and HR remained unaltered and SVR had decreased by $60 \%$ and $41 \%$ in the P and NP-group, respectively.

Table 2 shows the regional blood flows in baseline condition and after 2 hours of volume load. The baseline blood flows were comparable in both groups, except for a higher myometrial flow in the pregnant rats. The fraction of microspheres recovered from the lungs in both conditions were comparable in the 2 groups. The volume load led to a significant rise in renal and carcass

TABLE 1.

Hemodynamic variables in baseline and experimental condition (means \pm SD)

\begin{tabular}{|c|c|c|c|c|}
\hline & \multicolumn{2}{|l|}{ P-group } & \multicolumn{2}{|l|}{ NP-group } \\
\hline & baseline & $2 \mathrm{hrs}$ & baseline & $2 \mathrm{hrs}$ \\
\hline $\mathrm{CO}(\mathrm{m} \| / \mathrm{min})$ & $109 \pm 20$ & $155 \pm 38^{*}$ & $99 \pm 19$ & $141 \pm 31^{*}$ \\
\hline MAP (mmHg) & $77 \pm 12$ & $71 \pm 17$ & $102 \pm 24^{4}$ & $98 \pm 27$ \\
\hline $\mathrm{SVR}(\mathrm{mmHg} / \mathrm{ml} / \mathrm{min})$ & $0.7 \pm 0.2$ & $0.5 \pm 0.2^{*}$ & $1.4 \pm 0.7^{4}$ & $0.8 \pm 0.3^{*}$ \\
\hline HR (bpm) & $404 \pm 40$ & $374 \pm 51$ & $356 \pm 47$ & $346 \pm 33$ \\
\hline SV $(\mu l)$ & $275 \pm 65$ & $423 \pm 21 *$ & $291 \pm 40$ & $421 \pm 97 *$ \\
\hline
\end{tabular}

${ }^{*} \mathrm{p}<0.05$ (Wilcoxon Ranked Sign test)
${ }^{\#} \mathrm{p}<0.05$ (Mann-Whitney) 
TABLE 2.

Lung fraction (\%) and regional blood flows ( $\mathrm{ml} / \mathrm{min}$ ) before and after 2 hours hypervolemia

\begin{tabular}{lccccc}
\hline & \multicolumn{2}{c}{ P-group } & & \multicolumn{2}{c}{ NP-group } \\
\cline { 5 - 6 } & baseline & $2 \mathrm{hrs}$ & & baseline & $2 \mathrm{hrs}$ \\
& & & & \\
\hline lung fraction & $4.0 \pm 1.6$ & $2.6 \pm 0.9$ & & $2.5 \pm 2.4$ & $1.6 \pm 1.2$ \\
& & & & \\
blood flows: & & & & \\
renal & $12 \pm 3$ & $20 \pm 7 *$ & & $13 \pm 5$ & $23 \pm 9 *$ \\
portal & $28 \pm 6$ & $37 \pm 15$ & & $28 \pm 10$ & $38 \pm 13^{*}$ \\
brain & $2.4 \pm 0.6$ & $3.0 \pm 1.1$ & & $2.7 \pm 0.7$ & $4.5 \pm 1.2$ \\
skin & $9 \pm 3$ & $10 \pm 4$ & & $8 \pm 3$ & $8 \pm 3$ \\
carcass & $27 \pm 10$ & $41 \pm 13^{*}$ & & $33 \pm 10$ & $41 \pm 9^{*}$ \\
myometrial & $2.3 \pm 0.7$ & $1.7 \pm 0.6$ & & $0.3 \pm 0.1^{\#}$ & $0.3 \pm 0.1$ \\
placental & $2.2 \pm 1.0$ & $1.2 \pm 0.6^{*}$ & - & - \\
& & & & \\
\hline
\end{tabular}

${ }^{*} \mathrm{p}<0.05$ (Wilcoxon Signed Rank Test)

\# $\mathrm{p}<0.05$ (Mann-Whitney)

TABLE 3.

Percental change in regional blood flows after 2 hours hypervolemia

\begin{tabular}{lll}
\hline & P-group & NP-group \\
\hline renal & +76 & +87 \\
portal & NS & +37 \\
carcass & +81 & +28 \\
placental & -40 & - \\
\hline
\end{tabular}

flow (skeletal musle, bone, connective tissue) in both groups. In the NP group also portal (intestines and liver) flow had increased consistently, while in the $\mathrm{P}$ group portal flow tended to increase without reaching significance. In the $\mathrm{P}$ group placental blood flow (PBF) had decreased consistently.

The percentage change in renal, portal, carcass and placental flows in response to the volume load, is listed in table 3 . In both groups, renal blood flow 


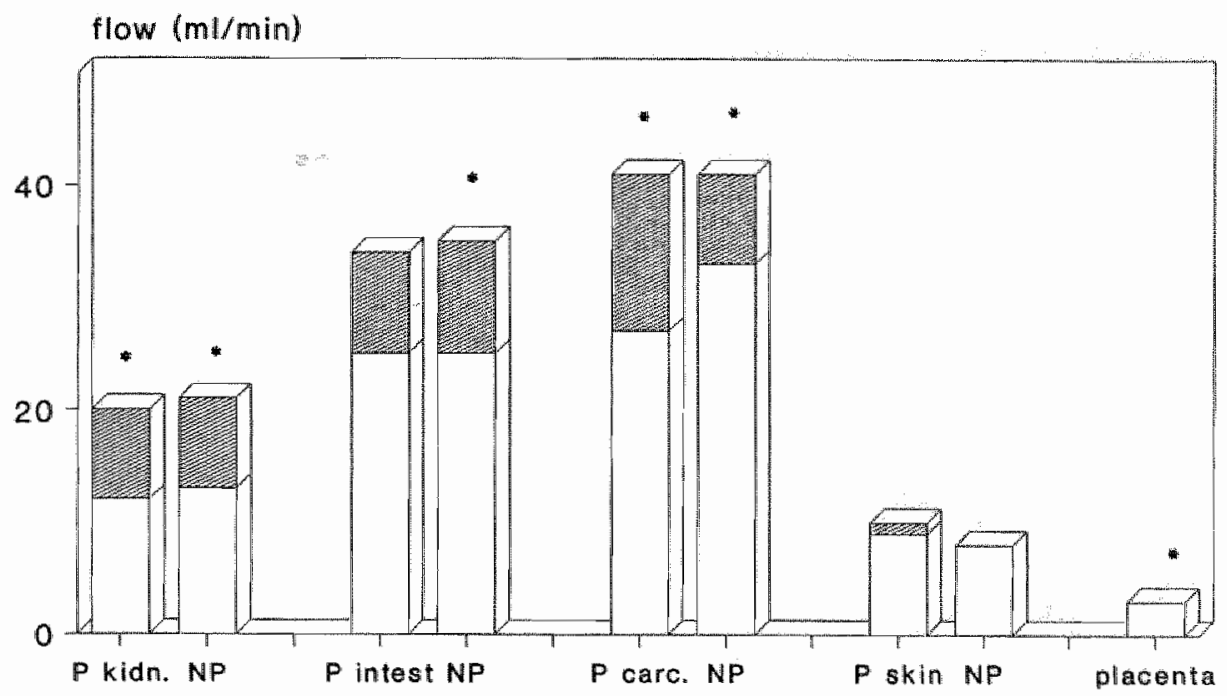

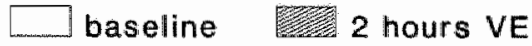

FIGURE 1.

Distribution of the extra CO after 2 hours hypervolemia. In each pair of bars the left bar represents the pregnant group, and the right bar the nonpregnant group. An asterix on top of the bar indicates a significant change from baseline.

increased by about $80 \%$. In the NP group both carcass and portal flow increased by about $30 \%$. In the $\mathrm{P}$ group carcass flow increased by $\approx 80 \%$ and $\mathrm{PBF}$ decreased by $40 \%$.

Figure 1 illustrates the distribution of the extra CO in the P and the NP group. Kidney flow increased by $10 \mathrm{ml} / \mathrm{min}$, and the remainder of the about $45 \mathrm{ml} / \mathrm{min}$ extra $\mathrm{CO}$ was distributed to the carcass and the portal bed.

Figure 2 and 3 illustrate the placental morphology in normal condition, and after subacute volume load. The dark cells are erythrocytes. In baseline they are located in both maternal and fetal vessels. The massively increased number of erythrocytes seen after 2 hours of volume expansion are crowding within the maternall lacunas where they compress the fetal trabeculas with the umbilical microvessels. 


\section{Chapter 3}

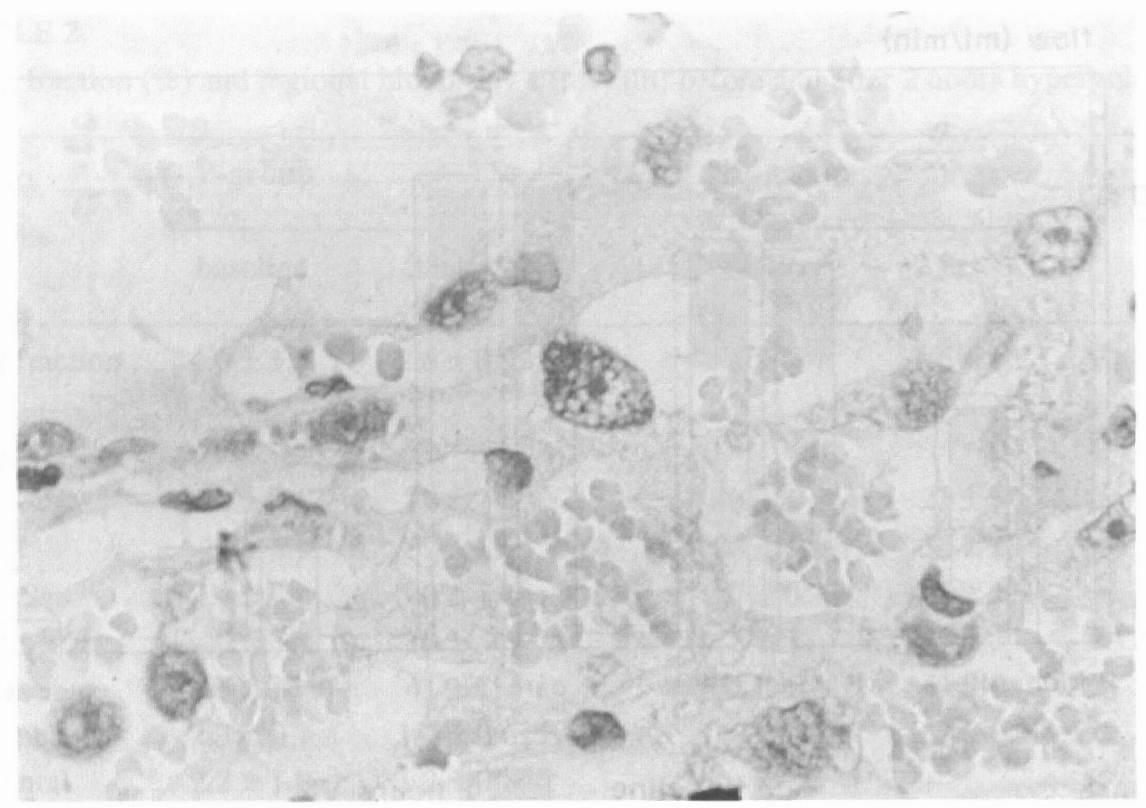

FIGURE 2.

Placental histology in normal rat (120 x magnification)

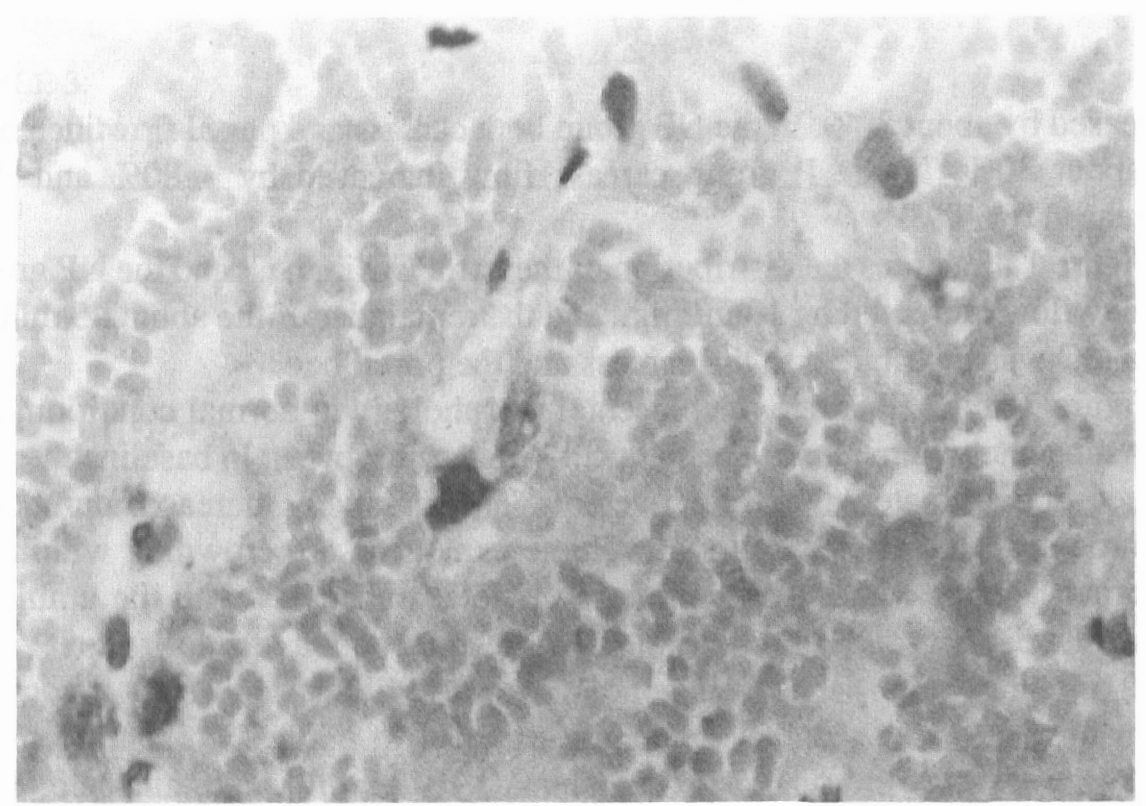

FIGURE 3.

Placental histology after volume expansion (120 x magnification) 


\section{DISCUSSION}

In a previous study in P and NP rats, the same slow, subacute volume load as employed in this study induced a rise in BV, $\mathrm{CO}$ and venous filling (chapter 2). However, no information was obtained about the exact fate of the extra $\mathrm{CO}$. The aim of the present study was to evaluate the fate of the surplus $\mathrm{CO}$. In the previous study, fluid balance and central hemodynamics (CO, MAP, and SVR) had stabilized at the end of the volume load (chapter 2). Inasmuch as also the regional blood flows are likely to have reached steady state by that time, an important condition for the application of the microsphere technique was met. In the rat the microspheres method enables reproducible measurements of all organ flows except for those to liver and spleen (Ishise et al., 1980). The latter limitation, however, is probably inherent to the lack of steady state in that validation study, in which blood flows were measured only 4 hours after catheter implantation. In addition, only 200 microspheres were recovered in the reference samples (Buckberg et al., 1971). Conversely, the present study was performed 2 days after surgery, and the reference samples contained at least 400 microspheres.

To our knowledge, no reliable studies have been reported on $\mathrm{CO}$ and regional blood flows in awake pregnant rats. In one study a mixture of $25 \mu \mathrm{m}$ and $50 \mu \mathrm{m}$ microspheres was injected in the abdominal aorta in half-awake pregnant rats (Yamaguchi et al., 1979). This experimental set-up limits the values of the obtained results, as anesthesia and surgical stress are known to interfere with the cardiovascular function (Maddox et al., 1977). Ahokas and co-workers (Ahokas et al., 1983) reported an elevated $\mathrm{CO}$ in term pregnant rats relative to nonpregnant controls (109 vs $76 \mathrm{ml} / \mathrm{min}$ ). However, these pregnant rats not only had hypertension, but also extremely low renal blood flows, and could therefore not be used in the comparison with our baseline data.

Mean baseline BV in $\mathrm{P}$ rats was $\approx 20 \%$ higher than that in NP rats, a somewhat smaller difference as previously reported for Sprague-Dawley rats still under anesthesia or recovered from surgery for only 3 hours (Atherton $e t$ al., 1982; Barron et al., 1984). In these studies, plasma volume was calculated on the basis of one sample, 5 minutes after injection of Evans blue. The larger fractional leakage of Evans blue to the extravascular space than of 125I-labeled albumin, may explain the observed difference with their findings.

The CO rise induced with the volume load was similar in P and NP rats. About one third of the surplus CO (table 3 ) was directed towards the kidneys, while the remainder was almost entirely directed towards the carcass (figure 1). A rise in portal blood flow was consistent in NP rats, and was present in 6 of 7 
$P$ rats. The higher renal blood flow complies with the accelerated diuresis. The increases in blood flow towards the carcass and the portal bed are more difficult to explain. These tissues are tightly autoregulated, and on the basis of the behavior of the animals during the volume load (quietly sitting without increased food intake) it seemed unlikely that these tissues required more nutritional flow during the volume load. Furthermore, it is unlikely that the observed decrease in hematocrit leads to a higher flow to the muscle, as studies in guinea pigs have shown that isovolemic hemodilution does not affect carcass and intestinal blood flows (Peeters et al., 1987). In a study on the microcircullation in rabbit tenuissimus muscle it was demonstrated that $50 \%$ of the blood flow in rest is shunted through $5-11 \mu \mathrm{m}$ arteriovenous shunts (Oude Vrielink et al., 1987; Lindbom and Arfors, 1984). During exercise local blood flow is redistributed away from these shunts towards the capillaries in the muscle. In the portal bed, it is likely that there are also functional arteriovenous shunts, which are smaller than $15 \mu \mathrm{m}$, as has been demonstrated for the rat (Lundgren, 1984). Assuming unchanged nutritional flow in our study, one can speculate that opening of these shunts led to a fall in vascular resistance in these tissues. This would imply that a large fraction of the $15 \mu \mathrm{m}$ microspheres recovered from carcass and portal tissues after volume loading may have been entrapped in these newly opened small $(5-11 \mu \mathrm{m})$ arteriovenous shunts. This would imply that the imposed subacute expansion of the vascular compartment by $20 \%$ produces excess "futile" $\mathrm{CO}$ which is safely shunted across the systemic circulation without jeopardizing the microcirculatory fluid flux between the capillary bed and interstitium.

The increase in $\mathrm{CO}$ after subacute, slow volume load is likely to be a result of a rise in mean circulatory filling pressure (Guyton et al., 1973). An elevated mean circulatory filling pressure could lead to a rise in systemic capillary pressure and thus also to edema formation (Guyton, 1986). The latter is counteracted by maximal relaxation of the venules and possibly also enhanced fluid removal by the lymphatic system. The presumably elevated mean circulatory filling pressure with no change in MAP, may have reduced the pressure gradient across the placental microcirculation. Absence of venules and a lymphatic drainage in this microcirculation, together with the peculiar rectangular branching pattern in the microcirculation of the rat placenta which lacks the possibility for capillary recruitment or closure, may be associated with a reduced ability to cope with an elevated venous pressure. Also, the lowering effects on the local shear forces may have created unfavorable rheologic conditions causing red cell sludging and accelerated formation of red cell aggregates. Evidence for this is provided by figure 3 , where microcirculatory congestion could be demonstrated. It is obvious that these phenomenona will further increase the resistance 
to flow in the placenta. Apart from these speculations, the present data suggest that the placental perfusion is particularly vulnerable to an increase in "stressed volume", caused by volume loading.

In conclusion, the results of this study indicate that an imposed subacute, steady-state expansion of the vascular compartment by $20 \%$ leads to a comparable response in $\mathrm{P}$ and NP rats. The $\mathrm{CO}$ rise in excess of the increased renal demands, appears to be funneled through small $(5-11 \mu \mathrm{m})$ arteriovenous shunts in carcass tissues and portal bed so as to protect the microcirculatory fluid exchange in the systemic capillary bed. It is speculated that the observed consistent compromize in PBF is a result of a concomitant fall in pressure gradient across the placental microcirculation, leading to microcirculatory congestion. 



\title{
Hypovolemia induced by 24 hours of water deprivation does not affect maternal hemodynamics in awake late-pregnant and nonpregnant rats
}

\author{
Peter Focco Boekkooi, Carla M Verkeste, and \\ Louis LH Peeters
}

From the Department of Obstetrics and Gynecology of the University of Limburg, Maastricht, the Netherlands

\section{ABSTRACT}

In the present study the hypothesis was tested that a prolonged hypovolemia is associated with a reduced cardiac output and a low renal blood flow, and a contracted venous filling. To this end, 6 late-pregnant and 7 nonpregnant rats were prepared with catheters in the left ventricle of the heart, the descending aorta, and the inferior vena cava. Cardiac output, regional blood flows, and mean arterial pressure were measured in baseline, and after 24 hours water deprivation. The latter manipulation reduced blood volume by $7 \%$ in both groups. A separate group of seven late-pregnant rats served as controls, and underwent the same protocol without exposure to water deprivation. In an additional study in 6 nonpregnant rats the outline of the inferior vena cava was photographed by $\mathrm{X}$-ray before and after water deprivation using a standardized procedure. After 24 hours thirsting, cardiac output and its distribution had not changed from baseline in both pregnant and nompregnant rats. Also, the expected growth in placental blood flow between day 19 and day 20 of pregnancy was preserved. The outline of the inferior vena cava had narrowed in all rats following water deprivation. In conclusion, in the awake late-pregnant rat a 
mild gradual reduction in blood volume leads to a compensatory mobilization of venous blood, which permits a maintained cardiac output and a preserved gestational growth of uteroplacental blood flow.

\section{INTRODUCTION}

Recently, we have found in awake late-pregnant rats, that an imposed slow, subacute volume load induced an increase in blood volume (BV) by $20 \%$, which was partially accomodated in the venous compartmant as so called "unstressed volume" (Rothe, 1986), and partially utilized to increase "stressed volume", as indicated by a rise in cardiac output (CO) in excess of nutritional requirements (chapter 2 and 3). This response was similar in the pregnant and the nonpregnant state, despite a $20 \%$ higher baseline BV in the late-pregnant rat (chapter 3). The response of the placental circulation to this subacute volume load was surprising: Placental blood flow (PBF) was consistently compromized. It was hypothesized that the rat placenta with its peculiar vascular microarchitecture lacks the protective mechanisms needed to preserve blood flow when venous pressure and filling state are increased. These responses raise the question as to whether a slow volume depletion triggers an opposite response in maternal hemodynamics: A reduction in the size of the venous compartment, a slightly reduced $\mathrm{CO}$ due to a fall in renal blood flow, and most importantly, a maintained PBF.

In this respect, the differences and similarities with the hemodynamic changes observed in pregnancies complicated by intrauterine growth retardation and preeclampsia may be important. In these pregnancies, BV (Chesley and Lindheimer, 1988), CO (Groenendijk et al., 1984; Belfort et al., 1989; Lindheimer and Katz, 1985) and PBF are reduced (Lunell et al., 1982). The fact that the BV reduction has been found to precede the other cardiovascular changes by weeks, suggests that this could play a key role in the pathogenesis of these pregnancy complications. (Gallery et al., 1979). By imposing a slow and mild volume depletion in the healthy late-pregnant rat, the understanding of the associated hemodynamic changes in response to hypovolemia could be improved, particularly with respect to PBF. It should be emphasized that velocity, magnitude and duration of the $\mathrm{BV}$ reduction are important factors in the response. In the most severe form of hypovolemia, a condition resembling hypovollemic shock (Guyton, 1986) can be expected to evolve with a compromized $\mathrm{CO}$ which is redistributed away from nonvital organs including the placenta. 
The objective of the present study was to test the hypothesis that a gradual mild reduction in $\mathrm{BV}$ not only decreases $\mathrm{CO}$ and renal blood flow, as a sign of volume conservation, but also induces a compensatory venoconstriction. The experiments consisted of the measurement of $\mathrm{CO}$ and regional blood flows in awake late-pregnant rats before and after 24 hours of water deprivation. The contribution of pregnancy to this response was determined by using nonpregnant rats as controls.

\section{MATERIALS AND METHODS}

Prior to the actual study, we performed a validation study in 2 separate groups of 19-days pregnant $(P, n=8)$ and nonpregnant $(N P, n=8)$ Wistar rats. All rats in this validation study and in the actual study were obtained from a local breeder (HSD, Zeist, the Netherlands). The validation study served to quantitate the effect of 24 hours water deprivation on BV and fluid balance in nonpregnant and late-pregnant Wistar rats in which manipulations were kept to a minimum. The change in BV was determined from the change in hematocrit (Hct) induced by 24 hours water deprivation (chapter 2, Katz et al., 1988). Hct was measured in duplicate (microcapillary technique) in a blood sample $(25 \mu \mathrm{l})$ obtained from the orbital venous plexus before (baseline) and after 1 day water deprivation. Blood sampling was performed while the animal was briefly sedated with ether. The impact of water deprivation on the fluid balance was determined by measuring the 24 hours urine output and water intake during the water deprivation.

After this initial evaluation the actual study was performed in six 19-days pregnant (P/exp) and seven nonpregnant rats (NP/exp). A second group of seven 19-days pregnant rats ( $\mathrm{P} / \mathrm{control}$ ) served as control. Two days prior to the experiment, the rats were anesthetized with ether and polyethylene catheters (PE-10, $\mathrm{OD} / \mathrm{ID}=0.61 / 0.28$, heat-sealed to a piece of $\mathrm{PE}-50$ tubing, $\mathrm{OD} / \mathrm{ID}=$ $0.92 / 0.58$ ) were inserted into the right carotid artery and a femoral artery, and advanced into the left ventricle of the heart and the abdominal aorta, respec tively. The catheters were tunneled subcutaneously and exteriorized between the shoulder blades. The day before the experiment, the rats were habituated to the large metabolic cages in which the experiments were to be performed.

Experiments were performed two days after surgery. During the experiment, hypovolemia was induced by 1 day water deprivation. Measurements were 
performed in baseline condition (in P/exp and $\mathrm{P} /$ control: the $19^{\text {th }}$ day of pregnancy) and on the subsequent day, after 1 day of water deprivation. The $\mathrm{P} / \mathrm{control}$ group had free access to water throughout the experimental period.

After connection and elongation of the animals' indwelling catheters, the rats were allowed to stabilize for at least 40 minutes. mean arterial pressure (MAP) and heart rate (HR) were monitored continuously. $\mathrm{CO}$ and its distribution were measured with $15 \mu \mathrm{m}$ microspheres using the reference sampling technique (Peeters et al., 1980). To this end, approximately $1.2 \times 10^{5}$ radioactive microspheres (NEN, Dreieich, West Germany) suspended in $0.2 \mathrm{ml}$ saline with Tween $80(0.05 \%)$ added to prevent aggregation, were injected into the left ventricle of the heart over a period of 15 seconds while a reference sample was withdrawn from the abdominal aorta at a rate of $0.5 \mathrm{ml} / \mathrm{min}$. Reference sampling encompassed the period from 10 seconds before the microspheres injection until 30 seconds after its completion. The blood withdrawn by reference sampling was replaced with fresh heparinized blood from a donor Wistar rat. MAP and HR were not influenced by the injection of microspheres. After the transfusion, the catheters were disconnected and the drinking bottle was removed (only in NP and P/exp groups). On the subsequent day the hemodynamic measurements were repeated using microspheres with a different radioactive label.

After the $2^{\text {nd }}$ microspheres experiment, the animals were sacrificed with an overdose of pentobarbital. All organs were dissected, weighed, and placed in counting vials. The radioactivity in each tissue aliquot and reference sample was determined with a sodium crystal scintillation counter (Packard, Delft). CO was calculated as follows:

$$
C O(\mathrm{~m} / \mathrm{min})=\frac{\text { counts per minute in total body } * \text { reference sampling rate }}{\text { counts per minute in reference sampling rate }}
$$

Regional blood flows were calculated as $\mathrm{CO} x$ fractional entrapment of microspheres, as described in detail elsewhere (Saxena et al., 1980). In all animals, mixing of the microspheres in the systemic circulation was considered adequate on the basis of a less than $5 \%$ difference in the fractional entrapment of microspheres in the kidneys (Ishise et al., 1980). All reference samples contained at least 400 microspheres.

Finally, in an additional study, 6 nonpregnant rats were prepared with two indwelling femoral vein catheters. On the subsequent day, $X$-ray pictures were taken according to a standardized protocol so as to visualize the outline of the inferior vena cava. Following the injection of contrast, an anterior posterior and a lateral picture of the inferior vena cava was taken. Details about the procedure 
are given in chapter 2 . The procedure was repeated after a period of 24 hours of water deprivation. A separate control group ( $n=6$ ) was subjected to the same protocol without the water deprivation.

Data are presented as means $\pm \mathrm{SD}$ throughout the text. Paired differences between control and experimental observations were evaluated by Wilcoxon Signed Rank Test. Differences between the changes in the P/exp group on the one hand and the P/control and NP/exp group on the other hand, were evaluated with the Mann-Whitney test. A probability of less than $5 \%$ (two-sided) was considered significant.

\section{RESULTS}

Table 1 lists the results regarding the effect of thirsting on BV and fluid balance obtained in the validation study. Pregnant rats were heavier and had a lower Hct. In both P and NP rats BV had decreased by $7 \%$ and body weight by 16-19 grams following 24 hours of water deprivation. The daily water intake in baseline was higher, and the urine output during water deprivation had decreased more in the P than in the NP group.

TABLE 1.

General changes after 1 day water deprivation in validation study (mean \pm SD)

\begin{tabular}{|c|c|c|c|c|}
\hline & \multicolumn{2}{|l|}{$P(n=8)$} & \multicolumn{2}{|l|}{$\mathrm{NP}(\mathrm{n}=8)$} \\
\hline & day 0 & day 1 & day 0 & day 1 \\
\hline Het (vol\%) & $43.6 \pm 1.6$ & $46.6 \pm 1.9 *$ & $48.8 \pm 1.9^{H}$ & $52.2 \pm 1.6^{*}$ \\
\hline Weight (gr) & $305 \pm 40$ & $290 \pm 43^{*}$ & $254 \pm 14^{\#}$ & $238 \pm 16^{*}$ \\
\hline Water intake (ml/day) & $37 \pm 7$ & 0 & $26 \pm 5^{\#}$ & 0 \\
\hline Urine output (ml/day) & $18 \pm 7$ & $4 \pm 2^{*}$ & $14 \pm 5$ & $10 \pm 3$ \\
\hline BV change (\%) & $-7 \pm 1 \%$ & & $-7 \pm 2 \%$ & \\
\hline Weight loss (gr) & $-16 \pm 7$ & & $-19 \pm 3$ & \\
\hline
\end{tabular}

means $\pm S D$

${ }^{*} \mathrm{p}<0.05$ (Wilcoxon Signed Rank Test)

$\# \mathrm{p}<0.05$ (Mann-Whitney) 
Chapter 4

TABLE 2.

Hemodynamic parameters before and after 24 hours water deprivation (actual study)

\begin{tabular}{|c|c|c|c|c|c|c|}
\hline \multirow{2}{*}{ 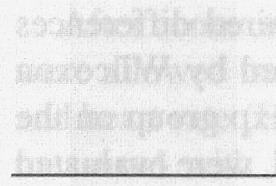 } & \multicolumn{2}{|l|}{ P/exp } & \multicolumn{2}{|l|}{ P/control } & \multicolumn{2}{|l|}{ NP-exp } \\
\hline & baseline & $24 \mathrm{hrs}$ & baseline & $24 \mathrm{hrs}$ & baseline & 24 hours \\
\hline $\mathrm{CO}(\mathrm{ml} / \mathrm{min})$ & $105 \pm 34$ & $96 \pm 21$ & $104 \pm 27$ & $109 \pm 19$ & $97 \pm 24$ & $94 \pm 29$ \\
\hline $\operatorname{MAP}(\mathrm{mmHg})$ & $107 \pm 13$ & $96 \pm 23$ & $90 \pm 7$ & $89 \pm 18$ & $104 \pm 13$ & $103 \pm 19$ \\
\hline SVR $(\mathrm{mmHg} / \mathrm{ml} / \mathrm{min})$ & $1.1 \pm 0.3$ & $1.0 \pm 0.3$ & $1.1 \pm 0.5$ & $0.9 \pm 0.3$ & $1.3 \pm 0.4$ & $1.2 \pm 0.4$ \\
\hline HR (bpm) & $413 \pm 29$ & $411 \pm 26$ & $400 \pm 51$ & $450 \pm 22$ & $403 \pm 33$ & $411 \pm 34$ \\
\hline $\mathrm{SV}(\mu \mathrm{l})$ & $259 \pm 95$ & $236 \pm 61$ & $265 \pm 109$ & $241 \pm 35$ & $242 \pm 62$ & $234 \pm 91$ \\
\hline
\end{tabular}

\section{means $\pm \mathrm{SD}$}

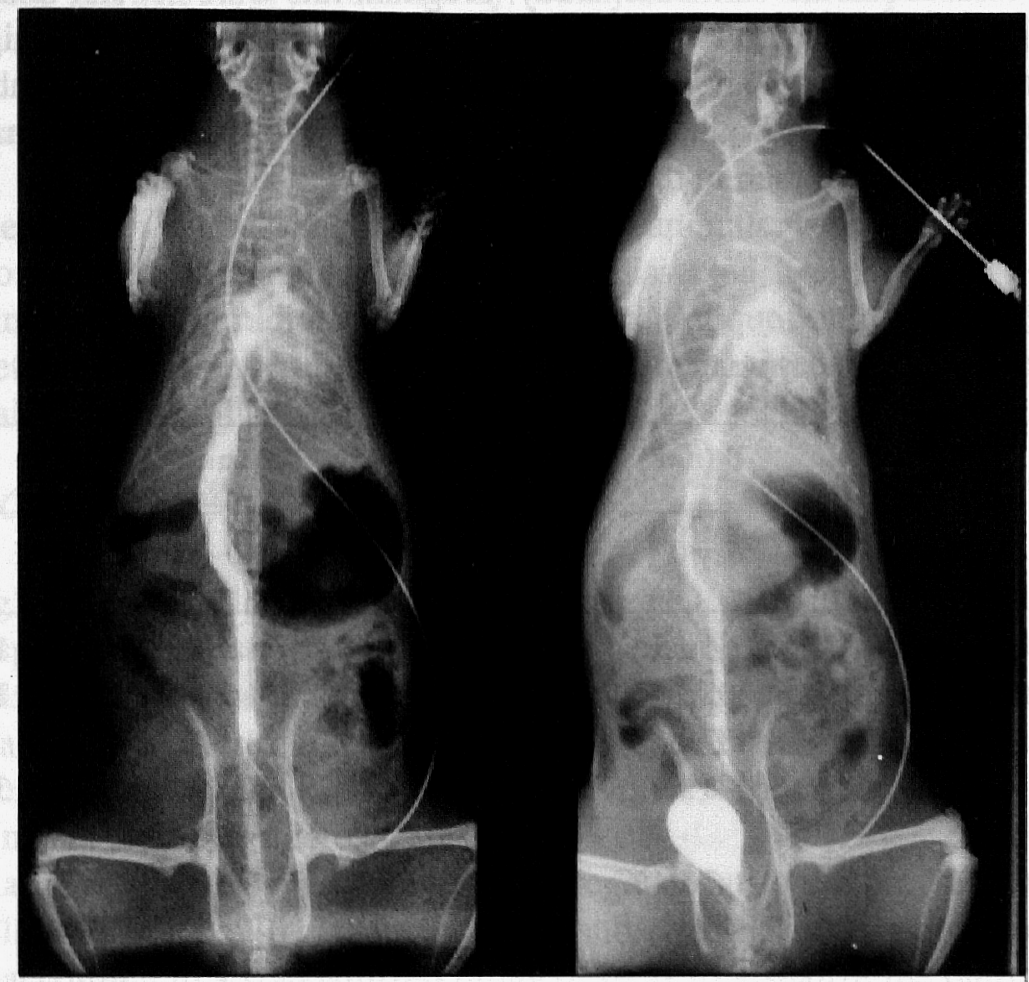

\section{FIGURE 1.}

Anterior posterior X-ray picture of inferior vena cava before (left panel) and after 24 hours thirsting (right panel). 
The hemodynamic parameters before, and after 24 hours thirst as measured in the actual study are listed in table 2. CO, MAP, systemic vascular resistance (SVR), HR, and stroke volume (SV) changed little and inconsistently in all 3 groups.

The diameter of the inferior vena cava had decreased in the two experimental groups. This reduction in venous filling was observed in the anterior posterior pictures. The diameter of the inferior vena cava as simultaneously visualized by the lateral pictures had not changed appreciably. In figure 1, the 2 anterior posterior pictures are shown as obtained in an animal subjected to 24 hours thirsting. In the control group, the diameter of the inferior vena cava had not changed after 24 hours.

Table 3 lists the lung fraction and organ flows in the 3 groups, in baseline and after 24 hours. In the P/exp and P/control group the lung fraction had decreased similarly and significantly, suggesting secondary leakage of microspheres. This phenomenon was not observed in the NP/exp group. The nonuterine organ flows in baseline condition and after 24 hours of water deprivation were comparable in the P/exp and NP group. Meanwhile, in the P/exp group PBF had

\section{TABLE 3.}

Lung fraction (\%) and regional blood flows $(\mathrm{ml} / \mathrm{min})$ at baseline and after 24 hours water deprivation.

\begin{tabular}{|c|c|c|c|c|c|c|}
\hline & \multicolumn{2}{|l|}{ P/exp } & \multicolumn{2}{|l|}{ P/control } & \multicolumn{2}{|l|}{ NP/exp } \\
\hline & baseline & $24 \mathrm{hrs}$ & baseline & $24 \mathrm{hrs}$ & baseline & $24 \mathrm{hrs}$ \\
\hline lung fraction (\%) & $5.9 \pm 2.8$ & $2.7 \pm 0.7^{*}$ & $5.8 \pm 2.3$ & $1.7 \pm 1.6^{*}$ & $2.5 \pm 2.1$ & $1.4 \pm 0.7$ \\
\hline \multicolumn{7}{|l|}{ organ flows: } \\
\hline kidneys & $11 \pm 4$ & $11 \pm 2$ & $13 \pm 5$ & $12 \pm 4$ & $16 \pm 5$ & $13 \pm 4$ \\
\hline portal bed & $26 \pm 9$ & $20 \pm 3$ & $24 \pm 10$ & $24 \pm 8$ & $26 \pm 6$ & $17 \pm 7$ \\
\hline brain & $3 \pm 1$ & $3 \pm 1$ & $3 \pm 1$ & $3 \pm 1$ & $3 \pm 1$ & $3 \pm 2$ \\
\hline skin & $11 \pm 4$ & $8 \pm 2$ & $11 \pm 2$ & $11 \pm 3$ & $8 \pm 3$ & $7 \pm 3$ \\
\hline carcass & $31 \pm 10$ & $32 \pm 14$ & $23 \pm 9$ & $32 \pm 8$ & $30 \pm 10$ & $42 \pm 15$ \\
\hline myometrium & $2.4 \pm 1.3$ & $1.7 \pm 0.4$ & $2.3 \pm 1.1$ & $1.9 \pm 0.8$ & $0.3 \pm 0.1$ & $0.3 \pm 0.2$ \\
\hline placentas & $1.4 \pm 1.1$ & $4.0 \pm 1.8^{*}$ & $\quad 0.7 \pm 0.5$ & $4.4 \pm 1.1$ & - & - \\
\hline
\end{tabular}

means \pm SD

${ }^{*} \mathrm{p}<0.05$ (Wilcoxon Signed Rank Test) 
increased after water deprivation to a value similar to that in the P/control group. In the P/exp and the NP/exp group organ flows were comparable before and after 24 hours thirst, although portal blood flow showed a tendency to decrease.

\section{DISCUSSION}

In order to accept or reject the hypothesis that $\mathrm{CO}$ and organ flows are protected against slowly induced mild volume depletion, the imposed BV reduction should be as selective as possible in order to minimize activation of the sympathetic nervous system. The advantage of 24 hours water deprivation as adopted in the present study is that it reduces BV not only gradually but also mildly, without causing demonstrable stress or discomfort to the animal. The weight loss of 16-19 $\mathrm{g}$ in the P/exp and NP/exp groups reflect the fall in total body water. This decrease is probably larger in the P rats, because from day 19 to day 20 of pregnancy, the weight gain of rats amounts to $20 \mathrm{~g}$. This method of $B V$ reduction was considered preferable over available alternative methods: Intraperitoneal injection of polyethylene glycol results in an acute instead of gradual decrease in BV (Barron et al., 1984; Gardiner et al., 1989) whereas chronic restriction of the water intake for e.g. 5 days as opposed to complete deprivation for a single day prolongs the induced catabolic state with increased likelihood for secondary effects on hemodynamics and BV. The water deprivation as employed in the present study, is known to raise vasopressin levels in both $\mathrm{P}$ and NP rats (Durr et al., 1981). In the present study BV decreased by $7 \%$ after 1 day thirst in both $P$ and NP rats. At day 19 of pregnancy, the BV of pregnant rats is still expanding, so the relative decrease in $\mathrm{BV}$ is larger in $\mathrm{P}$ than in NP rats. Our finding that $P$ rats drink more water than NP rats (table 1) confirms the results of Durr and coworkers (Durr et al., 1981), and supports the concept that pregnant rats suffer more from one day thirst than nonpregnant controls.

In the P/exp and in the NP/exp group, none of the hemodynamic parameters changed significantly, despite a $7 \%$ decrease in BV after 24 hours water deprivation. $\mathrm{CO}$ was maintained, supporting the concept of a compensatory venoconstriction in response to mild volume depletion in order to maintain $\mathrm{CO}$. This means that "stressed volume" is maintained at the cost of "unstressed volume" (Rothe, 1986). Support for this concept was obtained by demonstrating a decrease in the diameter of the inferior vena cava after one day thirsting relative to baseline (figure 1 ). 
None of the organ flows changed significantly in response to thirsting, except for PBF which had increased in the P/exp group. By comparing this rise with the change in PBF in the P/control group, it was possible to separate the rise in $\mathrm{PBF}$ due to advancing pregnancy from that associated with thirsting-related hypovolemia. This comparison indicated that the rise in PBF was entirely related to the advancement of pregnancy, thus not only confirming an unaffected growth in the uteroplacental perfusion during the induced manipulation, but also demonstrating the efficacy of the compensatory mechanisms. Although none of the organ flows had changed consistently after water deprivation, the lower fraction of $\mathrm{CO}$ recovered from the lungs after the water deprivation indicates secondary shunting of microspheres across the systemic circulation. In the $\mathrm{P} /$ control group and in the $\mathrm{P} / \mathrm{exp}$ group, a comparable shunting rate was observed (table 3 ). The more pronounced decrease in lung fraction in both $\mathrm{P}$ groups as compared to the NP group indicates that the placenta is likely to represent an important source of leakage. Inasmuch as this leakage was not seen in a previous study where rats were sacrificed about 2-3 hours after the first microspheres experiment (chapter 3), the leakage appears to occur slowly overnight. As the percentage fall in lung fraction did not differ between the 2 pregnant groups, this observation suggests that the microspheres technique leads to underestimation of PBF in late-pregnant rats when the animal is sacrificed 24 hours after the microspheres injection, irrespective of the manipulation. The consequences for the results in the present study, are that the values for baseline PBF are probably underestimated. By comparing the PBF determined on the $2^{\text {nd }}$ day in the P/exp with that in the P/control group, this technical limitation was circumvented.

In conclusion, the results of the present study suggest that, in awake latepregnant rats, a prolonged mild decrease in BV leads to a compensatory mobilization of venous blood so as to maintain venous return and $\mathrm{CO}$. Furthermore, we conclude that despite the probably larger impact of water deprivation on BV in the pregnant state, the response is comparable with that in the nonpregnant state.

With respect to possible clinical implications, one should realize that the 24 hours water deprivation as employed in the present study to reduce $\mathrm{BV}$, is associated with a certain rate, magnitude and duration in BV depletion. This is probably different from those occurring in the previously mentioned human pregnancy complications. Still, the present data suggest that mild BV depletion activates a highly efficient hemodynamic response which serves to protect systemic blood flow. In intrauterine growth retardation, this response may be impaired by the underlying disease, or may have become inadequate due to the magnitude and duration of the BV reduction. This is supported by the markedly 
elevated levels of atrial natriuretic peptide in preeclampsia (Thomsen et al., 1987). On the other hand, it is also possible that the observed failure of BV, CO, and PBF to increase appropiately in complicated pregnancy is coincidental, reflecting concomitantly developing, independent complications with a common yet unknown cause. 


\title{
The effect of volume expansion on placental blood flow in awake hypovolemic late-pregnant rats
}

\author{
Peter Focco Boekkooi MD, Carla M Verkeste, and \\ Louis LH Peeters MD PhD
}

From the Department of Obstetrics and Gynecology of the University of Limburg, Maastricht, the Netherlands

Accepted for publication in the American Journal of Obstetrics and Gynecology

\section{ABSTRACT}

In a previous study in normovolemic late-pregnant rats, we found that slow, subacute volume loading led to a fall in placental blood flow. In the present study the hypothesis was tested that slow volume loading when imposed to volume depleted rats, does not compromize placental blood flow. Mild hypovolemia was induced in late-pregnant rats by subjecting them to 24 hours thirsting, which decreased blood volume by $7 \%$. In this condition, the rats were subjected to a slow, 2 hour volume load, which was similar as previously performed in normovolemic rats. Volume expansion increased blood volume by $32 \%$ and cardiac output by $73 \%$. The extra cardiac output was distributed to kidneys, carcass, and portal bed. Placental blood flow had decreased by $31 \%$. Although the character of the response was comparable to the one previously observed in normovolemic rats, the magnitude of the changes was larger. The difference appeared to be caused by a delayed diuretic response. It is concluded that, compared with the response in normovolemic rats, the hemodynamic response to slow volume loading is comparable, but more pronounced, probably due to a protracted diuretic response. 


\section{INTRODUCTION}

The only causal treatment for preeclampsia is delivery of the fetus. However, when gestational age is less than $\approx 30$ weeks, the fetall risks associated with premature birth may be higher than those associated with preeclampsia. In recent years, symptomatic treatment of severe preeclampsia by volume expansion with plasma or plasma substitutes, rapidly gained popularity. The objective of this therapy is to "correct" the contracted plasma volume compartment in this disease (Goodlin et al., 1981). It has been demonstrated that this regime is often associated with a dramatic improvement in the patients' clinical condition, with rapid amelioration of the reduced cardiac output (CO), marginal urine output, and elevated peripheral vascular resistance (Gallery, 1984; Wallenburg, 1988; Wasserstrum et al., 1989). However, subjecting a patient to this treatment requires admission in an intensive care unit and hemodynamic monitoring with a Swan-Ganz catheter (Groenendijk et al., 1984). In addition, it is still unknown how the uteroplacental blood flow (UBF) responds to relatively rapid volume expansion. Conflicting evidence suggests both a variable decrease (Jouppila et al., 1983), and increase in UBF (Cloeren and Lippert, 1972; Siekmann et al., 1986) after volume expansion, but the employed techniques, isotope dilution (Jouppila et al., 1983; Cloeren and Lippert, 1972) and doppler velocity measurements made in a branch of the uterine artery (Siekmann et al., 1986), provide only indirect information on UBF.

Volume regulation is primarily controlled through stretch receptors located. in the large veins and the atria (Rothe, 1983). Besides, the veins have the structural ability to dilate slowly in response to a rapid increase in intraluminal pressure, the so-called stress-relaxation phenomenon (Guyton, 1986). However, the impact of conditions such as chronic venous underfilling (preeclampsia), or of the chronic exposure of the veins to a certain endocrine environment (pregnancy) on these 2 important aspects is unknown. In previous studies on volume regulation in the awake late-pregnant rat, it was demonstrated that the hemodynamic effect of slow, subacute volume loads was indeed primarily determined by the response of the venous compartment (chapter 2 to 4 ). In addition, although $\mathrm{CO}$ increased by a larger fraction than needed to satisfy nutritional requirements, UBF decreased consistently. These studies were performed in normovolemic late-pregnant rats. It is likely that the same volume load in a hypovolemic animal with a reduced content of the venous compartment, and also an increased venous tone, induces a different hemodynamic response. Particularly, the effect on the UBF is obscure. If the response is 
similar to that in normovolemia, UBF will fall in response to volume load. However, "correction" of the hypovolemia may also reduce sympathetic tone, which may neutralize or even reverse the expected negative effect on UBF.

The present study was designed to test the hypothesis that volume expansion in stable, hypovolemic late-pregnant rats not only increases $\mathrm{CO}$ and diuresis, but also UBF due to neutralization of the hypovolemic stress. To this end, late-pregnant rats which were mildly hypovolemic as at result of 24 hours thirsting, were subjected to slow, subacute volume loading by a steady-state infusion with a plasma substitute $\left(\right.$ Haemaccel $^{\circledR}$ ). $\mathrm{CO}$ and regional blood flows were measured with microspheres before and after 2 hours of volume load. To determine the contribution of pregnancy to the volume response, the same experiments were also performed in a nonpregnant control group.

\section{MATERIALS AND METHODS}

The study was performed in 20-days pregnant ( $P, n=7$ ) and nonpregnant (NP, $\mathrm{n}=6$ ), hypovolemic Wistar rats, obtained from a local breeder (HSD, Zeist, the Netherlands). A separate group of 7,20-days pregnant rats served as controls for the $\mathrm{P}$ rats $(\mathrm{C}, \mathrm{n}=7)$. Three days before the experiment, the rats were anesthetized with ether, and polyethylene catheters (PE-10, OD/ID $=0.61 / 0.28$, heat-sealed to a piece of $\mathrm{PE}-50$ tubing, $\mathrm{OD} / \mathrm{ID}=0.92 / 0.58$ ) were inserted into the right carotid artery, a femoral artery, and a femoral vein, and advanced into the left ventricle of the heart, the abdominal aorta, and the inferior vena cava, respectively. The catheters were tunneled subcutaneously and exteriorized between the shoulder blades. One day prior to the experiment, the rats were habituated to the large metabolism cages in which the experiments were to be performed.

After a recovery period of 2 days (in P: day 19 of pregnancy), the rats in the $P$ and NP group were deprived of water. After 24 hours thirst, the catheters were connected and elongated. Mean arterial pressure (MAP) and heart rate (HR) were monitored continuously, for 30 minutes prior to the bolus injection until after the $2^{\text {nd }}$ injection of microspheres. Urine output was measured each 30 minutes. When HR and MAP had been stable for at least 30 minutes, $\mathrm{CO}$ and its distribution were determined with $15 \mu \mathrm{m}$ microspheres using the reference sampling technique (Peeters et al., 1980). To this end, approximately $1.2 \times 10^{5}$ radioactive microspheres (NEN, Dreieich, West Germany) suspended in $0.2 \mathrm{ml}$ saline with Tween $80(0.05 \%)$ added to prevent aggregation, were injected into the left ventricle of the heart over a period of 15 seconds while a reference 


\section{INTRODUCTION}

The only causal treatment for preeclampsia is delivery of the fetus. However, when gestational age is less than $\approx 30$ weeks, the fetal risks associated with premature birth may be higher than those associated with preeclampsia. In recent years, symptomatic treatment of severe preeclampsia by volume expansion with plasma or plasma substitutes, rapidly gained popularity. The objective of this therapy is to "correct" the contracted plasma volume compartment in this disease (Goodlin et al., 1981). It has been demonstrated that this regime is often associated with a dramatic improvement in the patients' clinical condition, with rapid amelioration of the reduced cardiac output $(\mathrm{CO})$, marginal urine output, and elevated peripheral vascular resistance (Gallery, 1984; Wallenburg, 1988; Wasserstrum et al., 1989). However, subjecting a patient to this treatment requires admission in an intensive care unit and hemodynamic monitoring with a Swan-Ganz catheter (Groenendijk et al., 1984). In addition, it is still unknown how the uteroplacental blood flow (UBF) responds to relatively rapid volume expansion. Conflicting evidence suggests both a variable decrease (Jouppila et al., 1983), and increase in UBF (Cloeren and Lippert, 1972; Siekmann et al., 1986) after volume expansion, but the employed techniques, isotope dilution (Jouppila et al., 1983; Cloeren and Lippert, 1972) and doppler velocity measurements made in a branch of the uterine artery (Siekmann et al., 1986), provide only indirect information on UBF.

Volume regulation is primarily controlled through stretch receptors located in the large veins and the atria (Rothe, 1983). Besides, the veins have the structural ability to dilate slowly in response to a rapid increase in intraluminal pressure, the so-called stress-relaxation phenomenon (Guyton, 1986). However, the impact of conditions such as chronic venous underfilling (preeclampsia), or of the chronic exposure of the veins to a certain endocrine environment (pregnancy) on these 2 important aspects is unknown. In previous studies on volume regulation in the awake late-pregnant rat, it was demonstrated that the hemodynamic effect of slow, subacute volume loads was indeed primarily determined by the response of the venous compartment (chapter 2 to 4 ). In addition, although $\mathrm{CO}$ increased by a larger fraction than needed to satisfy nutritional requirements, UBF decreased consistently. These studies were performed in normovolemic late-pregnant rats. It is likely that the same volume load in a hypovolemic animal with a reduced content of the venous compartment, and also an increased venous tone, induces a different hemodynamic response. Particularly, the effect on the UBF is obscure. If the response is 
similar to that in normovolemia, UBF will fall in response to volume load. However, "correction" of the hypovolemia may also reduce sympathetic tone, which may neutralize or even reverse the expected negative effect on UBF.

The present study was designed to test the hypothesis that volume expansion in stable, hypovolemic late-pregnant rats not only increases $\mathrm{CO}$ and diuresis, but also UBF due to neutralization of the hypovolemic stress. To this end, late-pregnant rats which were mildly hypovolemic as a result of 24 hours thirsting, were subjected to slow, subacute volume loading by a steady-state infusion with a plasma substitute $\left(\mathrm{Haemaccel}^{\circ}\right.$ ). $\mathrm{CO}$ and regional blood flows were measured with microspheres before and after 2 hours of volume load. To determine the contribution of pregnancy to the volume response, the same experiments were also performed in a nonpregnant control group.

\section{MATERIALS AND METHODS}

The study was performed in 20-days pregnant $(\mathrm{P}, \mathrm{n}=7)$ and nonpregnant (NP, $\mathrm{n}=6$ ), hypovolemic Wistar rats, obtained from a local breeder (HSD, Zeist, the Netherlands). A separate group of 7,20-days pregnant rats served as controls for the $P$ rats $(C, n=7)$. Three days before the experiment, the rats were anesthetized with ether, and polyethylene catheters ( $\mathrm{PE}-10, \mathrm{OD} / \mathrm{ID}=0.61 / 10.28$, heat-sealed to a piece of $\mathrm{PE}-50$ tubing, $\mathrm{OD} / \mathrm{ID}=0.92 / 0.58$ ) were inserted into the right carotid artery, a femoral artery, and a femoral vein, and advanced into the left ventricle of the heart, the abdominal aorta, and the inferior vena cava, respectively. The catheters were tunneled subcutaneously and exteriorized between the shoulder blades. One day prior to the experiment, the rats were habituated to the large metabolism cages in which the experiments were to be performed.

After a recovery period of 2 days (in P: day 19 of pregnancy), the rats in the $P$ and NP group were deprived of water. After 24 hours thirst, the catheters were connected and elongated. Mean arterial pressure (MAP) and heart rate (HR) were monitored continuously, for 30 minutes prior to the bolus injection until after the $2^{\text {nd }}$ injection of microspheres. Urine output was measured each 30 minutes. When HR and MAP had been stable for at least 30 minutes, $\mathrm{CO}$ and its distribution were determined with $15 \mu \mathrm{m}$ microspheres using the reference sampling technique (Peeters et al., 1980). To this end, approximately $1.2 \times 10^{5}$ radioactive microspheres (NEN, Dreieich, West Germany) suspended in $0.2 \mathrm{ml}$ saline with Tween $80(0.05 \%)$ added to prevent aggregation, were injected into the left ventricle of the heart over a period of 15 seconds while a reference 
sample was withdrawn from the abdominal aorta at a rate of $0.5 \mathrm{ml} / \mathrm{min}$. Reference sampling encompassed the period between 10 seconds before the microspheres injection and 30 seconds after its completion. The blood withdrawn was replaced with fresh heparinized blood from a donor Wistar rat. After the baseline microspheres experiment an intravenous bolus injection of Haemaccel ${ }^{\oplus}$ (Hoechst) $(2 \mathrm{ml}$ ) was administered, immediately followed by a 2 hour infusion at a rate of $6 \mathrm{ml} /$ hour. Haemaccel ${ }^{3}$ is an isotonic colloid solution, composed of a polymer of urea and polypeptides. It is readily excreted in the urine, with little metabolic breakdown. The agent is isotonic, and therefore does not leak appreciably to the interstitial space following intravascular administration (Davies, 1987). Haemaccel ${ }^{2}$ is known to be well tolerated in rats, with no measurable effect on MAP, HR and respiration rate, even when infused in large amounts (Lowe and McNaughton, 1984).

After 2 hours continuous infusion, the microspheres experiment was repeated with a different radioactive label. In the $\mathrm{C}$ group only one blood flow measurement was performed, after a stabilization period of at least 30 minutes. During the experiment changes in blood volume were calculated from the observed changes in hematocrit (chapter 2 ).

After the $2^{\text {nd }}$ microspheres experiment, the animals were sacrificed with an overdose of pentobarbital. All organs were dissected and weighed. The radioactivity in each tissue aliquot and reference sample was determined with a sodium crystal scintillation counter (Packard, Delft). $\mathrm{CO}$ was calculated as follows:

$$
C O(\mathrm{~m} / \mathrm{min})=\frac{\text { counts per minute in total body } * \text { reference sampling rate }}{\text { counts per minute in reference sample }}
$$

Regional blood flows were then calculated as $\mathrm{CO} x$ fractional entrapment of microspheres as described in detail elsewhere (Saxena et al., 1980). Mixing of the microspheres after injection was considered adequate on the basis of a less than $5 \%$ difference in fractional entrapment of microspheres in the 2 kidneys (Ishise et al., 1980). This was the case in all animals. The number of microspheres recovered in the reference samples ranged from 400 to 700 .

Data are presented as means $\pm S D$ throughout the text. Paired data obtained after volume load and in baseline were evaluated with Wilcoxon Signed Rank Test. Differences between $P$ and NP and between $P$ and $C$, were tested by the Mann-Whitney test. A probability of less than 5\% (two-sided) was considered significant. 


\section{RESULTS}

One day of water deprivation decreased blood volume by $7 \%$ in both groups. Table 1 lists the baseline values for $\mathrm{CO}, \mathrm{MAP}$, systemic vascular resistance (SVR), stroke volume and body weight after 1 day thirsting and those in the $\mathrm{C}$ group. Pregnant rats were heavier than their age-matched nonpregnant countermates. Neither by paired analysis, nor by comparison of data of the $\mathrm{P}$ with the $\mathrm{C}$ group, had any of the hemodynamic variables changed in response to the water deprivation (chapter 4 ). The results of this analysis were comparable for $P$ and NP rats.

Volume expansion increased BV by $32 \%$ and $35 \%$ in the P and the NP group, respectively (table 2). In the $\mathrm{P}$ and NP group, volume load increased CO by $73 \%$ and $46 \%$, and decreased SVR by $39 \%$ and $23 \%$, respectively. The change in these 2 variables was smaller in the NP than in the $\mathrm{P}$ group. The rise in $\mathrm{CO}$ was mainly a result of a rise in stroke volume. Neither MAP nor HR had changed appreciably in the $\mathrm{P}$ and NP group.

The lung fraction and organ flows before and after volume expansion and those in the C-group are listed in table 3 . The volume load induced a rise in renal flow by $127 \%$ and $94 \%$ in the $\mathrm{P}$ and NP group, respectively. Portal flow increased by $60 \%$ in both groups, while carcass flow had increased only in the $P$ group. Blood flows to brain, skin, and myometrium had changed little and inconsistently in both groups. Figure 1 summarizes the results and shows the

TABLE 1.

Baseline values

\begin{tabular}{lccc}
\hline & P-group & C-group & NP-group \\
\hline body weight $(\mathrm{g})$ & $264 \pm 39$ & $252 \pm 17$ & $232 \pm 22^{*}$ \\
CO (ml/min) & $92 \pm 15$ & $109 \pm 19$ & $84 \pm 21$ \\
MAP (mmHg) & $95 \pm 21$ & $89 \pm 18$ & $104 \pm 12$ \\
SVR (mmHg/ml/min) & $1.0 \pm 0.2$ & $0.9 \pm 0.3$ & $1.3 \pm 0.4$ \\
HR (bpm) & $404 \pm 27$ & $450 \pm 22^{*}$ & $421 \pm 21$ \\
SV $(\mu \mathrm{l})$ & $229 \pm 43$ & $241 \pm 35$ & $208 \pm 45$
\end{tabular}

means $\pm \mathrm{SD}$

$* p<0.05$ (Mann-Whitney) 
Chapter 5

TABLE 2.

Percentage change in hemodynamic parameters after 2 hours hypervolemia

\begin{tabular}{lll} 
& P-group & NP-group \\
\hline blood volume & +32 & +35 \\
CO & +73 & $+46^{*}$ \\
MAP & NS & NS \\
SWR & -39 & $-23^{*}$ \\
HR & NS & NS \\
stroke volume & +68 & +58 \\
\hline
\end{tabular}

$* p<0.05$ (Mann-Whitney)

TABLE 3.

Lung fraction (\%) and regional blood flows ( $\mathrm{ml} / \mathrm{min} / 100 \mathrm{~g}$ ) before and after 2 hours hypervolemia

\begin{tabular}{|c|c|c|c|c|c|}
\hline & \multicolumn{2}{|l|}{ P-group } & \multirow{2}{*}{$\frac{\text { C-group }}{\text { baseline }}$} & \multicolumn{2}{|l|}{ NP-group } \\
\hline & baseline & $2 \mathrm{hrs}$ & & baseline & $2 \mathrm{hrs}$ \\
\hline lung fraction & $3.7 \pm 1.4$ & $1.7 \pm 0.6^{*}$ & $1.7 \pm 1.6$ & $1.9 \pm 0.7$ & $2.2 \pm 1.0$ \\
\hline \multicolumn{6}{|l|}{ organ flows: } \\
\hline kidneys & $10 \pm 2$ & $23 \pm 5^{*}$ & $12 \pm 4$ & $11 \pm 3$ & $20 \pm 6^{*}$ \\
\hline intestines & $20 \pm 4$ & $28 \pm 8$ & $22 \pm 8$ & $14 \pm 4$ & $20 \pm 6^{*}$ \\
\hline portal & $21 \pm 4$ & $33 \pm 7^{*}$ & $24 \pm 8$ & $15 \pm 5$ & $24 \pm 8 *$ \\
\hline brain & $2.6 \pm 0.7$ & $3.5 \pm 0.7$ & $3.0 \pm 1.0$ & $3.0 \pm 1.0$ & $4.1 \pm 1.7$ \\
\hline skin & $9 \pm 2$ & $10 \pm 4$ & $11 \pm 3$ & $7 \pm 1$ & $8 \pm 3$ \\
\hline carcass & $27 \pm 7$ & $39 \pm 10^{*}$ & $32 \pm 8$ & $32 \pm 17$ & $36 \pm 15$ \\
\hline myonetrium & $2.1 \pm 0.7$ & $2.0 \pm 0.6$ & $1.9 \pm 0.8$ & $0.6 \pm 0.3^{\#}$ & $0.4 \pm 0.2$ \\
\hline placentas & $2.9 \pm 1.3$ & $2.1 \pm 1.5$ & $4.4 \pm 1.1$ & - & - \\
\hline
\end{tabular}

$* p<0.05$ (Wilcoxon Signed Rank Test)

" $p<0.05$ (Mann-Whitney) 


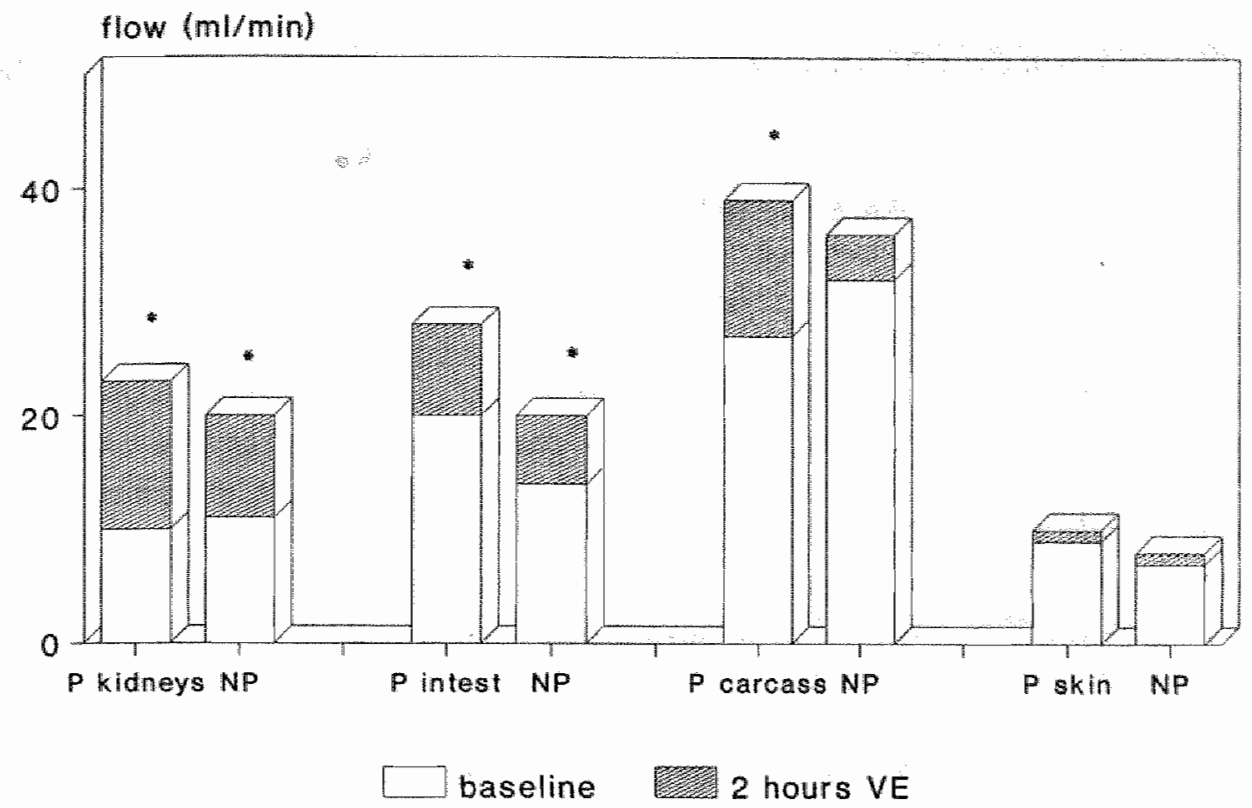

FIGURE 1.

Distribution of the extra $\mathrm{CO}$ after 2 hours hypervolemia. In each pair of bars the left bar represents the pregnant group, and the right bar the nonpregnant group. An asterix indicates a significant change from baseline.

distribution of the extra $\mathrm{CO}$ in both groups. The consistent fall in lung fraction $(\approx 2 \%)$ after the volume load only in the $\mathrm{P}$ group, may at least in part be caused by secondary dislodgement of microspheres from the placental microcirculathon. This phenomenon causes discrete but inconsistent underestimation of the baseline UBF (chapter 3 and 4). Therefore, UBF after 2 hours infusion in the P-group was compared with UBF in the C group. Lung fraction, itter size, fetal weight, and placental weight were comparable in the $P$ and the $C$ group. UBF was $80 \pm 22$ and $180 \pm 26 \mathrm{ml} / \mathrm{min} / \mathrm{kg}$ fetus in the $\mathrm{P}$ and $\mathrm{C}$ group, respectively. This difference was highly significant $(p<0.001)$.

Finally, the magnitude of the changes induced by the volume load in the present study was compared with that previously observed in 7 normovolemic late-pregnant rats and 6 nomovolemic nonpregnant rats subjected to the same protocol (chapter 3) (table 4). The volume-depleted rats showed a more pronounced hemodynamic response than the normovolemic rats. This difference was not observed in the NP rats. 
TABLE 4.

Change in hemodyriamic variables in response to volume load, in normovolemic and hypovolemic pregnant rats.

\begin{tabular}{|c|c|c|c|c|}
\hline & \multicolumn{2}{|c|}{ pregnant state } & \multicolumn{2}{|c|}{ nonpregnant state } \\
\hline & normovol. & hypovol. & normovol. & hypovol. \\
\hline Fluid retention & $9.3 \mathrm{ml}$ & $11.7 \mathrm{ml}^{*}$ & $9.1 \mathrm{ml}$ & $10.2 \mathrm{ml}$ \\
\hline Blood volume & $+19 \%$ & $+32 \%$ & $+22 \%$ & $+35 \%$ \\
\hline Cardiac output & $+43 \%$ & $+73 \%$ & $+45 \%$ & $+46 \%$ \\
\hline SVR & $-60 \%$ & $-39 \%$ & $-41 \%$ & $-23 \%$ \\
\hline \multicolumn{5}{|l|}{ organ flows: } \\
\hline Kidneys & $+76 \%$ & $+127 \% *$ & $+87 \%$ & $+94 \%$ \\
\hline Portal bed & NS & $+64 \% *$ & $+37 \%$ & $+46 \%$ \\
\hline Carcass & $+81 \%$ & $+48 \%$ & $+28 \%$ & ns \\
\hline Placentas & $-40 \%$ & $-31 \%$ & - & - \\
\hline
\end{tabular}

* \% change in hypovolemia different from that in normovolemia (Mann-Whitney).

\section{DISCUSSION}

The purpose of this study was to evaluate the effects of volume expansion on UBF and other hemodynamic variables in the mildly hypowolemic rat. Details about the hypovolemic model and the microsphere method when employed in pregnant rats have been reported previously (Chapter 2 to 4 ). In short, thirst-induced hypovolemia depletes both intra- and extravascular volume. Furthermore, the microspheres technique underestimates UBF slightly, if the rat is not sacrificed within 3 hours after the microspheres injection.

Maternal hypovolemia induced by one day water deprivation, led to a $7 \%$ reduction in BV in both pregnant and nonpregnant rats. The impact of this reduction on hemodynamics is likely to be larger in the P-group as the physiological blood volume expansion is reversed to blood volume reduction. The contracted inferior vena cava, as previously demonstrated by $\mathrm{X}$-ray imaging, complies with a decreased venous capacitance after 24 hours thirst (chapter 4 ). It probably indicates compensatory mobilization of unstressed blood volume 
from the venous capacitance vessels to maintain venous return (Rothe, 1986). The lack of a change in $\mathrm{CO}$ and organ flows in hypovolemia illustrates the efficacy of this compensation.

A slow, subacute volume expansion in the mildly hypovolemic pregnant rat triggers a similar pattern of changes in MAP, $\mathrm{CO}$, stroke volume, $\mathrm{HR}$ and organ flows as previously observed in the normovolemic state (chapter 2). There were a number of distinct quantitative differences (table 4). First, 2 hours of continuous Haemaccel ${ }^{\circledR}$ infusion led to a larger fluid retention in the hypovolemic, than in the normovolemic pregnant rat. Second, in the $\mathrm{P}$ rats the induced $\mathrm{CO}$ response in the hypovolemic state was significantly larger than in the normovolemic state. This indicates that the volume load in the hypovolemic pregnant rat not only triggers a larger rise in "unstressed volume" but also in "stressed volume" (Rothe, 1986). The slow onset of diuresis (after $\approx 60$ instead of 20 minutes) indicates a delayed or even a diminished diuretic response, giving rise to a larger total volume retention. This reflected in a larger BV expansion in the hypovolemic state $(32 \%)$ than in normovolemia $(19 \%)$. However, the effect on the stressed volume was more pronounced in pregnancy only (table 4). This is probably due to the stronger impact of thirsting on $P$ than on NP rats. This leads to a stronger delay for the diuretic response to develop in $\mathrm{P}$ than in NP rats. Consequently, the fluid retention in steady state was larger in $\mathrm{P}$ rats, causing more pronounced hemodynamic changes.

Expansion of unstressed volume is limited by the elasticity of the veins, a characteristic likely to be independent of filling state. Although baseline venoconstriction in the hypovolemic rats allows for $\approx 7 \%$ more volume capacity than in normovolemic rats, the slow diuretic response in hypovolemia seems to have led to a volume expansion in excess of maximal venous capacitance.

With respect to PBF, the pattern of blood flow changes in the hypovolemic animal was similar to that previously seen in the normovolemic rat. The mechanism responsible for this particular response is obscure. It has been speculated that acute volume expansion raises mean circulatory filling pressure. In the microcirculation, this will lead to a higher end-capillary hydrostatic pressure, giving rise to an increased fractional capillary filtration. The associated rise in extravascular fluid can be at least in part be buffered by the lymphatic system. Opening of small arteriovenous shunts in many tissues (Oude Vrielink et al, 1987; Lindbom and Arfors, 1984), and selective closure of precapillary sphincters in the capillary bed contribute to the reduction of the fluid filtration fraction in the capillaries. In contrast, the placental microcirculation lacks these compensatory mechanisms and, therefore, is more vulnerable to a decline in pressure gradient between distal portion of the spiral artery and the venous plexus draining the labyrinthine exchange area. The angle of branching of the micro- 
channels and also the already extremely low shear forces in this microcirculation (Peeters and Buchan, 1989) also have an unfavorable effect on local rheology when the perfusion pressure has decreased. This concept is supported by the histological changes observed in the rat placenta after volume load in the normovolemic rat (chapter 3).

These results can be used to speculate about the hemodynamic effects of volume expansion therapy in the preeclamptic patient. In doing so, one should keep in mind, that the present model differs in important aspects from the preeclamptic hemodynamic condition. The hypovolemic rat has a volume-depleted interstitium, normal blood pressure, normally grown fetuses and placentas, and normal volume regulation. The systemic microcirculation is not impaired by enhanced capillary leakage. Nevertheless, plasma volume contraction in preeclampsia coincides with an impaired renal function. This increases the risk for "overcorrection", defined as volume expansion in excess of maximal venous capacitance. Particularly this overcorrection seems to be unfavorable for intervillous perfusion. In this respect, the diuretic response as well as the rise in CO provide incomplete information about whether volume expansion has led to appropriate correction or overcorrection of the hypovolemic state. Whether this overcorrection can be prevented by reducing the strain put upon the volume regulatory system through a slower infusion rate needs further study. 


\section{Hemodynamics effects of slow blood volume expansion in awake late-pregnant rats}

Peter Focco Boekkooi, Carla M Verkeste, Pramod R Saxena* and Louis LH Peeters

From the Department of Obstetrics and Gynecology, University of Limburg, Maastricht, and the *Department of Pharmacology, Erasmus University, Rotterdam, the Netherlands

\section{ABSTRACT}

In a previous study in late-pregnant rats, placental blood flow had decreased by $30 \%$ in response to a subacute volume load imposed for a period of 2 hours. Inasmuch as the hemodynamic response to an imposed volume load varies with velocity and duration of a stretch stimulus excerted upon veins, it is possible that placental blood flow in that study had decreased because of a too rapid rate of volume loading. In the present study we tested the hypothesis that placental compromize in response to volume loading is prevented when the latter is imposed at a very low rate. In 10 chronically catheterized 20 -days pregnant rats, the hemodynamic response to a volume load imposed at a rate of one third of the one previously administered and continued for 12 hours was determined. Hemodynamics in a control group served as a reference. Prolonged, slow volume loading led to renal failure in 4 rats. In the 6 rats with presumably intact volume regulation, the induced rise in BV was larger than in the previous study in response to the rapid volume load. The hemodynamic response after both rates of infusion was comparable with respect to blood pressure (unchanged), cardiac output, and blood flows to kidneys, carcass and intestines (markedly increased). The response in blood flows to the placentas was highly variable, 
presumably depending on the volume regulatory response. This was suggested by the observed fetal death in the 4 rats with very low renal blood flow, and by the inverse relationship between placental blood flow and the magnitude of the "stressed volume" in the other 6 rats. It is concluded that placental blood flow is preserved during very slow volume load, provided that the volume regulatory response remains adequate.

\section{INTRODUCTION}

The hemodynamic effects in response to volume loading vary with the velocity by which the latter is imposed. This characteristic is mainly associated with a slow and gradual adlaptation in venous compliance irrespective velocity or duration of the volume stress (Guyton, 1986). The difference in circulatory response to a bolus injection as compared to a subacute 2 hours volume load with a plasma substitute illustrates this phenomenon (Haemaccel ${ }^{3}, 6 \mathrm{ml} /$ hour) (chapter 2). While the former induced an instantaneous rise in cardiac output (CO) with no concomitant change in inferior vena cava diameter (chapter 2), the latter triggered, besides a rise in $\mathrm{CO}$, a pronounced venodilation. This phenomenon, the so-called "stress-relaxation" (Alexander, 1956; Rothe, 1983) is a characteristic of veins and has a profound impact on venous compliance. In vivo, the effect consists of a secondary slow $(\approx 20$ minutes) adaptation in venous tone after a rapidly induced change in volume. This phenomenon serves to buffer short-term changes in venous filling state so as to limit fluctuations in venous return and thus in CO (Prather et al., 1969).

In pregnancy, BV increases gradually, over a period of weeks (rat) to months (human) (Hytten and Paintin, 1963; Clapp et al., 1988). It follows that slow adaptations in venous compliance such as stress-relaxation, or those induced by pregnancy hormones, could be important in the circulatory changes triggered by spontaneous or imposed changes in the filling state of the circulation. The previously observed hemodynamic response to subacute vollume load of the awake late-pregnant rat, which included a $30 \%$ fall in placental blood flow (PBF) (chapter 3), could be related the adopted rate of volume load in excess of venous capacity. However, whether the negative effect on PBF is caused by a too rapid volume load could not be determined in that study.

The objective of the present study was to test the hypothesis that the central veins accomodate a larger volume when the rate of volume loading is reduced. This would imply that a slower rate of volume loading may protect PBF against the supposed risk of too much excess $\mathrm{CO}$. To this end, we determined in 10 
awake late-pregnant rats, the hemodynamic response to a very slow volume

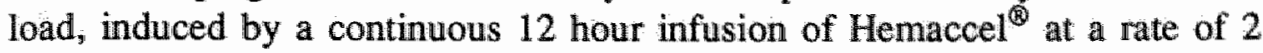
$\mathrm{ml} /$ hour. The obtained results were compared with those previously obtained in response to a more rapid volume load induced by a 2 hour infusion at $6 \mathrm{ml} / \mathrm{hour}$.

\section{MATERIALS AND METHODS}

The study was performed in 20-days pregnant Wistar rats $(P, n=10)$ obtained from a local breeder (HSD, Zeist, the Netherlands). A group of 20-days pregnant Wistar rats served as controls $(C, n=7)$. Two days before the experiment the rats were anesthetized with ether, and polyethylene catheters (PE-10, OD/ID $=0.61 / 0.28$, heat-sealed to a piece of $\mathrm{PE}-50$ tubing, $\mathrm{OD} / \mathrm{ID}=0.92 / 0.58$ ) were inserted into the right carotid artery, a femoral artery and a femoral vein, and advanced into the left ventricle of the heart, the abdominal aorta, and the inferior vena cava, respectively. The catheters were tunneled subcutaneously and exteriorized between the shoulder blades. The day before the experiment, the rats were habituated to the metabolic cages in which the experiments were performed.

The experiment consisted of an intravenous bolus injection $(2 \mathrm{ml})$ followed by a 12 hour infusion of Haemaccel ${ }^{\circledR}$ (Hoechst) at a rate of $2 \mathrm{ml} /$ hour. This rate was one third of that previously adopted in a study on the effects of short-term ( 2 hour) volume load (chapter 2 and 3 ). The characteristics of this component have been described in chapter 2. During the experiment changes in BV were calculated from the observed changes in hematocrit (chapter 2).

MAP and HR were monitored continuously, from 40 minutes before the bolus injection until after discontinuation of the infusion. The fluid balance was estimated hourly from the difference between cumulative fluid load and urine output. After 12 hours very slow volume loading, $\mathrm{CO}$ and its distribution were measured with $15 \mu \mathrm{m}$ microspheres using the reference sampling technique (Peeters et al., 1980). To this end, approximately $1.2 \times 10^{5}$ radioactive microspheres (NEN, Dreieich, West Germany) suspended in $0.2 \mathrm{ml}$ saline were injected into the left ventricle of the heart over a period of $15 \mathrm{sec}$. Tween 80 $(0.05 \%)$ was added to the suspension to prevent aggregation. A reference sample was withdrawn from the abdominal aorta at a constant rate of 0.5 $\mathrm{ml} / \mathrm{min}$, starting 10 seconds before, and continuing until 30 seconds after the microspheres injection. In the control group of seven 20-days pregnant rats, the 
experiment was initiated by monitoring MAP and HR. After 30 minutes steady state in these parameters, $\mathrm{CO}$ and organ flows were determined with the microspheres method, similarly as described for the experimental group.

After completion of reference sampling, the animals in both groups were sacrificed with an overdose of pentobarbital. All organs were dissected and weighed. The radioactivity in each tissue aliquot and reference sample was determined with a sodium crystal scintillation counter (Packard, Delft). CO was calculated as follows:

$$
C O\left(m y_{\text {min }}\right)=\frac{c p m \text { total body } * \text { reference sampling rate }}{c p m \text { in reference sample }}
$$

Regional blood flows were calculated as $\mathrm{CO} x$ fractional entrapment of microspheres as described in detail elsewhere (Saxena et al., 1980). In all animals mixing of the microspheres after their injection into the left ventricle was considered adequate on the basis of a less than $5 \%$ difference in fractional entrapment of microspheres in the two kidneys (Ishise et al., 1980). All reference samples contained at least 400 microspheres.

Data are presented as means $\pm \mathrm{SD}$ throughout the text. The hemodynamic values as obtained after the very slow volume load (SVL) were compared with those in the control group and those after more rapid volume load (RVL) reported previously (chapter 3 ) by the Mann-Witney Test. PBF was evaluated by Spearman correlation in its relation with various organ flows. A p-value of less than 5\% (two-sided) was considered significant.

\section{RESULTS}

The volume load induced two clearly different responses of the renal blood flow. Twelve hours of volume load resulted in a markedly higher renal blood flow in 6 rats (P1, more than 1 SD above the control group) and a sharply reduced renal blood flow in 4 rats ( $\mathrm{P} 2$, more than 1 SD below the control group) (table 1). The low renal blood flow in the latter animals was paralleled by a progressive fluid accumulation (figure 1) and, in the last 4 hours of volume load, development of hypertension (figure 2). In contrast, in the other 6 rats fluid balance (figure 1), and MAP were maintained during the last 4 hours of volume load (figure 2). As renal failure with disturbed fluid balance was associated with an entirely different flow response to the volume load (table 1), it was decided to analyze the results of these 4 rats separately. 
TABLE 1 .

Maternal characterics, $\mathrm{CO}$ and regional blood flows per $100 \mathrm{~g}$ organ weight in the control group, the 6 P1 rats, and the 4 P2 rats.

\begin{tabular}{lccc}
\hline & control & P1 (n=6) & P2 (n=4) \\
\hline SVR (mmHg/ml/min) & $0.9 \pm 0.3$ & $0.4 \pm 0.1^{*}$ & $1.2 \pm 0.5$ \\
SV ( $\mu \mathrm{l})$ & $241 \pm 35$ & $443 \pm 76^{*}$ & $297 \pm 54$ \\
HR (bpm) & $450 \pm 22$ & $417 \pm 29$ & $316 \pm 52^{*}$ \\
CO (ml/min) & $109 \pm 19$ & $186 \pm 33^{*}$ & $100 \pm 31$ \\
Hct (vol\%) & $35 \pm 2$ & $25 \pm 4^{*}$ & $29 \pm 5^{*}$ \\
& & & \\
Organ flows & & & \\
kidneys & $544 \pm 151$ & $931 \pm 254^{*}$ & $190 \pm 58^{*}$ \\
intestines & $273 \pm 92$ & $342 \pm 76^{*}$ & $160 \pm 91$ \\
portall bed & $144 \pm 39$ & $175 \pm 52^{*}$ & $66 \pm 31$ \\
brain & $174 \pm 52$ & $223 \pm 50^{*}$ & $125 \pm 24$ \\
skin & $31 \pm 9$ & $40 \pm 13$ & $15 \pm 4$ \\
carcass & $23 \pm 5$ & $32 \pm 8^{*}$ & $17 \pm 4$ \\
myometrium & $42 \pm 14$ & $49 \pm 17$ & $15 \pm 5$ \\
placentas (ml/min) & $4.4 \pm 1.1$ & $4 \pm 3$ & $0.16 \pm .09^{*}$ \\
placentas $(/ \mathrm{kg}$ fetus) & $181 \pm 26$ & $118 \pm 78$ & $5 \pm 2^{*}$ \\
& & & \\
\hline
\end{tabular}

* significant difference with the control group $(\mathrm{p}<0.05)$

Slow secondary leakage of microspheres from the placentas leads to progressive underestimation of the PBF in late-pregnant rat when the lag time between microsphere injection and sacrifice exceeds 3 hours (chapter 3 and 4). To minimize the influence of this methodological problem on the analysis of the response of PBF, blood flow data after 12 hours volume load were compared with those obtained in the control group with the same lag time (5-10 minutes) between the microspheres experiment and sacrifice.

SVL in the present study induced a highly variable increase in BV, ranging from 17 to $90 \%$. Table 2 lists the hemodynamic values after SVL and RVL. The direction and magnitude of the changes after SVL and RVL were comparable for almost all hemodynamic variables: MAP remained unaltered, systemic vascular resistance (SVR) decreased by $\approx 60 \%$, and CO rose by $60-70 \%$. The extra $\mathrm{CO}$ was distributed to kidneys, splanchnic bed and carcass. In addition to a rise in HR, and in brain flow, the response of PBF was different after SVL; 


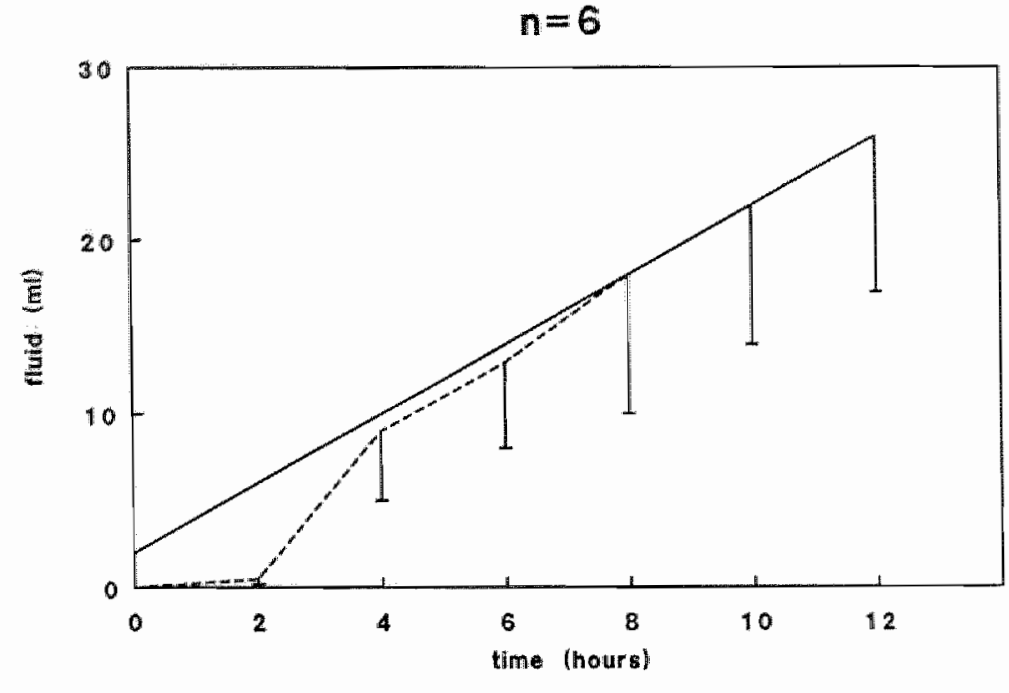

Haemacoel

Lrine output

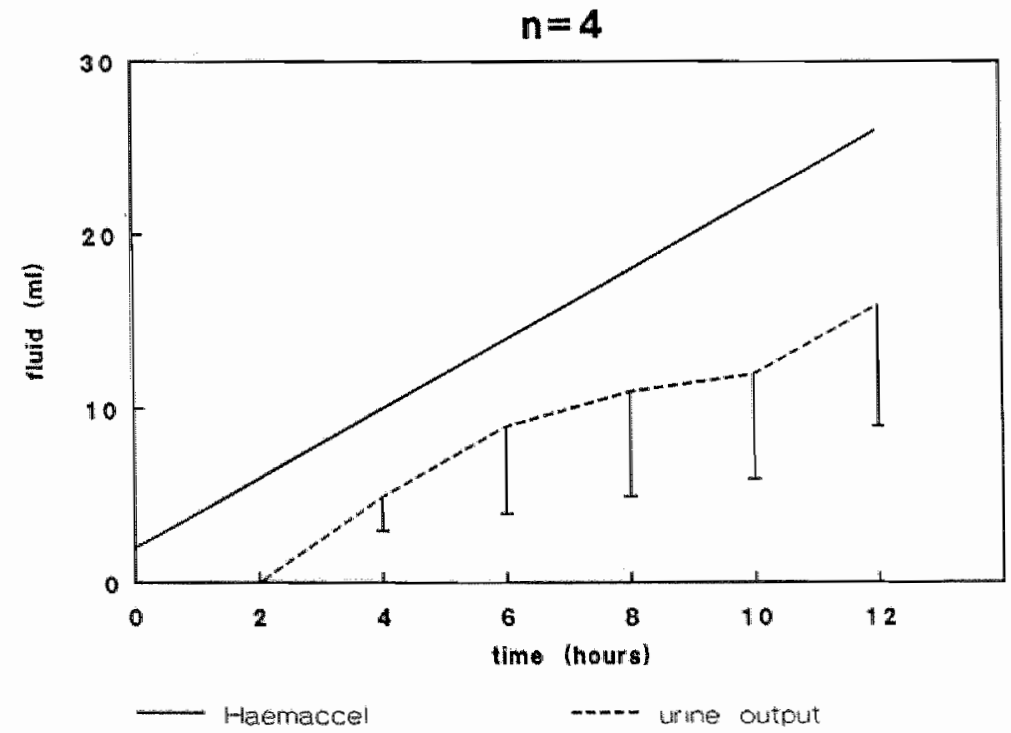

\section{FIGURE 1 .}

Fluid balance in 6 rats with normal renal response (upper panel), and in 4 rats with renal failure (lower panel). The accumulated fluid is depicted on the ordinate. 

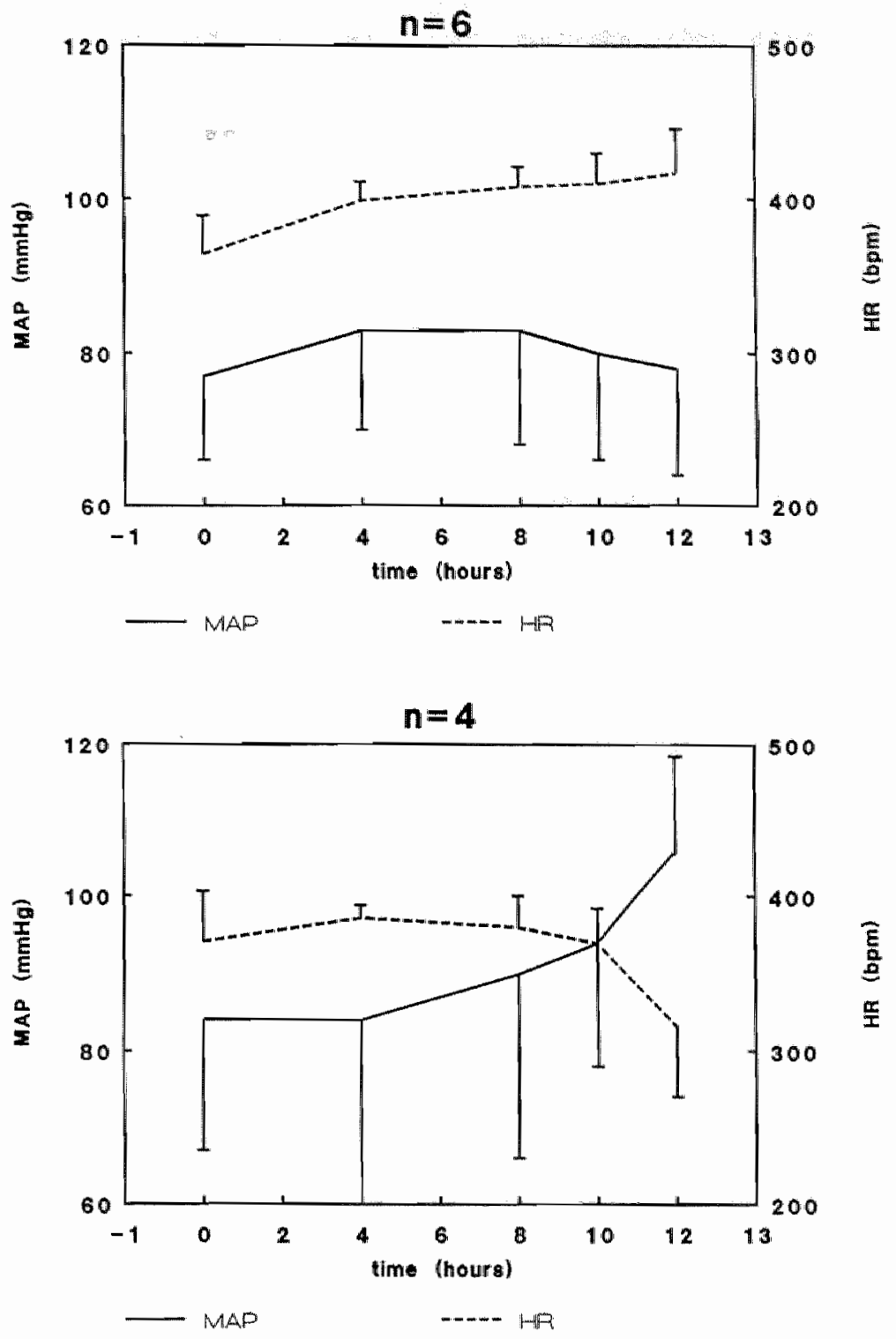

FIGURE 2.

MAP and HR in the 6 rats with normal renal response (upper panel), and in the 4 rats with renal failure (lower panei). 
Chapter 6

TABL 2 .

Hemodynamic variables and regional blood flows (ml/min/loog) after rapid volume load (6 $\mathrm{ml} / \mathrm{h}$ ) as compared to those induced by slow volume load $(2 \mathrm{ml} / \mathrm{h})$.

\begin{tabular}{lcc}
\hline & RVL & SVL \\
\hline change in BV & $19 \pm 10$ & $46 \pm 29$ \\
CO & $161 \pm 29$ & $186 \pm 33$ \\
SVR & $0.4 \pm 0.1$ & $0.4 \pm 0.1$ \\
renall flow & $943 \pm 33$ & $931 \pm 254$ \\
intestinal flow & $364 \pm 68$ & $342 \pm 76$ \\
carcass flow & $28 \pm 8$ & $32 \pm 8$ \\
placental flow (/kg fetus) & $66 \pm 29$ & $118 \pm 78$ \\
\hline
\end{tabular}

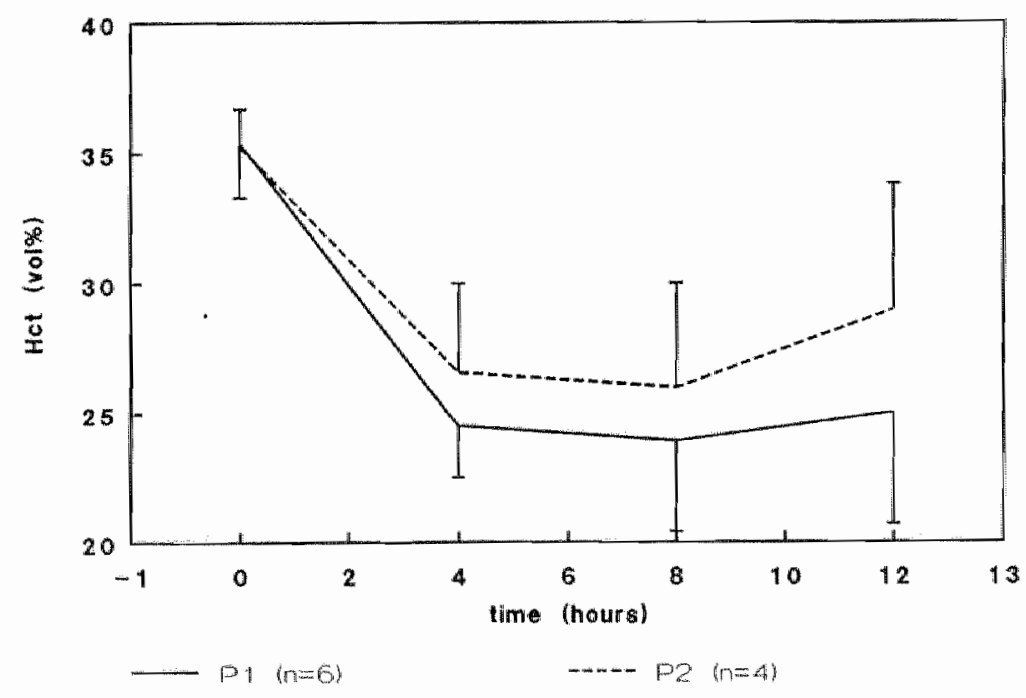

FIGURE 3.

Changes in hematocrit during infusion in the 6 rats with normal renal response $(P 1)$, and in 4 rats with renal failure $(P 2)$. 
while RVL induced a consistent fall in PBF, SVL had a variable and inconsistent effect on PBF. The high variation in PBF after SVL was further explored by evaluating the covariation between $\mathrm{PBF}$ on the one hand, and percentage $\mathrm{BV}$ increase and other organ flows on the other hand. PBF varied independently of the BV expansion, but correlated inversely with carcass flow (Spearman correlation coefficient, $r=0.80 ; \mathrm{p}<0.05)$. $\mathrm{P} 2$ rats tended to have a larger BV rise than $P 1$ rats (fig 3).

Finally, the 4 rats with low renal blood flows had a normal $\mathrm{CO}$ and distribution to other organs as compared with the control group (table 1). Only PBF was virtually zero, indicative of fetal death. Renal failure in these 4 rats could not be predicted on the basis of an altered fluid balance, or any other hemodynamic parameter determined at baseline.

\section{DISCUSSION}

Previous studies suggested that the observed consistent fall in PBF in response to a subacute slow volume load, was caused by a too high infusion rate (chapter 3 and 5). The purpose of the present study was to test the hypothesis that a three times slower infusion rate would be associated with a maintained PBF. Stable fluid balance (fig 1 ) and BV (fig 3 ) were reached after 5 hours. The much slower infusion rate was expected not only to put less strain upon the kidneys but also to be associated with stable hemodynamics throughout the newly imposed steady-state period. Therefore, the volume load was continued for 7 hours after establishing steady state. To our surprise, the stress put upon the volume regulatory system not only appeared to be much larger but also cumulative with ongoing volume loading. This was suggested by the signs of renal failure observed in 4 of 10 rats in these 7 hours. Apparently, long-term "mild" volume load imposes more stress upon the kidneys than short-term "modest" volume stress. It also suggests that the strain put upon the kidneys is more determined by duration and total cumulative amount ( $24 \mathrm{ml}$ instead of 12 $\mathrm{ml}$, used previously) of the volume loading than by the infusion rate. This surprising observation may have important repercussions for pregnancy. First, the exaggerated pressure put upon the kidneys in the period of normal gestational BV expansion could induce renal dysfunction and in this way contribute to the development of preeclampsia and intrauterine growth retardation. This hypothesis is supported by preliminary data from a study performed in our clinic (Duvekot et al., 1990). Second, it disclosed marked inter-animal variation in volume handling capacity which remains undetected in the unstressed condi- 
tion. In the 4 rats that seemed to have developed renal failure, pregnancy had resulted in intra-uterine death. This suggests that fetal well-being is rapidly compromized as soon as the volume regulatory response becomes inadequate.

SVL in the 6 rats with presumably adequate volume regulatory response, induced a similar hemodynamic response as did RVL, with respect to MAP (unchanged), $\mathrm{CO}$ and the blood flows to kidneys, intestines and carcass (table 2). The increase in BV was larger but also more variable, probably also associated with the inter-animal variation in volume regulatory response. Also, PBF did not fall consistently as observed after RVL, but responded with an inconsistent and variable change. The inverse correlation between the change in PBF and that in CO and carcass flow supported a negative effect on PBF of a concomitant larger expansion of the "stressed" volume compartment. On the basis of this phenomenon, the large variation in $\mathrm{BV}$, renal blood flow and PBF, together with the observed hemodynamic changes in the 4 rats with presumed renal failure (table 1), the following sequence of events in response to SVL is proposed:

Initially SVL induces a similar stable hemodynamic response as described after RVL in chapter 2 and 3. However, continued requirement for accelerated diuresis for more than 5 hours, results, after a variable period, in renal dysfunction and renewed additional volume retention with extra "expansion" of the stressed volume compartment. At this time PBF decreases for reasons detailed in chapter 3. The additional rise in $\mathrm{CO}$ now threatens the capillary exchange function in vital organs which is a highly stressful condition (Guyton, 1986) and triggers a progressive rise in sympathetic tone together with release of catecholamines. The resulting systemic vasoconstriction further reduces PBF to a value not compatible with fetal survival. Besides, concomitant renal vasoconstriction leads to further compromise of the volume regulatory response. In the 2 of 6 rats with the lowest PBF, fluid balance, hematocrit and MAP at the time of blood flow measurement, were stable. Apparently, these variables are initially preserved while volume regulation begins to decompensate.

This sequence of events suggests that the enhanced variation in the various hemodynamic changes in response to SVL, can be explained as resulting from inter-animal differences in the point of time during SVL, where the volume regulatory response becomes inadequate.

In conclusion, the present data indicate that stress on the volume regulatory system is primarily determined by the duration and magnitude of the volume load rather than by the rate of its administration. A possible negative effect of SVL on PBF was more determined by the adequacy of the volume regulatory response than by the employed very slow rate of volume loading. 


\section{General discussion and conclusions}

In uncomplicated human pregnancy, $\mathrm{BV}$ and $\mathrm{CO}$ increase gradually by about 30-40\%. The underlying mechanisms for these adaptive changes which have been reviewed in chapter 1 , are poorly understood. It is generally believed that the gestational rise in $\mathrm{BV}$ is needed both to sustain the increase in $\mathrm{CO}$ and to allow the progressive growth in uteroplacental perfusion. However, this concept misses a scientific basis as the following questions have not been answered yet:

1 What triggers the gestational BV rise?

2 Is the gestational $\mathrm{BV}$ rise causally related to the concerted increase in $\mathrm{CO}$, and if so, how?

3 What is the impact of the elevated BV in pregnancy on the hemodynamic response to volume changes?

The objective of the present series of studies was in the first place, to address the latter question. In the second place, the results of these studies were used in the context of the related literature, to better understand the spontaneous $\mathrm{CO} /$ $B V$ relationship in normal pregnancy.

Experiments were performed in the awake rat, adequately recovered from surgery. The rat was considered an appropriate model for these studies as BV in the late-pregnant rat has increased to about $20 \%$ above nonpregnant values. In addition, the reported resemblence between the cardiovascular reflexes in pregnant rats with those in pregnant women was considered to be an advantage.

In the first study (chapter 2), the hemodynamic response to rapid volume load by bolus injection ( $2 \mathrm{ml}$ Haemaccel ${ }^{\mathbb{Q}}$, corresponding with $\approx 10 \%$ of BV) was determined and compared with the response to subacute volume load (steady-state infusion for 2 hours at a rate of $6 \mathrm{ml} /$ hour). The rapid volume load increased CO and MAP by $30 \%$ and 5\%, respectively, in both P and NP rats, but induced only a modest fall in SVR and no appreciable change in the calibre of the large veins. After the subacute volume load, the magnitude of the increase in BV and CO were comparable, but the hemodynamic response was markedly different: The response to subacute volume load was characterized by steady state in fluid balance, HR, MAP, and SVR. Furthermore, MAP had returned to baseline values allowing an additional reduction in SVR. In contrast to rapid volume load, the subacute volume load was associated with a consistent in- 
crease in the calibre of the large veins, probably reflecting the so-called "stressrelaxation" response of the veins. This phenomenon describes the slow relaxation of a vein when exposed to an acute rise in intraluminar pressure. It is caused by the relatively slow increase in the lenght of muscle fibers in the venous wall in response to acute stretch.

The data of this study suggest that the hemodynamic response to a rapid volume load consists predominantly of a rise in "stressed volume" while that to a subacute volume load consists also of a rise in the size of the venous compartment ("unstressed volume") and a fully activated volume regulatory response. As stretching of the large central veins and the right atrium forms an important stimulus for the volume regulatory response, the gradually developing venodilatation and accelerating diuresis may well be causally related.

To our knowledge no comparable data have been reported on the hemodynamic response to rapid or chronic volume load in the uncomplicated pregnant state. Most experimental data in nonpregnant animals were obtained in anesthetized animals and only in response to bolus injections. Nevertheless, these studies confirm the almost instantaneous rise in $\mathrm{CO}$ and MAP rise after rapid volume load as found in the present study. Another observation in those studies was a concomitant rise in mean circulatory filling pressure, a variable not quantitated in our studies. On the basis of our results and the data reported in the literature, it was concluded that the rate of volume loading represents an important variable in the hemodynamic response to volume load. The magnitude of the responses after both types of volume load had not changed in pregnancy despite the preexisting physiologic hypervolemia.

The steady state as reached with the continuous infusion in the first study was considered indicative of an adequately developed hemodynamic response to volume load. This study failed to answer the question as to whether $\mathrm{CO}$ had increased by a fraction proportional to or in excess of the expected increased renal flow demands. In order to determine the fate of the extra $\mathrm{CO}$, a subsequent study was performed to quantitate the $\mathrm{CO}$ distribution (microspheres) before and 2 hours after the same subacute volume load as described above (chapter 3 ).

$\mathrm{CO}$ had increased in large excess of the accelerated renal flow demands, the extra increase being predominantly distributed to the carcass (skeletal muscle, bone and connective tissue) and, in NP rats, also to the portal bed. The increase in carcass flow occurred without noticeable increase in muscle activity. Therefore, the increased fractional recovery of microspheres in the carcass was interpreted as being an expression of increased shunting across small $(5-11 \mu \mathrm{m})$ arteriovenous shunts with no change in nutritional flow. This concept is supported by the abundant presence of these small shunts in connective tissue. In rest, $50 \%$ of the blood flow to skeletal structures is directed towards these 
shunts. In case of a rapid rise in nutritional demands, blood flow is redistributed away from these shunts. Although further studies are needed to explore the role of the shunting characteristics across skeletal structures in conditions of excess $\mathrm{CO}$, it seems obvious that such a shunting mechanism would provide excellent protection of the capillary bed against excess blood flow and the associated risk for disturbance of the capillary fluid exchange. In NP rats, portal blood flow increased significantly, while in $\mathrm{P}$ rats portal blood flow tended to increase as well. As the portal bed is also characterized by an abundant presence of small arteriovenous shunts, the rise in portal flow was also considered to reflect enhanced shunting.

Two hours steady-state volume load not only induced higher flows to kidneys and carcass but also a consistent fall in PBF. By histological examination of the placentas after subacute volume load, the placental microcirculation was found to be severely congested giving rise to compression of the fetal microvessels. If the hemochorial placenta of the rat can be assumed to lack a venoarterial reflex as has been reported for the guinea pig, this response could be a direct consequence of a rise in venous pressure provoked by the volume load. Congestion can be expected to trigger unfavorable rheological changes in the blood such as increased red cell aggregation and activation of the clotting cascade. These phenomena may initiate a viscious circle which can be expected to contribute to the observed consistent fall in PBF.

The qualitative hemodynamic response to steady-state volume load was comparable in $\mathrm{P}$ and NP rats, and consisted of dilatation of the large veins, an increase in renal blood flow to sustain renal fluid dissipation and an increase in carcass flow. On the basis of these results it was hypothesized that the response to mild gradual volume depletion is accomplished by the same volume regulatory mechanisms and thus consists of changes opposite to those observed after volume expansion, namely, venoconstriction, a fall in renal blood flow and a fall in the fractional distribution of $\mathrm{CO}$ to the carcass.

To test this hypothesis, a study was performed in which BV was gradually reduced to $93 \%$ of baseline by subjecting the experimental animals to 24 hours of water deprivation (chapter 4 ). This resulted in a decrease in the calibre of the central veins. However, renal blood flow and carcass flow were maintained, as were other regional blood flows, CO, MAP, and HR. The failure of renal and carcass flow to decrease was considered a consequence of the only small reduction in BV which could be adequately compensated by venoconstriction to maintain "stressed volume" at the expense of "unstressed volume". Also in this study, the hemodynamic response did not differ between $P$ and NP rats. As BV is still expanding at day 19 of pregnancy, and also daily water intake in $P$ rats is larger than in NP rats, 24 hours water deprivation represents a higher volume 
stress in $\mathrm{P}$ than in NP rats. Interestingly, the only measurable difference between $\mathrm{P}$ and NP rats in this respect, was a more pronounced reduction in urine output in $\mathbf{P}$ rats, without a concomitant reduction in renal blood flow. This may indicate that in P as well as in NP rats, volume conservation is effectively regulated by venoconstriction, provided that the imposed $\mathrm{BV}$ reduction is mild and induced slowly. To the best of our knowledge, no data are available on the effect of thirsting on $\mathrm{CO}$ distribution in pregnancy. One should realize that thirsting in itself may have unwanted metabolic side effects, particularly in pregnancy, which may complicate the hemodynamic response to the volume depletion. However, from a theoretical point of view, it is unlikely that these side effects invalidate the most important conclusion from this study, namely that the hemodynamic response to volume depletion is the preservation of venous return and $\mathrm{CO}$ through venoconstriction.

In clinical obstetrics it has been proposed that volume expansion is beneficial for maternal hemodynamics including PBF in preeclamptic patients in which the plasma volume compartment is constricted. This treatment is advocated on the basis of the observed increase in $\mathrm{CO}$, fall in SVR and improved renal function in these patients in response to intravenous administration of plasma expanders. However, in these studies no information could be obtained about the effect of BV expansion on placental perfusion. In chapter 3, PBF was found to decrease rather than to increase after subacute volume load, indicating that volume expansion therapy when used in complicated pregnancy, is associated with a potential risk for the fetus. However, it is likely that the hemodynamic response to volume load is altered in preeclampsia, as both unstressed (low BV) and stressed volume (low $\mathrm{CO}$ ) are reduced, and vascular responsiveness is increased (increased sensitivity to MAP and angiotensin). Therefore, the hypothesis was tested that the subacute volume load as used in normovolemic pregnant rats, (chapter 5) induces a similar qualitative but different quantitative hemodynamic response in hypovolemic pregnant rats. Indeed, volume depleted pregnant rats ( 24 hours thirsting) also responded to subacute volume load by expansion of both stressed ( $\mathrm{CO}$ ) and unstressed volume (venodilatation) and a reestablished steady state in fluid balance, MAP and HR. However, the overall effects in the volume depleted state appeared to be more pronounced, probably as a result of the much slower diuretic response relative to that in the normovolemic rats: A larger rise in $\mathrm{CO}$ indicated the extra strain put upon the stressed volume, while the clearly more expanded total BV ( $32 \%$ as compared to $19 \%$ ) was considered suggestive of a larger increase in the unstressed volume compartment. An additional aspect was that BV depletion probably had a larger 
impact in $\mathrm{P}$ than in NP rats. In the volume depleted rats, $\mathrm{PBF}$ had also decreased consistently, but the magnitude of the decrease did not differ from that observed in the normovolemic state.

It follows that subacute volume load in the volume depleted state bears a similar risk for placental compromise as in the normovolemic pregnant rats. However, the slower diuretic response is associated with an increased risk for volume overloading. It is obvious that the hemodynamic state induced by thirsting in the healthy pregnant rat differs markedly from that developed in the preeclamptic patient. Nevertheless, the results from chapter 5 may indicate that the cardiovascular system of preeclamptic patients may become more easily overloaded when these patients are subjected to volume expansion therapy, particularly when plasma expanders are administered rapidly. Furthermore, these data provide some evidence that such a regimen is not without risk for the usually marginally perfused placenta.

In the preceding studies it was shown that the hemodynamic response to volume loading in both the $P$ and the NP state consisted of an instantaneous rise in $\mathrm{CO}$ and MAP, a fairly rapid fall in SVR $(\approx 5$ minutes $)$ and a relatively slow development of both venodilatation and diuretic response $(\approx 20-30$ minutes $)$. After 2 hours infusion, in steady state, the impact of these different response times seems to have disappeared. However, the rate and lenght of subacute volume loading in the present study was chosen arbitrarily. Therefore, it remained obscure whether the extent of the venodilatation or the diuretic response would further increase if the volume load would be induced more slowly and over a longer period of time.

In the last study of this thesis (chapter 6), the hypothesis was tested that, relative to the subacute volume load $(6 \mathrm{ml} /$ hour $)$, a slower volume load would induce a larger venodilatation and less strain on the volume regulatory system, thus diminishing stressed volume. It was expected that this would be beneficial for the placental perfusion. Ten late-pregnant rats were subjected to slow volume load ( $2 \mathrm{ml} / \mathrm{hour}$ ) for a a period of 12 hours. The increase in $\mathrm{CO}$, renal blood flow and carcass flow was comparable to the one observed previously after the subacute volume load (chapter 3). The venous filling state was not determined in this study as the technique provides only qualitative information. The larger BV expansion in this study as compared to that after the subacute volume load suggested that also the unstressed volume compartment had increased by a larger fraction. An important observation in this study was the large scatter in data points. The variation in the $\mathrm{CO}$ response showed a remarkable inverse correlation with the change in placental blood flow: A modest rise 
in CO was paralleled by no change in PBF whereas a relatively high CO rise was paralleled by a marked fall in PBF. Slow volume expansion led to renal failure in 4 of the 10 rats. In these animals, PBF was almost reduced to zero.

The data of this study suggested that slow volume loading induces a highly variable increase in both the stressed and unstressed volume compartment. The variation in the response appeared to be related to the adequacy of the diuretic response. An inadequate response lead to a larger BV expansion culminating in volume overloading and associated signs such as a rise in MAP, renal failure and sharply reduced placental perfusion.

\section{FINAL CONCLUSIONS}

The objective of the present series of studies was to determine in the awake rat, the qualitative and quantitative hemodynamic response to volume load in late pregnancy and to compare this with the response in the nonpregnant state. The results obtained in these studies, supplemented with relevant data reported in the literature, allow the following final conclusions:

1 Volume load imposed to the circulation is distributed over the arterial side or "stressed volume compartment" (CO rise) and venous side or "unstressed volume compartment" (venodilatation). In addition, it activates the volume regulatory system (diuresis) and seems to promote the opening of small arteriovenous shunts in carcass and portal bed (NP only). These responses develop at different rates: The CO/MAP rise occurs instantaneously, the presumed opening of systemic shunts (probably triggered by baroreceptor activation and release of catecholamines) occurs rapidly ( $<5$ minutes), and finally, the diuretic response and the venodilatation occur relatively slowly (20-30 minutes). This concept suggests that:

1a a rapid volume load by bolus injection (rapid volume loading) causes predominantly a rise in stressed volume and related effects such as a rise in MAP, a rise in $\mathrm{CO}$, partial opening of systemic shunts, and virtually no effect on the unstressed volume.

$1 \mathrm{~b}$ volume load administered by continuous infusion at an intermediate rate (subacute volume loading) causes a rise in $\mathrm{CO}$, a complete opening of arteriovenous shunts, a presumably maximal venodilatation and a maximal diuretic response. 
1c volume load administered by continuous infusion at a slow rate (slow wolume loading), but over a longer period induces a similar hemodynamic response as described under $1 \mathrm{~b}$. However, the prolonged strain put upon the kidneys to sustain the accelerated diuresis bears a higher risk for renal damage.

1d Slow volume depletion leads only to a reduction in unstressed volume. This consists of a volume shift from the unstressed to the stressed compartment, so as to maintain $\mathrm{CO}$.

2 The hemodynamic response to volume load in the late-pregnant rat is similar to that in the nonpregnant rat, in spite of the $\approx 20 \%$ higher baseline $\mathrm{BV}$ in pregnancy. It follows that the physiologic hypervolemia of pregnancy has no consequences for the hemodynamic response to a superimposed volume load.

3 In pregnancy, placental blood flow is particularly vulnerable to a (sub)acute rise in stressed volume.

4 The hemodynamic response to volume load in a hypovolemic state differs from that in the normovolemic state by the slower development of the diuretic response causing an extra expansion of both the stressed and unstressed volume compartment.

With respect to the spontaneous interrelationship between $\mathrm{CO}$ and $\mathrm{BV}$ in pregnancy these data suggest: 1 . That the qualitative and quantitative response to volume load appears to be similar in the pregnant as in the nonpregnant state, despite a $20 \%$ higher $\mathrm{BV}$ in pregnancy. 2 . That, in addition to 1 ., the large capacity of the venous compartment to buffer additional volume as seen in the present studies, and the reported lack of a rise in venous pressure, indicate that the slow BV expansion in pregnancy is associated with little "spill-over" of the increasing BV into the stressed volume compartment. This aspect may support the concept that the concerted increases in BV and $\mathrm{CO}$ in pregnancy develop independently. 



\section{References}

Ahokas RA, Anderson GD, Lipshitz J 1983 Cardiac output and uteroplacental blood flow in diet-restricted and diet-repleted pregnant rats. Am J Obstet Gynecol 146:6-13

Ahokas RA, Reynolds SL, Anderson GD, Lipshitz J 1984 Maternal organ distribution of cardiac output in the diet-restricted pregnant rat. J Nutr 114:2262-2268

Alexander RS, Edwards WS, Ankeney JL 1953 The distensibility characteristics of the portal vascular bed. Circ Res 1:271-277

Alexander RS 1955 Venomotor tone in hemorrhage and shock. Circ Res 3:181-190

Alexander RS 1956 Reflex alterations in venomotor tone produced by venous congestion. Circ $\operatorname{Res} 4 \% 49-53$

Assali NS, Vaughn DL 1977 B 1 ood wolume in pre-eclampsia: fantasy and reality. Am J Obstet Gynecol 129:355-359

Atherton JC, Dark JM, Garland HO, Morgan MRA, Pidgeon J, Soni S 1982 Changes in water and electrolyte balance, plasma volume and composition during pregnancy in the rat. J Physiol 330:81-93

Atherton JC, Green R 1987 Renal tubular function in the gravid rat. Bail Clin Obstet Gynecol $1: 815-834$

Banet M, Guyton AC 1971 Effect of body metabolism on cardiac output: role of the central nervous system. Am J Physiol 220:662-666

Barron WM, Stamoutsos BA, Lindheimer MD 1984 Role of volume in the regulation of vasopressin secretion during pregnancy in the rat. J Clin Invest 73:923-932

Barron WM 1987 Water metabolism and vasopressin secretion during pregnancy. Bail Clin Obstet Gynecol 1:853-871

Barron WM, Lindheimer MD 1988 Osmoregulation in pseudopregnant and prolactin-treated rats: comparison with normal gestation. Am J Physiol 254:R478-R484

Barron WM, Murphy MB, Lindheimer MD 1990 Management of hypertension during pregnancy.. In: Laragh BH, Brewer BM (eds) Hypertension: Pathophysiology, diagnosis and management. Raven Press, New York, pp 1809-1827

Batra S, Bjellin L, Martensson L, Sjogren C 1985 Effect of oestrogen and progesterone on the blood flow of the lower urinary tract of the rabbit. Acta Physiol Scand 123:191-194

Batra S, Bjellin L, Sjogren C, Iosif S, Widmark E 1986 Increases in blood flow of the female rabbit urethra following low doses estrogens. J Urology 136:1360-1362

Baylis C 1984 Renal hemodynamics and volume control during pregnancy in the rat. Semin Nephrol 4:208-220

Baylis C, Badr K, Collins R 1985 Effects of chronic prolactin administration on renal hemodynamics in the rat. Endo 117:722-729

Baylis C 1987a Glomerular filtration and volume regulation in gravid animal models. Bail Clin Obstet Gynecol 1:789-813 
Baylis PH $1987 \mathrm{~b}$ Osmoregulation and control of vasopiressin secretion in healthy humans. Am IPhysiol 253:R671-R678

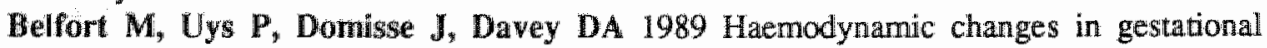
proteinuric hypertension: the effects of rapid wolume expansion and vasodilator therapy. $\mathrm{Br}$ J Obstet Gynaecol 96:634-641

Bond AL, August P, Druzin ML, Atlas SA, Sealey JE, Laragh JH 1989 Atrial natriuretic factor in normal and hypertensive pregnancy. Am J Obstet Gynecol 160:1112-1116

Brands MW, Freeman RH 1989 Aldosteron and renin "Mhibition by atrial natriuretic factor in potassium-loaded rats. Am J Physiol 257:R1423-R1428

Brar HS, Do Y, Tam HB, Valenzuela GJ, Murray RD, Longo LD, er al 1986 Uteroplacental unit as a source of elewayed circulating prorenin levels in normal pregnancy. Am J Obstet Gynecol 1155:1223-1226

Braunstein GD, Rasor J, Adler D, Damzer H, Wade ME 1976 Serum human chorionic gonadotropin levels throughout normal pregnancy. Am J Obstet Gynecol 126:678-681

Broughton Pipkin F 1988 The renin-angiotensin system in normal and hypertensive pregnancies. In: Rubin PC (ed) Handbook of Hypertension (wol 10) Hypertension in pregnancy, Elsevier, Amsterdam, pp 118-151

Brown MA, Crawford GA, Horgan EA, Gallery EDM 1988a Arginine Vasopressin in primigravid human pregnancy. J Reprod Med 33:35-40

Brown MA, Gallery EDM, Ross MR, Esber RP 1988b Sodium excretion in normal and hypertensive pregnancy: a prospective study. Am J Obstet Gynecol 159:297-309

Bruce NW 1976 The distribution of bllood flow to the reproductive organs of rats near-term. J Reprod Fert 46:359-362

Buckberg GD, Luck JC, Payne BD 1971 Some sources of error in measuring regional blood flow with radioactive microspheres. J Appl Physiol 31:598-604

Burwell CS 1938 The placenta as a modified arteriovenous fistula, considered in relation to the circulatory adjustments to pregnancy. Am J Med Sci 195:1-7

Campbell DM, MacGillavry I 1972 Comparison of maternal response in first and second pregnancies in relation to baby weight. J Obstet Gynaecol Br Commonw 79:684-693

Capeless EL, Clapp JF 1989 Cardiovascular changes in early phase of pregnancy. Am J Obstet Gynecol 161:1449-1453

Chesley LC, Talledo E, Bohler CS, Zuspan FP 1965 Vascular reactivity to angiotensin II and norepinephrine in pregnant and nonpregnant women. Am J Obstet Gynecol 91:837-842

Chesley LC, Duffus GM 1971 Posture and apparent plasma volume in late pregnancy. JObstet Gynaecol Br Commonw 78:406-412

Chesley LC 1972 Plasma and red cell volumes during pregnancy. Am J Obstet Gynecol $112: 440-450$

Chesley LC, Lindheimer MD 1988 Renal hemodynamics and intravascular volume in normal and hypertensive pregnancy. In: Rubin PC (ed) Handbook of Hypertension (vol 10) Hypertension in pregnancy, Elsevier, Amsterdam, pp 38-65

Clapp JF, Seaward BL, Sleamaker RS, Hiser J 1988 Matemal physiologic adaptations to early human pregnancy. Am J Obstet Gynecol 159:1456-1460

Clark SL, Cotton DB, Lee W, Bishop C, Hill T, Southwick J, et al 1989 Central hemody namic assessment of normal term pregnancy. Am J Obstet Gynecol 161:1439-1442

Cloeren SE, Lippert TH 1972 Effect of plasma expanders in toxemia of pregnancy. N Engl J Med 287:1356 
Conrad KP 1987 Possible mechanisms for changes in renal hemodynamics duning pregnancy: studies from animal models. An J of Kidn Dis 9:253-259

Conway J 1966 Hemodynamic consequences of induced changes in blood volume. Circ Res 18:190-198

Crawford ES, Turell DJ, Alexander JK 1963 Aorta-inferior vena caval fistula of neoplastic origin. Hemodynamic and coronary blood flow studies. Circulation $27: 414$

Crispell KR, Porter B, Nieset RT 1950 Studies of plasma volume using human serum albumin tagged with radioactive iodine. J Clin Invest 29:513-516

Davies MJ 1987 Polygeline. Develop Biol Standard 67:129-131

Davis LE, Hohimer AR, Giraud GD, Paul MS, Morton MJ 1989 Vascular pressure-volume relationships in pregnant and estrogen-treated guinea pigs. Am J Physiol 257:R 1205-R 1211

Davison JM, Vallotton MB, Lindheimer MD 1981 Plasma osmolality and urinary concentration and dilution during and after pregnancy: evidence that lateral recumbency inhibits maximal urinary concentrating ability. Br J Obster Gynaecol 88:472-479

Davison JM 1984 Renal haemodynamics and volume homeostasis in pregnancy. Scand J Clin Lab Invest Suppl 169:15-27

Davison JM 1985 The physiology of the renal tract in pregnancy. Clin Obstet Gynecol 28:257-265

Davison JM, Shiells EA, Philips PR, Lindheimer MD 1988 Serial evaluation of vasopressin release and thirst in human pregnancy. J Clin Invest 81:798-806

De Swiet M 1988 The physiology of normal pregnancy. In: Rubin PC (ed) Handbook of Hypertension (vol 10) Hypertension in pregnancy, Elsevier, Amsterdam, pp 1-9

Dekker GA 1989 Prediction and prevention of pregnancy-induced hypertensive disorders. Thesis Erasmus University Rotterdam, Rotterdam, the Netherlands

Douglas BH, Harlan JC, Langford HG, Richardson TQ 1967 Effect of hypervolemia and elevated arterial pressure on circulatory dynamics of pregnant animals. Am J Obstet Gynecol 98:889-894

Duffus GM, MacGillivray I, Dennis KJ 1971 The relationship between baby weight and changes in maternal weight, total body water, plasma volume, electrolytes and proteins and urinary oestriol excretion. J Obstet Gynaecol Br Commonw 78:97-104

Dunlop J, Davison JM 1987 Renal hemodynamics and tubular function in human pregnancy. Bail Clin Obstet Gynaecol 1:769-787

Durr JA, Stamoutsos B, Lindheimer MD 1981 Osmoregulation during pregnancy in the rat. $\mathrm{J}$ Clin Invest 68:337-346

Durr JA 1989 Maternal fluid adaptation to pregnancy. In: Brace RA, Ross MG, Robillard JE (eds) Reproductive and Perinatal Medicine, vol 11. Perinatology Presss, Los Angeles, pp 227-270

Duvekot JJ, Evers JLH, Cheriex E, Pieters F, Menheere P, Peeters LLH 1990 Altered early hemodynamic/renal adlaptation to pregnancy: a potential contributor to later development of IUGR and/or preeclamsia? Proceedings of VII World congress of hypertension in pregnancy, Perugia, Italy (abstract)

Easterling TR, Watts DH, Schmucker BC, Benedetti TJ 1987 Measurement of cardiac output during pregnancy: validation of doppler technique and clinical observations in preeclampsia. Obstet Gynecol 69:845-850

Elkarib AO, Garland HO, Green R 1983 Acute and chronic effects of progesterone and prolactin on renal function in the rat. J Physiol 337:389-400 
Eskay R, Zufowska-Grojec Z, Haass M, Dawe JR, Zamir N 1986 Circulating atrial natriuretic peptides in conscious rats: Regulation of release by multiple factors. Science $232: 636-639$

Everett RB, Worley RJ, MacDonald PC, Gant NF 1978 Vascular reactivity to angiotensin II in human pregnancy. Semin Perinatol 2:3-13

Fadnes HO, Oian P 1989 Transcapillary fuid balance and plasma volume regulation: a review. Obstet Gynecol Surv 44:769-773

Frank C, Wang H, Lammerant J, Miller R, Wegria R 1955 An experimental study of the immediate hemodynamic adjustments to acute arteriovenous fistulae of various sizes. J Clin Invest $34: 722$

Fullerton WT, Hytten FE, Klopper AI, McKay E 1965 A case of quadruplet pregnancy. J Obstet Gynaecol Br Commonw 72:791-796

Gallery EDM, Hunyor SN, Gyory AZ 1979 Plasma volume contraction: a significant factor in both pregnancy-associated hypertension preeclampsia and chronic hypertension in pregnancy. Q J Med 48:593-602

Gallery EDM 1982 Pregnancy-associated hypertension: Interrelationships of volume and blood pressure changes. Clin Exper Hypert 1:39-47

Gallery EDM 1984 Volume homeostasis in normal and hypertensive human pregnancy. Semin Nephrol $4: 221-231$

Gant NF, Chand S, Whalley PJ, MacDonald PC 1973 A study of angiotensin II pressor reponse throughout primigravid pregnancy. J Clin Invest 52, 2682-2689

Gardiner SM, Compton AM, Bennett T 1989 Regional hemodynamic changes following hypovolemia in cinscious rats. Am J Physiol 256:R1076-1083

Garland HO, Atherton JC, Baylis C, Morgan MRA, Milne CM 1987 Hormone profiles for progesterone, oestradiol, prolactin, plasma renin activity, aldosterone and corticosterone during pregnancy and pseudopregnancy in two strains of rat: correlation with renal studies. J Endocrinol 113:435-444

Glaviano VV 1963 Evidence for an arteriovenous fistula in the gravid uterus. Surg Gynecol Obstet 124:301-304

Goodlin RC, Quaife MA, Dirksen JW 1981 The significance, diagnosis, and treatment of maternal hypovolemia as associated with fetal/maternal illness. Semin Perinatol 5:163-174

Goodlin RC 1982 Why treat "physiologic" anemias of pregnancy? J Reprod Med 27:639-646

Goodlin RC Dobry CA, Anderson JC, Woods RE, Quaife M 1983 Clinical signs of normal plasma volume expansion during pregnancy. Am J Obstet Gynecol 145:1001-1009

Goodlin RC, Niebauer MJ, Holmberg MJ, Zucker IM 1984 Mean circulatory filling pressune in rabbits. Am J Obstet Gynecol 148:224-225

Goodlin RC, Woods RE, McKinnery ME, Hofschire PJ, Ruscel-Churchill GA 1985 Elevated static pressure and pregnancy well-being. Am J Obstet Gynecol 152:462-466

Greenway CV, Lister GE 1974 Capacitance effects and blood reservoir function in the splanchnic vascular bed during non-hypotensive haemorrhage and blood volume expansion in anaesthetized cats. J Physiol 237:279-294

Greenway CV, Lautt WW 1986 Blood volume, the venous system, preload, and cardiac output. Can J Physiol Pharmacol 64:383-387

Groenendijk R, Trimbos BMJ, Wallenburg HCS 1984 Hemodynamic measurements in preeclampsia: Preliminary observations. Am J Obstet Gynecol 150:232-236

Guyton AC 1955 Determination of cardiac output by equating venous return curves with cardiac response curves. Physiol Rev 35:123-129 
Guyton AC, Lindsey AW, Kaufmann BN, Abernathy JB 1958 Effect of blood transfusion and hemorrhage on cardiac output and on the venous return curve. An J Physiol 194:263267

Guyton AC, Jones CE, Coleman TG 1973 Cardiac output and its regulation. 2nd edition. Saunders, Philadelphia

Guyton AC, Jones CE 1974 Cardiovascular physiology. 1st edition, University Park Press, Baltimore

Guyton AC 1986 Textbook of medical physiology. 7th edition, Saunders, Philadelphta

Hakumaki MOK, Hyodynmaa SJ 1984 Influence of intravenous saline infusion on the aortic baroreceptor and left atrial B-type receptor activity in dogs. Acta Physiol Scand 122:203208

Haneda K, Hessel II EA, Thomas R, Huntsman LL 1986 Cardiovascular response to rapid infusion of lactated Ringer's. Tohoku J Exp Med 149:397-406

Hart MV, Hosenpud JD, Hohimer AR, Morton MJ 1985 Hemodynamies during pregnancy and sex steroid administration in guinea pigs. Am J Physiol 249:R179-R185

Hilton JG, Kanter DM, Hays DR, Bowen EH, Golub JR, Keatings JH et al 1955 The effect of acute arteriovenous fistulae on renal functions. J Clin Invest 34:732

Hirth C, Stasch J-P, John A, Kazda S, Morich F, Neuser D, et al 1986 The renal response to acute hypervolemia is caused by atrial natriuretic peptides. J Cardiovasc Pharmacol $8: 268-275$

Huggins RA, Smith EL, Seibert RA 1956 Adjustments of the circulatory system in normal dogs to massive transfusions. Am J Physiol 186:92-96

Hytten FE, Paintin DB 1963 Increase in plasma volume during normal pregnancy. J Obstet Gynaecol Br Commonw 70:402-407

Hytten FE, Chamberlain G 1980 Clinical Physiology in Obstetrics. Blackwell Scientific Publications, Oxford

Hytten FE 1985 Blood volume changes in normal pregnancy. Clin Haematol 14:601-612

Ishise S Pegram BL, Yamamoto J Kitamura, Frohlich Y 1980 Reference sample microspheres method: cardiac output and blood flows in conscious rat. Am J Physiol 239:H443H449

Jouppila P, Jouppila R, Koivula A 1983 Albumin infusion does not alter the intervillous blood flow in severe pre-eclampsia. Acta Obster Gynecol Scand 62:345-348

Kase NG, Reyniak JV 1985 Endocrinology of pregnancy. Mount Sinai J Med 52: 11-34

Katz AI, Lindheimer MD 1973 Renal handling of acute sodium loads in pregnancy. Am J Physiol 225:696-699

Katz VL, McMurray R, Berry MJ, Cephaio RC 1988 Fetall and uterine responses to immersion and exercise. Obstet Gynecol 72:225-230

Kaufmann BN, Lindsey AW, Guyton AC 1954 Relationship of the mean circulatory filling pressure, right atrial pressure and venous return in dead dogs. Am J Physiol 179:650

Kohara K, Otsuka A, Ogihara T, Mikami H, Katahira K, Kumahara Y 1987 Contribution of elevated peripheral resistance to acute volume loaded hypertension in dogs. Clin Exp Hypert A9(12):2113-2129

Kristensen CG, Nakagawa Y, Coe F, Lindheimer MD 1986 Effect of atrial natriuretic factor in rat pregnancy. Am J Physiol 250:R589-R594

Lang RE, Unger T, Ganten D 1987 Atrial natriuretic peptide: a new factor in blood pressure control. J Hypert 5:255-271 
Laragh JH, Sealy JE, Ledingham JGG, Newton MA 1967 Oral contraceptives. JAMA $201: 918-922$

Lees MM, Taylor SH, Scott DB, Kerr MG 1967 A study of cardiac output at rest throughout pregnancy. J Obstet Gynaecol Br Commonw 74:319-328

Lindbom L, Arfors KE 1984 Non-homogeneous blocd flow distribution in the rabbit tenuissimus muscle. Acta Physiol Scand $122 * 225-233$

Lindheimer MD, Katz AI 1985 Renal physiology in pregnancy. In: Seldin DW, Giebisch G (eds) The kidney: Physiology and pathophysiology: Raven Press, New York, pp 2017-2041

Lindheimer MD, Barron WM, Durr J, Dawison JM 1987 Water homeostasis and vasopressin relatese during rodent and human gestation. Am J Kidn Dis 9:270-275

Linzell JL. 1960 Mammary-gland blood flow and oxygen, glucose and volatile fatty acid uptake in the conscious goat. J Physiol 153:492-509

Longo LD 1983 Maternal blood volume and cardiac output during pregnancy: a hypothesis of endocrinologic control. Am J Physiol 245:R720-R729

Longo LD, Hardesty JS 1984 a Maternal blood volume: measurement, hypothesis of control, and clinical considerations. Rev Perinatol Med 5:35-59

Longo LD 1984 b Intrauterine growth retardation: a "mosaic" hypothesis of pathophysiology. Sem Perinatol 8:62-72

Lowe KC, McNaughton DC 1984 Acute physiological responses during blood substitution with colloidal gelatin in conscious rats. Exp 40:700-701

Ludbrook J, Graham WF 1984 The role of cardiac receptor and arterial baroreceptor reflexes in control of the circulation during acute change of blood volume in the conscious rabbit. Circ Res 54:424-435

Lund CJ, Donowan JC 1967 Blood volume during pregnancy. Am J Obstet Gynecol 98:393403

Lundgren O (1984) Microcirculation of the gastrointestinal tract and pancreas. In: Renkin EM, Michel CC (eds) Handbook of Physiology: The cardiovascular system, vol 4, part 2. Williams \& Wilkins, Baltimore, pp 799-864

Lunell NO, Nyland LE, Lewander R, Sarbry B 1982 Uteroplacental blood flow in pre-eclampsia measurements with Indium-113m and a computer-linked gamma camera. Clin Exp Hypert 1:105-117

Maddox DA, Price DC, Rector FC 1977 Effects of surgery on plasma volume and salt and water excretion in rats. Am J Physiol 233:F600-F606

Martin C 1980 Physiologic changes during pregnancy: the mother. In: Quilligan EJ, Kretchmer $\mathrm{N}$ (eds) Fetal and maternal medicine. John Wiley and sons, New York, pp 141-180

Menard J, Malmejac A, Milliez $\mathbf{P} 1970$ Influence of diethylstilbestrol on the renin-angiotensin system of male rats. Endo 86:774-780

Metcalfe J, Parer JT 1966 Cardiovascular changes during pregnancy in ewes. Am J Physiol $210: 821-825$

Metcalfe J, Stock MK, Barron DH 1988 Maternal physiology during gestation. In: Knobil E; Neil J (eds) The physiology of reproduction. Raven Press, New York, pp 2145-2146

Metzler CH, Ramsay DJ 1989 Physiological doses of atrial peptide inhibit angiotensin II-stimulated aldosterone secretion. Am J Physiol 256:R1155-R1159

Milsom I, Hedner J, Hedner T 1988 Plasma atrial natriuretic peptide (ANP) and maternal hemodynamic changes during normal pregnancy. Acta Obstet Gynecol Scand 67:717-722 
Mizelle HL, Hall JE, Hillebrandt DA 1989 Atrial natriuretic peptide and pressure natriuresis: interactions with the renin-angiotensin system. Am J Physiol 257:R 1169:R1174

Morton M, Tsang H, Hohimer R, Ross D, Thornburg K, Faber R, al 1984 Left ventricular size, output, and structure during guinea pig pregnancy. Am J Physiol 246:R40-R48

Nadel AS, Ballermann BJ, Pederson S, Brenner BM 1988 Intertelationships among atrial peptides, renin, and blood volume in pregnant rats: Am J Physiol 254:R793-R800

Naden RP, Gant NF, Rosenfeld CR 1984 The pressor response to angiotensin II: the roles of peripheral and cardiac responses in pregnant and nonpregnant sheep. Am J Obstet Gynecol 148:450-457

Naden RP, Rosenfeld CR 1985 Systemic and uterine responsiveness to angiotensin II and norepinephrine in estrogen-treated nompregnant sheep. Am J Obstet Gynecol 153:417-425

Oian P, Malteau JM 1985 Transcapillary forces in normal pregnant women. Acta Med Scand Suppl 693:19-22

Oude Vrielink HHE, Slaaf DW, Tangelder GJ, Reneman RS 1987 Does capillary recruitment exist in young rabbit skeletal muscle? Int J Microcirc: Clin Exp 6:321-332

Paintin DB 1963 The haematocrit ratio in pregnancy. J Obstet Gynaecol Br Commonw 70:807-810

Peeters LH, Guilters G, Martin CB 1980 Distribution of cardiac output in the unstressed pregnant guinea pig. Am J Obstet Gynecol 138:1177-1184

Peeters LLH, Verkeste CM, Saxena PM, Wallenburg HCS 1987 Hemodynamic effects of isovolemic hemodilution and hemoconcentration in the awake late-pregnant guinea pig. Pediatr Res 21:584-589

Peeters LLH, Buchan PC 1989 Blood viscosity in pregnancy. Rev Perinatal Med 6:53-89

Phippard AF, Horvath JS, Glynn EM, Garner MG, Fletcher PJ, Duggin GG et al 1986 Circulatory adaptations to pregnancy serial studies of haemodynamics, blood volume, renin and aldosterone in the baboon Papio hamadryas. J Hypert 4:773-779

Pirani BBK, Campbell DM, MacGillivray 1973 Plasma volume in normal first pregnancy. J Obstet Gynaecol Br Commonw 80:884-887

Porciuncula CI, Armstrong GG, Guyton AC, Stone HL 1964 Delayed compliance in the external jugular vein of the dog. Am J Physiol 207:728-732

Prather JW, Taylor AE, Guyton AC 1969 Effect of blood volume, mean circulatory pressure, and stress relaxation on cardiac ouput. Am I Physiol 216:467-472

Pritchard JA, Barnes AC, Bright RH 1955 The effect of the supine position on renal function in the near-term pregnant woman. J Clin Invest 34:777-781

Pritchard JA 1965a Changes in the blood volume during pregnancy and delivery. Anesthesiol. 26:393-399

Pritchard JA 1965 blood volume changes in pregnancy and the puerperium IV Anemia associated with hydatiform mole. Am J Obstet Gynecol 91:621-629

Reckelhoff JF, Samsell L, Baylis C 1989 Failure of an acute 10-15\% plasma volume expansion in the virgin female rat to mimic the increased glomerular filtration rate (GFR) and altered glomerular hemodynamics seen at midterm pregnancy. Clin Exp Hyper B8(3):533-549

Resnik R, Killman AP, Battaglia FC, Makowski EL, Meschia G 1974 The stimulation of uterine blood flow by various estrogens. Endo 94:1192-1196

Resnik R 1983 Endocrine modulation of uterine blood flow in pregnancy. Clin Perinatol 10:567-573 
Richardson TQ, Stallings JO, Guyton AC 1961 Pressure-volume curves in live, intact dogs. Am J Physiol 201:471-474

Robertson EG 1969 Oedema in normal pregnancy. J Reprod Fert Suppl 9:27-36

Robertson EG 1971 The natural history of aedema during pregnancy. J Obstet Gynaecol Br Commonw 78:520-529

Robson SC, Dunlop W, Moore M, Hunter S 1987 Combined Doppler and echocardiographic measurement of cardiac output: theory and application in pregnancy. Br J Obstet Gynaecol 94:1014-1027

Robson SC, Hunter S, Boys RJ, Dunlop W 1989 Hemodynamic changes during twin pitegnancy. Am J Obstet Gynecol 161:1273-1278

Rollin C, Kucharczyk J, Lemoine J, Bichet D, Tsang BK 1989 Osmoregulation of vasopressin secretion and thirst during the estrous cycle of pigs. Am J Physiol 256:R270-R275

Rosenfeld CR, Morris FH, Battaglia FC, Makowski EL, Meschia G 1976 Effect of estradiol-17\% on blood flow to reproductive and nonreproductive tissues in pregnant ewes. Am J Obstet Gynecol 124:619-629

Rosenfeld CR 1977 Distribution of cardiac output in ovine pregnancy. Am J Physiol 232:H231H 235

Rosenfeld CR, Jackson GM 1984 Estrogen-induced refractoriness to the pressor effects of infused angiotensin II. Am J Obstet Gynecol 148:429-435

Rothe CF, Drees JA 1976 Vascular capacitance and fluid shifts in dogs during prolonged hemorrhagic hypotension. Circ Res 38:347-356

Rothe CF 1983 Reflex control of veins and vascular capacitance. Physiol Rev 63:1281-1342

Rothe CF 1986 Physiology of venous return. Arch Int Med 146:977-982

Rovinsky JJ, Jaffin H Cardiovascular hemodynamics in pregnancy I 1965 Blood and plasma volumes in multiple pregnancy. Am I Obstet Gynecol 93:1-15

Rovinsky JJ, Jaffin H 1966 Cardiovascular hemodynamics in pregnancy II Cardiac output and left ventricular work in multiple pregnancy. Am J Obstet Gynecol 95:781-786

Saxena PR, Schamhardt HC, Forsyth RP, Loeve J 1980 Computer Programs for the radioactive microsphere technique. Determination of regional blood flows and other hemodynamic variables in different experimental conditions. Comp Prog Biomed 12:63-84

Schrier RW, Durr JA 1987 Pregnancy: an overfill or underfill state. Am J Kidn Dis 9:284-289

Schrier RW 1988a Pathogenesis of sodium and water retention in high-output and low-output cardiac failure, nephrotic syndrome, cirrhosis, and pregnancy, I. N Engl J Med 319:10651072

Schrier RW 1988b Pathogenesis of sodium and water retention in high-output and low-output cardiac failure, nephrotic syndrome, cirrhosis, and pregnancy, II. N Engl J Med 319:11271134

Share L 1988 Role of vasopressin in cardiovascular regulation. Physiol Rev 68:1248-1284

Siekmann U, Heilmann L, Klosa W, Quaas W, Schillinger H 1986 Simultaneous investigations of maternal cardiac output and fetal blood flow during hypervolemic hemodilution in preeclampsia preliminary observations. J Perinat Med 14:59-69

Slater AJ, Gude N, Clarke IJ, Walters WAJ 1986 Haemodynamic changes and left ventricular performance during high-dose oestrogen administration to male transsexuals. $\mathrm{Br} \mathrm{J}$ Obstet Gynaecol 93:532-538

Smith TL, Hutchins PM 1979 Central hemodynamics in the developmental stage of spontaneous hypertension in the unanesthetized rat. Hypertension 1:508-517 
Smits JFM, Colleman TG, Smith TL, Kasbergen CM, Van Essen H, Struyker-Boudier HAJ 1982 Antihypertensive effect of propanolol in conscious spontaneously hypertensive rat. J Cardiovasc Pharmacol 4:903-914

St-Louns J, Parent A, Gutkowska J, Genest J, Schiffrin EL 1988 Vasorelaxation and vascular binding sites for atrial natriuretic peptide in pregnant rats. Am J Physiol 254:H1217-H1033

Steegers EAP 1990 Salt and pregnancy. Thesis, University of Nijmegen. Pasmans, Den Haag

Sweeney TE, Sarelius IH 1989 Arteriolar control of capillary cell flow in striated musle. Circ Res 64:112-120

Tamai T, Matsura S, Tatsuni N, Nunotani T, Sagawa N 1984 Role of sex steroid hormones in relative refractoreiness to angiotensin II during pregnancy. Am J Obstet Gynecol 149:177-183

Taylor DJ, Lind T 1979 Red cell mass during and after nomal pregnancy. Br J Obstet Gynaecol 86:364-370

Thaler I, Manor D, Itskovitz J, Rottem S, Levit N, Timor-Tritsch et al 1990 Changes in uterine blood flow during human pregnancy. Am J Obstet Gynecol 162:121-125

Thomsen JK, Storm TL, Thamsborg G, de Nulley M, Bodker B, Skouby S 1987 Atrial natriuretic peptide concentrations in pre-eclampsia. Br Med J 294:1508-1510

Thomsen JK, Storm TL, Thamsborg G, de Nulley M, Bodker B, Skouby S 1988 Increased concentration of circulating atrial natriuretic peptide during normal pregnancy. Eur J Obstet Gynecol Reprod Biol 27:197-201

Tulchinski D, Hobel CJ, Yeager E, Marshall JR 1972 Plasma estrone, estradiol, estriol, progesterone, and 17-hydroxyprogesterone in human pregnancy. Am J Obstet Gynecol 112:1095-1100

Tulchinsky D 1983 Endocrine assessments of fetal-placental well-being. Clin Perinatol 10:763. 776

Ueda S, Fortune V, Bull BS, Valenzuela GJ, Longo LD 1986 Estrogen effects on plasma volume, arterial blood pressure, interstitial space, plasma proteins, and blood viscosity in sheep. Am J Obstet Gynecol 155:195-200

Ueland K, Parer JT 1966 Effects of estrogens on the cardiovascular system of the ewe. Am J Obstet Gynecol 96:401-406

Ueland K, Novy MJ, Peterson EN, Metcalfe J 1969 Maternal cardiovascular dynamics: IV The influence of gestational age on the maternal cardiovascular response to posture and exercise. Am J Obstet Gynecol 104:856-864

Ueland K 1976 Maternal cardiovascular dynamics. VII. Intrapartum blood volume changes. Am J Obstet Gynecol 126:671-677

Veille JC, Morton MJ, Burry KJ 1985 Maternal cardiovascular adaptations to twin pregnancy. Am J Obstet Gynecol 153:261-263

Visser W, Dorpel vd MA, Derkx FHM, Wallenburg HCS, Schalekamp MADH 1987 Atrial natriuretic peptide and haemodynamics in untreated pre-eclampsia. J Hypert 5 (suppl 5):S33-\$35

Vries de J 1990 Atrial Natriuretic peptides. Thesis, University of Maastricht. Datawyse, Maastricht.

Walker J, Garland HO 1985 Single nephron function during prolactin-induced pseudopregnancy in the rat. J Endocrinol $107: 127-133$

Walker LA, Buscemi-Bergin M, Gellai M 1983 Renal hemodynmics in conscious rats: effects of anesthesia, surgery, and recovery. Am J Physiol 245:F67-F74 
Wallenburg HCS 1988 Hemodynamics in hypertensive pregnancy. In: Rubin PC (ed) Handbook of Hypertension (wol 10) Hypertension in pregnancy, Elsevier. Amsterdam, pp 68-101

Walters WA W, Lim YL 1969 Cardiovascular dymamics in women receiving oral contraceptive therapy. Lancet:879-881

Watters WAW, Lin YL 1970 Changes in the matemal cardiovascular system during human pregnaney. Surg Gynecol Obstet 131:765-784

Warren JV, Branion ES, Weens HS, Stead EA 1948 Effect of increasing the blood wolume and right atrial pressure on the circulation of normal subjects by intravenous infusions. Am J Med 4:193-200

Warren JV, Elkin DC, Nickerson $\mathbf{J} 1951$ The blood volume in patients with arteriovenous fistulas. I Clin Invest 30:220-226

Wasserstrum N, Kirshon B, Willis RS, Moise KJ, Cotton DB. Quantitative hemodynamic effects of acute volume expansion in severe preeclampsia. Obstet Gynecol 1989;73:546550

Winner W 1965 The role of the placenta in the systemic circulation; a reappraisal. Obstet Gynecol Surv 20:545-554

Yamaguchi R, Shintani M, Ishibashi S, Ushioda E, Nishikawa Y (1979) Uteroplacental blood flow and uteroplacental shunt rates in normal and prolonged pregnancies in rats. Tohoku J Exp Med 127:389-296

Zucker IH, Gorman AJ, Cornish KG, Lang M 1985 Impaired atrial receptor modulation or renal nerve activity in dogs with chronic volume overload. Cardiovase Res 19:411-418 


\section{Summary}

In normal human pregnancy $\mathrm{BV}$ and $\mathrm{CO}$ increase by about $30-40 \%$. Although the teleological reason for these adaptive changes is poorly understood, it is generally believed that the gestational rise in BV is needed to permit not only an increase in $\mathrm{CO}$, but also a growth in uteroplacental perfusion. Experimental data reported previously and reviewed in chapter 1, suggest that the response of $\mathrm{CO}$ to an imposed change in $\mathrm{BV}$ varies with the rate of change in $\mathrm{BV}$. In pregnancy, the rate of BV change is very slow. It follows that the available data in the literature contribute little to our understanding of the spontaneous relationship between the slowly increasing $\mathrm{BV}$ and $\mathrm{CO}$ in pregnancy. In the present thesis, the following questions were addressed: 1 . How does the hemodynamic response to an induced rise in BV vary with the rate of BV expansion? 2. What is the response to an induced decrease in BV? 3. Is the cardiovascular response to $\mathrm{BV}$ alterations changed in pregnancy, because baseline BV is markedly elevated? Experiments were performed in awake late-pregnant rats. The rat was considered an appropriate model for these studies, as BV has increased by $20-30 \%$ in late pregnancy, and changes in renal function and in pregnancy hormone levels resemble those observed in human pregnancy. In addition, cardiovascular reflexes in rats resemble those in man.

In chapter 2 , the hemodynamic response to rapid volume load (bolus injection), is compared with the response to a subacute slow ( 2 hours) volume load. It is concluded that the hemodynamic response to a rapid volume load consists primarily of an instantaneous rise in CO ("stressed" volume). In contrast, the hemodynamic response to subacute volume loading is characterized by a con comitant venodilation (increased "unstressed" volume). The response to volume loads is similar in pregnant and nonpregnant rats.

Chapter 3 shows that the extra $\mathrm{CO}$ after subacute volume load, is not only distributed to the kidneys, but also to the carcass (skeletal muscle, connective tissue, and bones) and portal (liver and intestines) bed. It is speculated that, in the carcass and portal bed, small $(5-11 \mu \mathrm{m})$ arteriovenous shunts are opened so as to protect the capillary bed against excess blood flow. PBF has decreased consistently, presumably as a result of unfavorable flowing properties of red cells in the placental microcirculation, and a lack of protective mechanisms against a raised venous pressure. 
In chapter 4 the effects of a slow volume depletion (24 hours) are studied. While venous filling decreases during hypovolemia, $\mathrm{CO}$ and regional blood flows remain unaltered. Apparently, "stressed" volume is maintained at the expense of "unstressed" wolume. Again, the response is qualitatively and quantitatively similar in pregnant and nonpregnant rats. Another important finding is that the gestational rise in PBF is not curtailed by the volume depletion.

In chapter 5 the effect is studied of an imposed volume load in the mildly volume-depleted rat. In clinical obstetrics it has been proposed that volume expansion is beneficial for matemal hemodynamics in preeclamptic patients, in which plasma volume is contracted. Volume expansion in the hypovolemic rat elicits a comparable but stronger response as compared to in the normovolemic rat. This is indicated by the larger increase in CO and renal blood flow. Also in hypovolemic rats, PBF has decreased. Extrapolation to human pregnancy complicated by preeclampsia should be done with caution, as volume depleted rats differ markedly from preeclamptic patients. Nevertheless, the data from chapter 5 suggest that volume loading, particularly when administered too rapidly or in too large amounts can have adverse effects on placental perfusion. This is more so in case of an underfilled intravascular compartment, as delayed diuretic response increases the risk for volume overloading.

In chapter 6 , the rate of volume expansion is only one third of the rate employed in the previous experiments. Also after very slow volume loading, $\mathrm{CO}$, renal blood flow, carcass and portal blood flow have increased relative to baseline. However, PBF does not fall consistently, but appears to be maintained unless the volume regulatory response becomes inadequate. An interesting observation in this study is that PBF is always compromized in rats with an impaired renal function.

In chapter 7, the following conclusions are drawn:

1. An imposed volume load is distributed over the stressed and unstressed volume compartment. A rapid volume load leads predominantly to a rise in stressed volume, while subacute volume loading leads to a rise in unstressed volume as well. Very slow volume loading over a longer period elicits a similar cardiovascular response. However, the apparently increased strain put upon the kidneys is associated with a higher incidence of renal failure. Slow volume depletion reduces unstressed volume only.

2. Despite a $20 \%$ higher blood volume in pregnancy, the hemodynamic response of pregnant rats to changes in volume is similar to that of nonpregnant rats.

3. The placental circulation is more vulnerable to volume loads than the nonuterine circulation. 
4. The different response to a similar volume load in the hypovolemic state as compared to that in the normovolemic state, consists of an extra expansion of the stressed volume, which is probably associated with a delayed diuretic response in hypovolemia. 


\section{Samenvatting}

Tijdens de ongestoorde zwangerschap bij de mens nemen zowel het moederlijk bloedvolume als het hartminuutvolume (de hoeveelheid bloed die het hart per minuut rond pompt) toe met ongeveer 30-40\%. Hoewel de teleologische reden van deze aanpassing aan de zwangerschap vooralsnog onbekend is, wordt algemeen aangenomen dat de toename in bloedvolume enerzijds nodig is om het hartminuutvolume te doen toenemen en anderzijds om een ongestoorde groei van de placentaire doorbloeding te waarborgen. Onderzoeksgegevens uit de literatuur, samengevat in hoofdstuk 1 , suggereren dat bij een geïnduceerde bloedvolumeverandering de respons van het hart-vaatstelsel varieert met de snelheid van deze verandering. Omdat de verandering in bloedvolume tijdens de zwangerschap erg langzaam is, dragen de nu beschikbare gegevens weinig bij aan ons begrip van de spontane relatie tussen bloedvolume en hartminuutvolume tijdens de zwangerschap. De volgende vraagstellingen zijn in dit proefschrift onderzocht: 1 . Hoe hangt de hemodynamische respons bij een geïnduceerde bloedvolume toename samen met de snelheid van die verandering? 2 . Wat is de respons op een geïnduceerde verlaging van bloedvolume? 3 . Is de respons van het vaatbed op een bloedvolumeverandering anders tijdens de zwangerschap, omdat het bloedvolume in de zwangerschap groter is? De experimenten werden uitgevoerd in wakkere laat-drachtige ratten. De drachtige rat werd als model gekozen, omdat bij dit dier tijdens de dracht het bloedvolume toeneemt met ongeveer $20-30 \%$, en omdat de veranderingen in nierfunctie en zwangerschapshormonen lijken op die in de menselijke zwangerschap. Bovendien lijken de cardiovasculaire reakties van de rat op die van de mens.

In hoofdstuk 2 wordt de hemodynamische respons op een snelle volumetoename (d.m.v. een bolusinjectie) vergeleken met de respons op een subacute langzame ( 2 uur) volumetoename. De resultaten suggereren dat een snelle volumebelasting leidt tot een onmiddellijke toename in hartminuutvolume (toegenomen actief circulerend volume). Een subacute volumebelasting daarentegen, leidt tevens tot een toename in veneuze vulling (toegenomen passief circulerend volume). Er is geen verschil in respons tussen de drachtige en niet drachtige rat.

Hoofdstuk 3 toont aan dat het extra hartminuutvolume na de subacute volumebelasting niet alleen ten goede komt aan de nieren (volumeregulatie), 
maar ook aan het karkas (spieren, bindweefsel, botten) en aan het portale (darmen en lever) vaatbed. Op basis van deze gegevens wordt gespeculeerd dat in het karkas en het portale vaatbed, kleine arterioveneuze shunts open gaan, zodat het capillairbed beschermd wordt tegen een te grote bloeddoorstroming. De placentaire doorblôeding neemt af bij deze volumebelasting, hetgeen wordt verklaard als een gevolg van slechte rheologische omstandigheden in de placentaire microcirculatie, en het ontbreken van een beschermingsmechanisme tegen een toegenomen hoge veneuze druk.

In hoofdstuk 4 worden de effecten van een langzame milde volumedepletie bestudeerd. Hoewell de veneuze vulling hierbij afneemt, bleven het hartminuutvolume en de regionale bloeddoorstroming gelijk. Kennelijk wordt het actief circulerend volume constant gehouden ten koste van het passief circulerend volume. Ook hier is er geen verschil in respons tussen de drachtige en de niet-drachtige dieren. Een andere belangrijke bevinding is dat de normale toename in placentaire doorstroming onaangetast blijft.

In hoofdstuk 5 wordt het effect beschreven van volumebelasting bij een hypovolemische rat. In de literatuur wordt beschreven dat volume vergroting bij ernstige vormen van preeclampsie (met een verminderd bloedvolume), een gunstig effect heeft op de moederlijke circulatie. Bij de hypovolemische rat leidt volumebelasting tot een overeenkomstige maar meer uitgesproken reaktie vergeleken met de normovolemische rat. Het hartminuutvolume en de nierdoorbloeding nemen sterker toe, en wederom neemt de placentaire doorbloeding af. Het extrapoleren van deze gegevens naar patiënten met preeclampsie is gevaarlijk, omdat er nogal wat verschillen zijn tussen een hypovolemische rat en een preeclampsiepatiënt. Desondanks kan men uit deze gegevens afleiden dat volumebelasting, indien te snel toegediend, een slecht effect kan hebben op de placentaire doorbloeding.

In hoofdstuk 6 is de snelheid van volumebelasting een derde van die in de vorige experimenten. Ook nu nemen het hartminuutvolume, de nierdoorstroming, en de bloedstroom naar het karkas en het portale vaatbed toe. De placentaire doorbloeding daarentegen, lijkt niet af te nemen zolang de volumeregulatie adequaat blijft. In ratten met een sterk verlaagde nierdoorstroming werd steeds ook intra-uterine vruchtdood geconstateerd.

In hoofdstuk 7 worden de volgende conclusies getrokken: 
1. Een geinduceerde volumebelasting wordt verdeeld over het actief en het passief circulerend volume. Een snelle volumebelasting leidt tot een toename in het actief circulerend volume, terwijl een subacute belasting ook leidt tot een toename in passief circulerend volume. Langzame volume belasting geeft een vergelijkbare respons, maar door de toegenomen belasting van de nieren is er een grotere kans op een falende nierfunctie. Een langzame volumevermindering leidt slechts tot een afname in het passief circulerend volume.

2. Hoewel het bloedvolume hoger is tijdens de zwangerschap, is de hemodynamische reaktie op volumeverandering bij drachtige ratten hetzelfde als bij niet-drachtige ratten.

3. De placentaire circulatie is gevoeliger voor volumebelasting dan de nietplacentaire vaatgebieden.

4. Het verschil in reaktie op volumebelasting tussen de hypovolemische en de normovolemische rat wat betreft hartminuutvolume en nierdoorbloeding, is waarschijnlijk te verklaren vanuit het vertraagd op gang komen van de diuretische respons in de hypovolemische rat. 


\section{Nawoord}

De weg van een onderzoeker naar zijn proefschrift is lang en niet zonder gevaren. Zonder de hulp van anderen is het niet mogelijk om deze weg zonder al te veel kleerscheuren te volgen. Op deze plats wil ik dan ook iedereen hartelijk danken die betrokken is geweest bij de totstandkoming van dit proefschrift. Ik ben veel dank verschuldigd aan de volgende mensen:

Allereerst prof. dr. J. de Haan, die als voorzitter van de vakgroep mij de mogelijkheid heeft gegeven om dit onderzoek te verrichten. Hij was altijd, hoe is mij nog steeds een raadsel, precies op de hoogte waar ik op elk moment mee bezig was.

Mijn co-promotor dr. Louis Peeters, die op de momenten dat ik wat somber gestemd raakte over de afloop, met enorm enthousiasme en creativiteit oplos singen aandroeg. Bovendien heeft hij menig uurtje in zijn vrije tijd opgeofferd aan dit proefschrift, om weer eens iets "gevoelig te verbeteren", zoals hij het uitdrukte. Zijn ongelofelijke inzet is een onmisbare bijdrage geweest.

Mijn kamergenote en promovenda Carla Verkeste, met wie ik vooral in het begin, menig experiment samen heb uitgevoerd. Zij bezit inderdaad twee rechterhanden. De overige promovendi, Guido Muysers en Hans van Huisseling, samen hebben we geregeld een biertje gedronken om de onderzoeksfrustraties te vergeten.

De medewerkers van de proefdiervoorzieningen, Frans Weekers, Eep van Dam, Peter Kelderman, en alle anderen, voor de gezellige medewerking. In het bijzonder wil ik May Bost bedanken, die heel wat röntgenfoto's met mij gemaakt heeft. Van de afdeling Fysiologie, Theo van der Nagel, die altijd bereid was om te helpen.

Met de medewerkers van de afdeling Farmacologie heb ik veel en plezierig contact gehad. Sjaak Debets en Caroline Thijssen hebben uitermate zorgvuldig proefdieren geopereerd, en hebben op een zeer vriendelijke wijze bij de metingen geholpen.

Jan Geilen, van de electronische dienst, heeft menigmaal een voor mij onverklaarbare storing in de meetapparatuur verholpen. 
Een aantal mensen hebben de moeite en de tijd genomen om het manuscript, in verschillende stadia, kritisch door te lezen, en commentaar te leveren. $\mathrm{Dr}$. Gerard Bos, die als immunoloog toch weer een hele andere invalshoek had, en met goede suggesties kwam. Dr. Ben Janssen, farmacoloog en echt wetenschapper, die soms pijnlijke, maar wel goede kritiek leverde.

$I$ would like to thank prof. dr. Bob Cephalo, who read parts of the manuscript, and gave me some good suggestions. Also, I greatly appreciate the help of dr. Sarah Jones, who carefully read the manuscript, and corrected the English spelling and grammar.

De leden van de beoordelingscommissie, voor de goede suggesties en opbouwende kritiek.

Mijn ouders, die, zichzelf wegcijferend, mij in al mijn beslissingen onvoorwaardelijk gesteund hebben.

Tenslotte natuurlijk Annemarie, die ongewild betrokken raakte bij mijn promotiegebeuren en vervolgens dit proefschrift van een motto voorzag. Gelukkig toonde zij op de juiste momenten een gezond relativeringsvermogen. 


\section{Curriculum vitae}

Peter Focco Boekkooi was born on the 28th of January, 1963. He attended Grammar School (Gymnasium $\beta$ ) at the Eindhovense Protestantse Scholengemeenschap (1975-1981). From 1981 to 1988 he went to Medical School in Maastricht (University of Limburg, Maastricht, the Netherlands). During his medical studies he worked as a Research Assistant at the departments of General Medicine (dr. A. de Bruijne), and Neurology (dr. M. de Krom). He took clerkships at the Guangdong Medical College, Guangzhou, the People's Republic of China (1986), where he studied Primary Health Care and Acupuncture, and at the department of Radiology in the Middlesex Hospital, London, United Kingdom (1987). From January 1988 to July 1990 he worked as a Research Fellow at the department of Obstetrics and Gynecology (head: prof. dr. J. de Haan), University of Limburg, Maastricht, where he wrote this thesis. Currently, he works as a Research Fellow at the department of Pediatrics (prof. A.M. Rudolph), Cardiovascular Research Institute, University of Callfornia, San Francisco, United States. 